THE EFFECT OF HEAT-TREATING TEMPERATURES ON INDUCED COMPRESSIVE RESIDUAL STRESS AND FATIGUE LIFE IN 300M LANDING GEAR STEEL DUE TO SHOT PEENING

\author{
By \\ Hiten Awasthi \\ Bachelor of Engineering, \\ Ryerson University, Toronto, 2008

\begin{abstract}
A Thesis
Presented to Ryerson University

In partial fulfillment of the Requirement for the degree of Master of Applied Science In program of

Mechanical Engineering
\end{abstract}

Toronto, Ontario, Canada, 2012

(C) Hiten Awasthi 2012 


\section{AUTHOR'S DECLARATION}

I hereby declare that I am the sole author of this thesis. This is a true copy of the thesis, including any required final revisions, as accepted by my examiners.

I authorize Ryerson University to lend this thesis to other institutions or individuals for the purpose of scholarly research.

I further authorize Ryerson University to reproduce this thesis by photocopying or by other means, in total or in part, at the request of other institutions or individuals for the purpose of scholarly research.

I understand that my thesis may be made electronically available to the public. 


\title{
THE EFFECT OF HEAT-TREATING TEMPERATURES ON INDUCED COMPRESSIVE RESIDUAL STRESS AND FATIGUE LIFE IN 300M LANDING GEAR STEEL DUE TO SHOT PEENING
}

\author{
Master of Applied Science in Mechanical Engineering \\ Ryerson University, Toronto, 2012
}

Hiten Awasthi, 2012

\begin{abstract}
The main objective of the study is to model the behavior of residual stresses in shot peened $300 \mathrm{M}$ landing gear steel affected by heat treatment. It is well known that residual stresses can have a significant influence on the mechanical behavior of major components under stresses. Therefore, information regarding the stability of existing residual stress states is of significant importance. In this experiment, special attention is paid to consequences of the heat treatment processes on compressive residual stresses induced in material by shot peening. The relaxation in residual stress due to addition of thermal energy by heat treatment at different temperatures and times is investigated. An existing model was used to create a stress relaxation equation for 300M high strength steels. Effect of heat treatment on residual stress distribution at subsurface level is also be examined. The current study will focus on the initial compressive residual stress field produced by common aerospace peening conditions and by how much isothermal exposures alter this stress and factors affecting the stress relaxation as well as fatigue life of the affected components.
\end{abstract}




\section{ACKNOWLEDGEMENTS}

I would like to express my gratitude to Dr. Ahmad Varvani for his helpful guidance and support during my M.A.Sc studies at Ryerson University. I express my deep gratitude for his excellent advise, detailed review and constructive comments during my research. Dr. Varvani's time and efforts are greatly appreciated. NSERC financial support through Dr. Varvani is also very much appreciated.

I would also like to thank in particular Dr. Roque Panza-Giosa from Goodrich Landing Gear Systems, Oakville for his constant interest, guidance as well as financial and material support for this project. I would also like to express my appreciation for Mr. Peter Davies and Mr. Don Velazquez from Goodrich Landing Gear Services, Burlington for providing me with time and space to make this experiment possible. I would like to extend my thanks to Mr. Livingston Peck for letting me use his laboratory for heat treatments. I would also like to appreciate Mr. Brad Baird, for his assistance in numerical analysis in the present thesis.

My deepest thanks go to my parents and also my grandmother who has always encouraged and supported me to follow my academic and career goals. 


\section{TABLE OF CONTENTS}

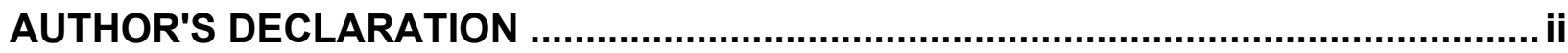

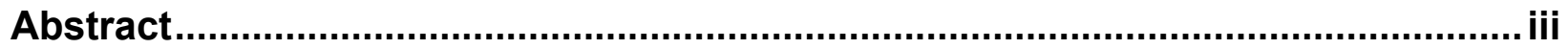

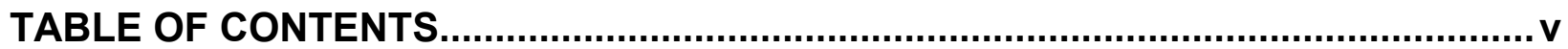

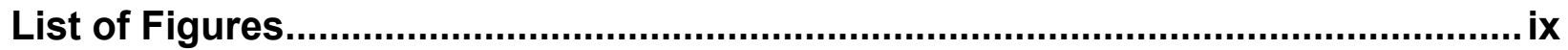

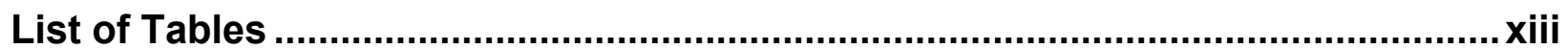

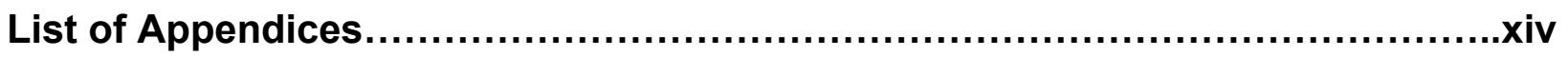

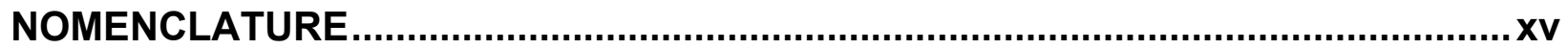

Objective and Scope of the Present Thesis ..................................................... xviiii

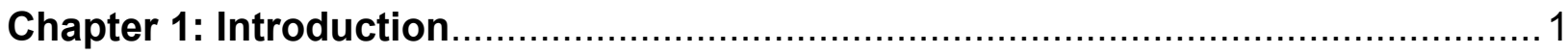

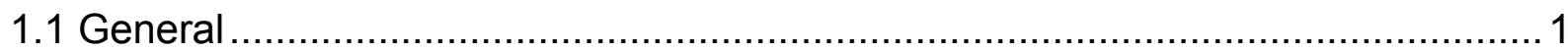

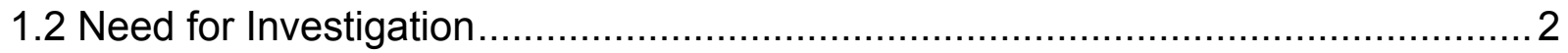

Chapter 2: Literature Review and Background.................................................

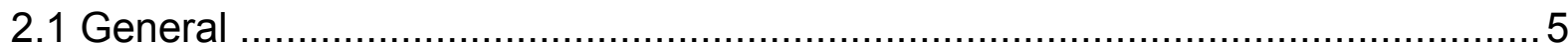

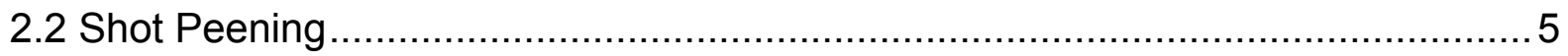

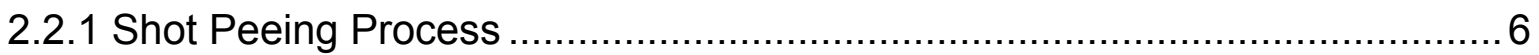


2.2.2 Parameters Affecting Shot Peening Process

2.2.3 Shot Peening and Fatigue Response of Materials ..................................12

2.4 Residual Stresses and Thermal Relaxation ............................................... 15

2.4.1 Effect of Temperature.......................................................

2.4.2 Previous Studies on Thermal Relaxation of Residual Stress .....................20

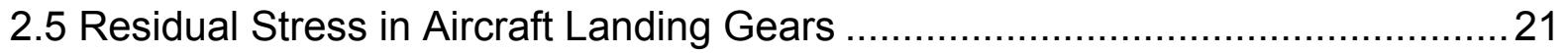

2.5.1 Landing Gear Components Processing ..............................................25

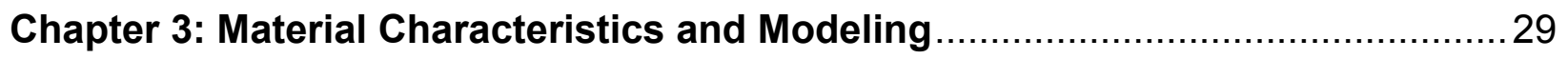

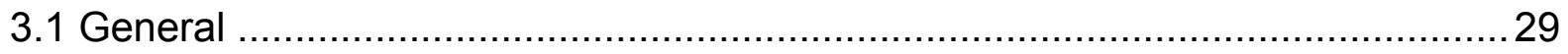

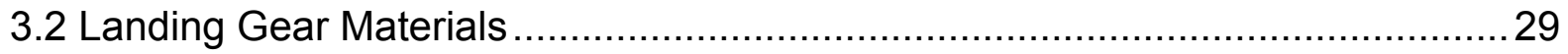

3.3 Zener-Wert-Avrami function of Residual Stress Relaxation ............................37

3.4 Effect of Residual Stress in Fatigue-life Calculations.........................................4 44

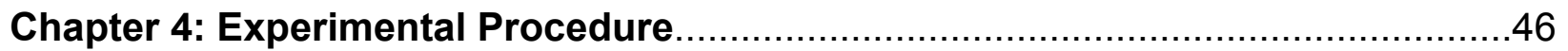

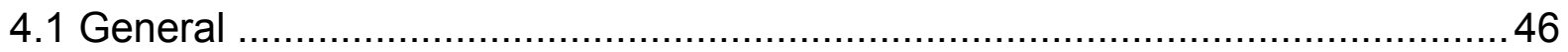

4.2 Residual Stress Measurement Methods …............................................... 46

4.3 Deflection Method to Determine Residual stress ....................................... 48

4.3.1 Specimen Preparation for Deflection Method .........................................50

4.3.2 Material Specifications and Properties ……........................................52 
4.3.3 Shot Peening Procedure for 300M Steel Strips.

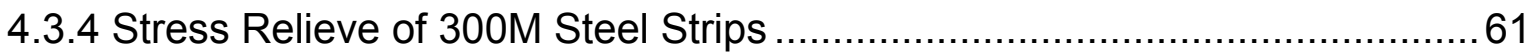

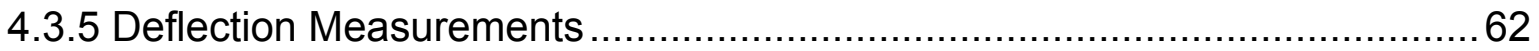

4.4 X-ray Diffraction Method to Determine Residual stress ...................................63

4.4.1 Measuring Residual Stress using X-ray Diffraction Method .......................65

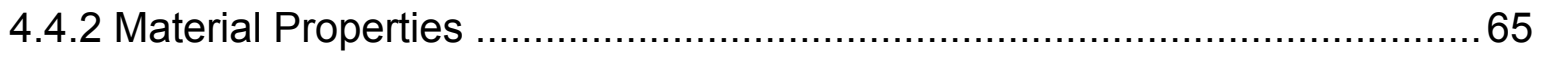

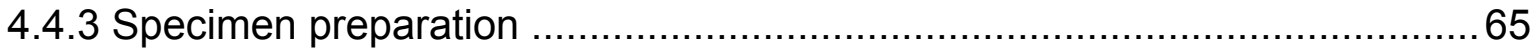

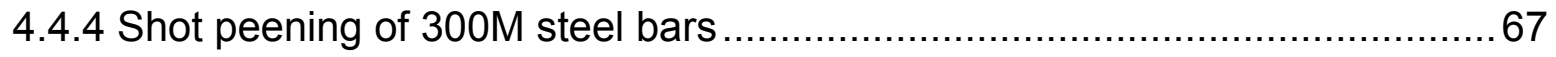

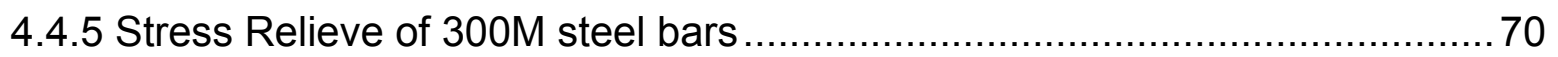

4.4.6 Residual Stress Measurement using X-ray Diffraction Principles ................71

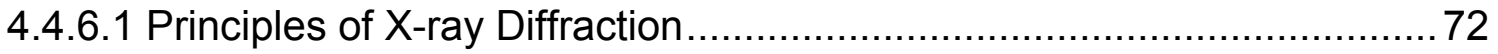

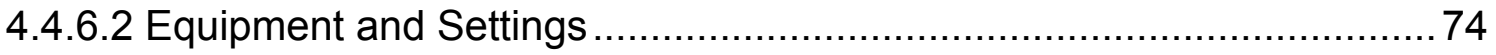

4.4.6.3 Electro-polishing Layer Removal ............................................... 79

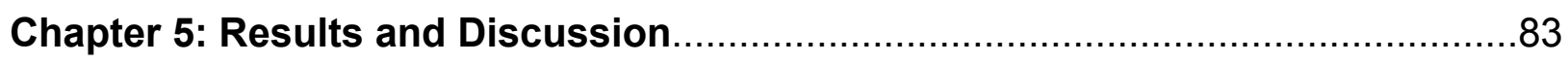

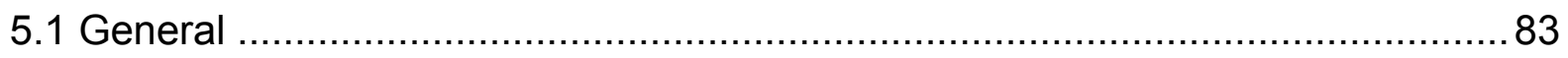

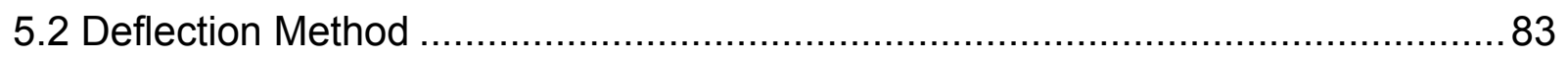

5.2.1 Calculation of Residual Stress Relaxation ............................................ 84

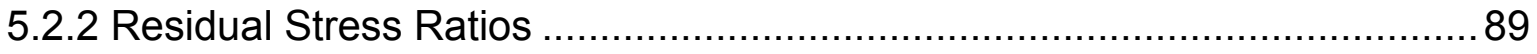

5.2.3 Determination of Activation Energy ..................................................... 91 
5.2.4 Comparison of Results and Discussion

5.3 X-ray diffraction Measurement Method Results ..............................................97

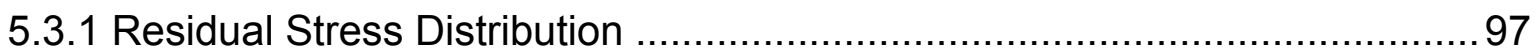

5.3.2 Effect of Heat Treating Temperature .................................................. 100

5.4 Effect of Residual Stress Relaxation on Fatigue ........................................ 104

5.4.1 Residual Stress and Fatigue Life Formulation .................................... 104

5.4.2 Effect of depth of residual stress on S-N curve .................................107

Chapter 6: Conclusions and Future Recommendations..................................111

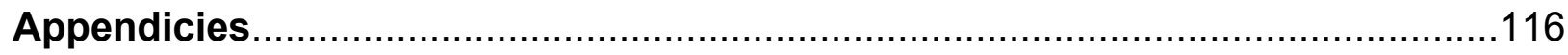

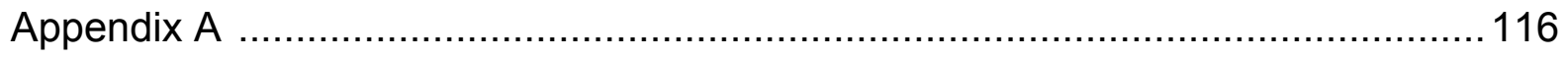

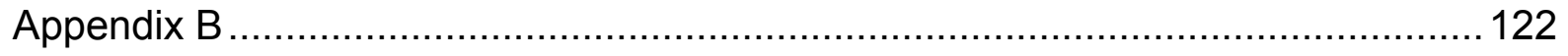

Appendix C:

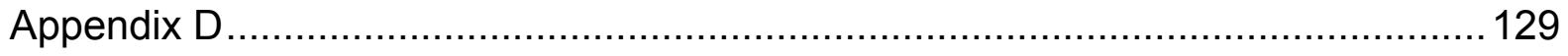

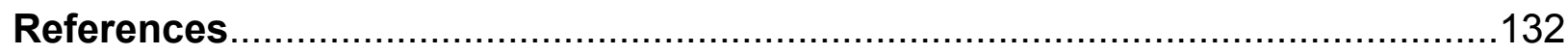




\section{List of Figures}

Figure 2-1: Properties of work piece influenced by shot peening ….......................... 6

Figure 2-2: Impact of Shot creates compressive stress ….....................................

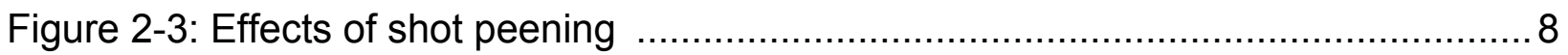

Figure 2-4: Parameters influencing results of shot peening process .......................... 9

Figure 2-5: Benefit of compressive residual stresses on fatigue life caused by a

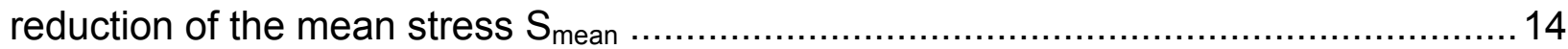

Figure 2-6: Residual Stress-depth distribution for various coverage levels (After and

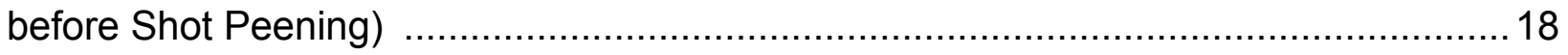

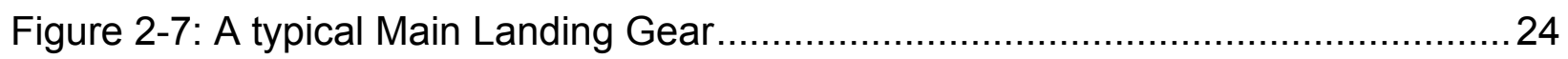

Figure 3-1: Stress-Strain curve of 300M alloy steel at room and low temperatures ......34

Figure 3-2: Effect of temperature in ultimate tensile strength and tensile yield strength of

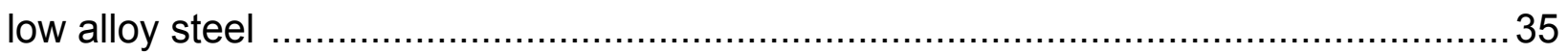

Figure 3-3: Effect of temperature on compressive yield strength and shear ultimate

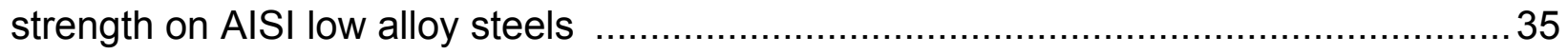

Figure 3-4: Effect of temperature on modulus of elasticity of low-alloy steels ...............36

Figure 3-5: S-N curves for unnotched 300M alloy steel forging …............................. 36

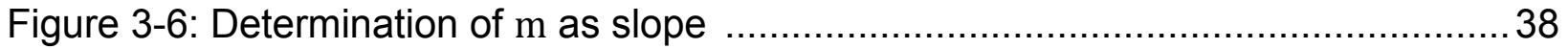

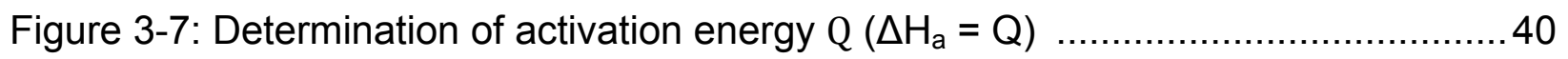

Figure 3-8: Plot showing determination of activation energy from slopes of straight lines

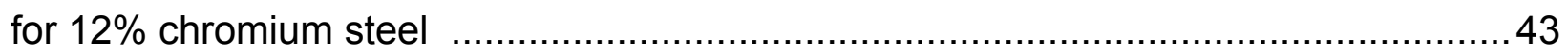

Figure 3-9: Superimposing of residual stress and service stress .............................44

Figure 4-1: Effect of shot peening on thin plate .................................................... 48 


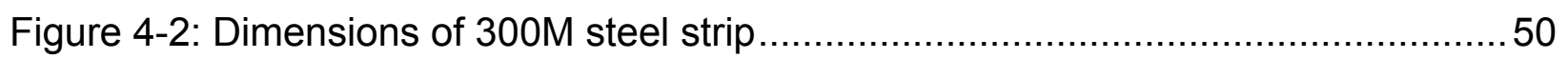

Figure 4-3: Image of 300M steel strip with same dimensions as Almen Strip...............51

Figure 4-4: Vibro-engraved strip identification ................................................... 52

Figure 4-5: Image of Test specimen holder or Almen block.......................................54

Figure 4-6: Dimensions of Almen Strip test holder ...............................................5

Figure 4-7: "Turtle fixture" holding Almen strip blocks............................................. 55

Figure 4-8: Almen Gauge for measuring curvature of Almen strips .............................56

Figure 4-9: Almen Gauge with Almen strip between 4 spindles..................................57

Figure 4-10: Screen shot of Shot Peening software screen operating at 1500 RPM.....59

Figure 4-11: 300M steel Almen strips clamped to Almen block during stress relieve ....61

Figure 4-12: Industrial Oven with 300M steel Almen Strips .....................................62

Figure 4-13: Measurement of change in d-spacings by X-ray diffraction .....................64

Figure 4-14: 300M steel specimen bar design and dimensions ...............................66

Figure 4-15: Specimens - Before and after shot peening …................................... 67

Figure 4-16: Hardness testing machine with specimen ........................................... 68

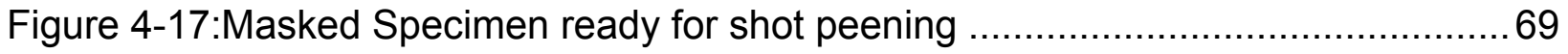

Figure 4-18: Example of vibro-engraving on specimen.............................................. 70

Figure 4-19:Inside the Industrial Oven with specimens ….................................... 71

Figure 4-20: Inter-atomic d-spacings in unstressed material grains ….......................72

Figure 4-21: Reflection of X-ray beam from stressed material grain ..........................73

Figure 4-22: X-ray diffraction machine used to measure residual stress (LXRD) ..........75

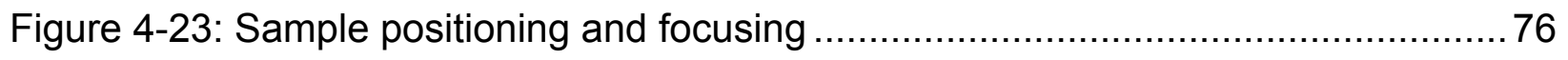

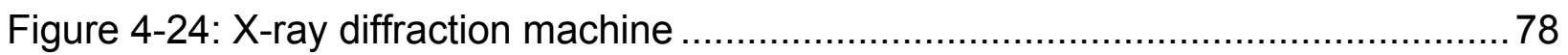




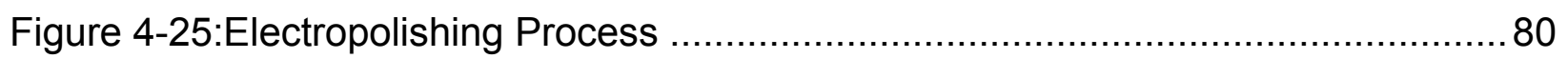

Figure 4-26: Instrument used for measuring depth accurately ............................... 81

Figure 4-27: Accurate measurement and mapping of depth ................................... 81

Figure 4-28: Determination of accurate depth using computer controlled instrument.... 82

Figure 5-1: Actual Residual Stress ratio for all heat treatment temperatures as a function

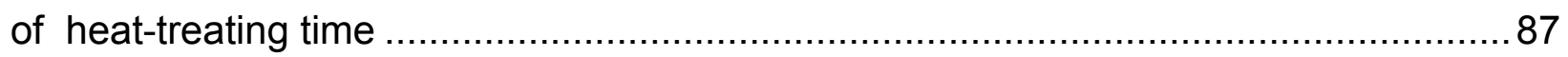

Figure 5-2: Influence of heat-treating time on residual stress ..................................... 89

Figure 5-3: Best Fit parallel curves at various heat-treating temperatures to obtain slope using MATLAB

Figure 5-4: Actual and predicted slopes for determination of Activation Energy (Q) .....92 Figure 5-5: Calculated residual stress ratio at arbitrary heat treatment temperatures as a

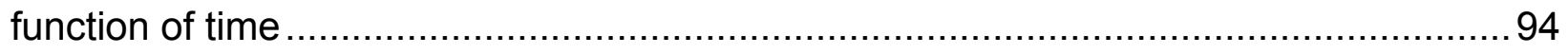

Figure 5-6:Calculated residual stress ratio at arbitrary heat treatment times as a function

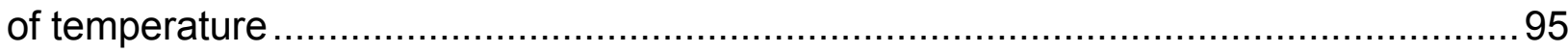

Figure 5-7: Residual stress distribution in $300 \mathrm{M}$ steel due to shot peening as function of

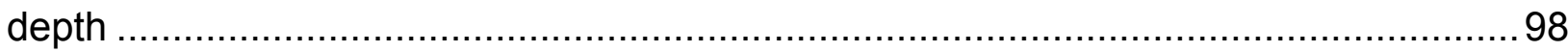

Figure 5-8: Residual Stress formation (a) Stretching surface layer (b) Hertzian pressure [55] 99

Figure 5-9: Residual Stress relaxation as a function of depth ................................... 101

Figure 5-10: Comparison of residual stresses relaxation at different depths due to

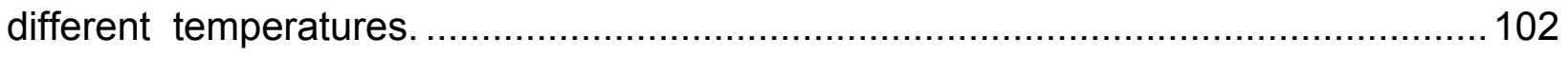

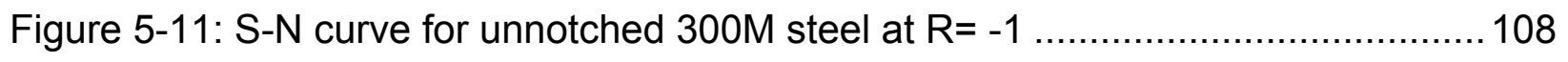

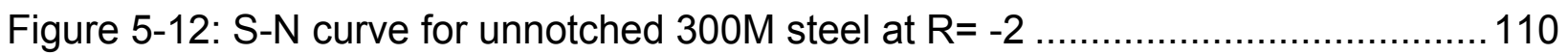


Figure A1: Residual stress distribution at room temperature for all specimens tested 119 Figure A2: Residual stress distribution after heat treating at $375^{\circ} \mathrm{F}$ for 4 hours for all specimens tested

Figure A3: Residual stress distribution after heat treating at $525^{\circ} \mathrm{F}$ for 4 hours for all specimens tested 120 


\section{List of Tables}

Table 2-1: Examples of applications and results of Shot Peening .............................15

Table 3-1: Composition of 300M steel bars by weight percentage .............................31

Table 3-2: Mechanical properties of 300M steel [40] …............................................. 32

Table 4-1: Composition of $300 \mathrm{M}$ steel strips by weight percentage ............................53

Table 4-2: Mechanical Properties of 300M steel strip ...........................................53

Table 4-3: Deflection Measurements after shot peening …......................................60

Table 4-4: X-ray Diffraction machine Set-up parameters ........................................79

Table 5-1: Percentage relaxation residual stress after heat treatment at each

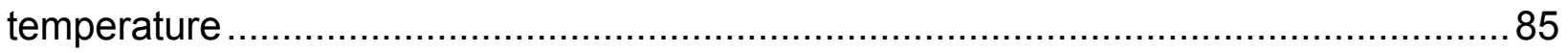

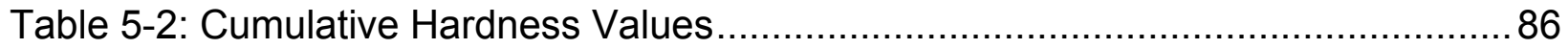

Table 5-3: Zener-Wart-Avrami Function parameters determined from experiment .......91

Table 5-4: Average residual stress at each depth of shot peened and heat treated

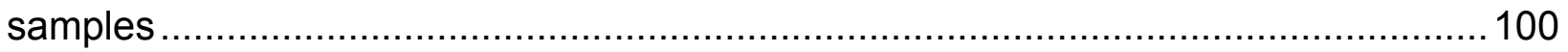

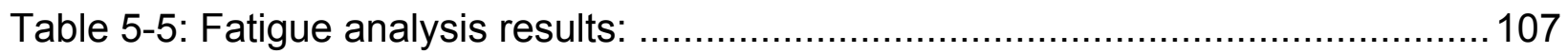

Table A1: Residual Stress readings for shot peened only specimens ......................116

Table A2: Residual Stress readings for shot peened and stress relieved at $375^{\circ} \mathrm{F} \ldots .117$

Table A3: Residual Stress readings for shot peened and stress relieved at $525^{\circ} \mathrm{F} \ldots .118$

Table A4: Deflection measurements values after each stress relieve interval ...........121

Table B1: Percent Residual Stress remaining in each strip (actual).........................122

Table B2: Calculated Percent Residual Stress remaining after heat treatment............122

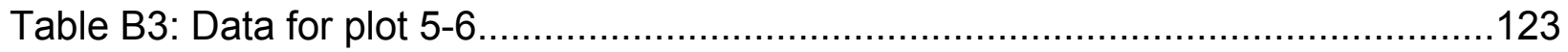




\section{List of Appendices}

Appendix A: Experiment Observation Data .........................................116

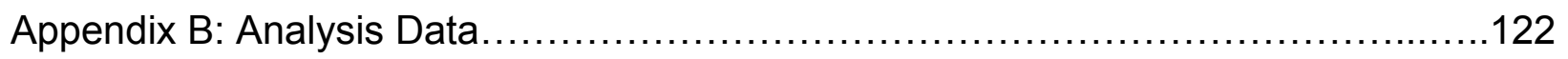

Appendix C: MATLAB Code to generate plots for calculation of activation energy .....124

Appendix D: MATLAB Code for generation of S-N plots..............................129 


\section{NOMENCLATURE}

Acronym

AISI

AMS

ASTM

BMS

$\mathrm{eV}$

HSS

HRC

MLG

MPI

NDT

NLG

rpm

RS

SAE

S-N

UHSS

UTS

YS
Definition

American Iron and Steel Institute

Aerospace Material Specification

American Society for Testing and Materials

Boeing Material Specification

Electron Volts

High Strength Steel

Rockwell C Hardness

Main Landing Gear

Magnetic Particle Inspection

Non-Destructive Testing

Nose Landing Gear

Revolution per minute

Residual Stress

Society for Automotive Engineers

Stress-Life

Ultra-High Strength Steel

Ultimate Tensile Strength

Yield Strength 


\begin{tabular}{|c|c|c|}
\hline$d$ & Deflection & Inches \\
\hline$d_{0}$ & Unstressed lattice spacings & $\AA$ \\
\hline$d_{f}$ & Final stress lattice spacings & $\AA$ \\
\hline$\epsilon_{e}$ & Elastic Strain & \\
\hline$\epsilon_{p}, \epsilon_{r}(z)$ & Plastic Strain & \\
\hline$E$ & Modulus of Elasticity & ksi \\
\hline$F_{t u}, \sigma_{u}, S_{u}$ & Ultimate Tensile Strength & ksi \\
\hline$F_{t y}$ & Tensile Yield Strength & ksi \\
\hline$F_{s u}$ & Shear Ultimate Strength & ksi \\
\hline$F_{c y}$ & Compressive Yield Strength & ksi \\
\hline$G$ & Shear Modulus & ksi \\
\hline$k$ & Boltzmann's Constant & $\mathrm{eV} \mathrm{K}^{-1}$ \\
\hline$L$ & Length & inches \\
\hline$\lambda$ & Wavelength of X-ray Radiation & $\AA$ \\
\hline$N_{f}$ & Cycles to failure & \\
\hline$\sigma_{a}$ & Applied/alternating Stress & ksi \\
\hline$\sigma_{D}$ & Reverse Tensile Fatigue Limit & ksi \\
\hline$\sigma_{E S}$ & Elastic Stress & ksi \\
\hline
\end{tabular}




$\begin{array}{clc}\sigma_{e q} & \text { Equivalent Stress } & \mathrm{ksi} \\ \sigma_{m}, S_{m} & \text { Mean Stress } & \mathrm{ksi} \\ \sigma_{R}, \sigma_{R S} & \text { Residual Stress } & \mathrm{ksi} \\ \sigma_{S} & \text { Service Stress } & \mathrm{ksi} \\ \sigma_{o} & \text { Initial Residual Stress } & \mathrm{ksi} \\ \sigma_{r s}^{T} & \text { Residual Stress at temperature T } & \mathrm{ksi} \\ Q, \Delta H & \text { Activation energy or enthalpy } & \mathrm{eV} \\ R & \text { Stress Ratio } & \\ t & \text { Time (final) } & \\ t_{o} & \text { Time (initial) } & \text { hours or minutes } \\ T, T_{a} & \text { Heat Treatment Temperature } & \text { hours or minutes } \\ T_{m} & \text { Moison's Ratio } & { }^{\circ} \mathrm{F} \\ \tau_{m a x} & \text { Melting Temperature } & { }^{\circ} \mathrm{F} \\ & \text { Maximum Shear Stress } & \mathrm{ksi} \\ & & \text { inches } \\ & & \end{array}$




\section{Objective and Scope of the Present Thesis}

Aircraft landing gear components are often shot peened to enhance their fatigue life and durability due to induced compressive residual stresses. These components sometimes are subjected to high heat-treating temperature as part of component processing during production, overhaul or in-service where residual stress may be compromised.

The main objective of the present thesis is to examine induced residual stresses in shot peened $300 \mathrm{M}$ landing gear steel samples at various heat-treating temperatures and times. Residual stress relaxation in peened $300 \mathrm{M}$ samples heat treated at various temperatures is discussed. Compressive residual stresses of this material are measured at subsurface levels using deflection and X-ray techniques.

Special attention is devoted to examine the consequences of heat-treating process on compressive residual stress distribution induced in subsurface layers of $300 \mathrm{M}$ over shot peening process. The relaxation in residual stress as landing gear material is heat treated at various temperatures and times is also investigated.

The ultimate objective of the present study is to realistically evaluate the influence of residual stress, and stress relaxation on fatigue life of $300 \mathrm{M}$ steel components at various temperatures and offer an analysis to estimate fatigue life of $300 \mathrm{M}$ components at the presence of induced residual stresses. The outcomes of the proposed research is believed to enhance understanding of how residual stresses affect fatigue performance of load-bearing landing gear components in service. 


\section{CHAPTER 1}

\section{Introduction}

\subsection{General}

Industry has long been taken advantage of shot peening process to improve fatigue properties and durability of metallic materials. Since early 1920's when hand peening with specific hammers was used in the race-car industry to improve the fatigue life, cold working the part in this manner has reveled many surface enhancing benefits [1]. Shot peening has proved to be a powerful instrument in enhancing the resistance of materials to various kinds of stress-induced damage, particularly against damage due to cyclic loading in air or in aggressive environments.

The use of shot peening to improve fatigue life has also been regulated by different industries. In aerospace industry where materials exhibiting high strength to weight ratio such as landing gear $300 \mathrm{M}$ steel alloys are selected along with reliability over the life of aircraft. Materials like high-strength steels are used in applications where component must be able to bear high loads fatigue cycles. In modern aircrafts, landing gears are made of high strength steels, which exhibit excellent mechanical properties but are prone to fatigue failure arising from corrosion or nicks. In order to increase fatigue resistance, compressive residual stresses are often purposely introduced around these areas through processes like shot peening. High strength steel alloy components are 
shot peened to create a layer of compressive residual stress at the surface to delay crack initiation and initial crack growth caused by fatigue or stress corrosion hence increasing the fatigue life of the component. Compressive residual stresses are also known to improve the wear resistance of the material. In addition, there is an increase in surface hardness due to shot peening technique. The induced compressive residual stresses in the wake of shot peening are result of the locally occurring plastic deformation on the surface of the work piece and are produced by the impact of individual peening particles.

\subsection{Need for Investigation}

The aim of shot peening is to obtain high compressive residual stresses that reach as deep as possible into the work-piece. It is well established that a controlled shot peening improves materials performance including increased mean high cycle fatigue performance, and increased tolerance to small defects. This increased damage tolerance is due to reduced stress intensity factor ranges by the shot peening induced compressive residual stresses [2]. The compressive residual stress however is relaxed in-service due to thermal conditions and some mechanical processes, alleviating the potential benefit of compressive stress. The stability or relaxation behavior of these residual stresses at thermal or mechanical loadings is thus of vital importance for the components in-service and for the accuracy and robustness of the life prediction.

The initial life prescribed by the manufacturer for the aircraft and landing gears are conservative due to uncertainties in the design analysis and life cycle test at certification 
stage [4]. Landing gears are long cycle accessories and have high production costs. It is of prime importance to make maximum use of landing gears in terms of number of landings while possess a durable performance in aircraft. Depending on manufacturer instructions, landing gears are typically overhauled every 8-10 years, where life extension is provided through NDT, shot peening and plating processes to restore all components back to original dimensions. During overhaul process, each component is unique in terms of damage from corrosion and wear, hence the uncertainty in overhaul process when compared with manufacturing process include many special operations where processing temperatures during heat treatment results in relaxation in residual stress induced by shot peening process. Currently, there is no method of knowing how much relaxation has taken place due to processing, therefore it becomes very important to know the relaxation behavior of components going back to service after restoration.

The relaxation of compressive residual stress occurs under thermal exposure, static loading, and cyclic loading conditions. In ferritic steels, recrystallization occurs at half the melting temperature of the material, therefore a complete relaxation of compressive residual stress induced at this temperature is expected if a component is heat-treated for several hours [3].

The process of thermal relaxation is attributed to the reduction of the residual stress over dislocation movement of atoms driven by the reduction of stored energy. These mechanisms involve the extinction of metastable lattice defects, creep-controlled 
dislocation rearrangement and recrystallization at higher temperature [4].

The current study will mainly focus on thermal relaxation behavior of the high strength $300 \mathrm{M}$ steel used in aircraft landing gears. This will be evaluated by focusing on the initial compressive residual stress induced in $300 \mathrm{M}$ steel through shot peening industrial equipment and how the residual stress is altered by isothermal exposures with respect to annealing time will be discussed. The effect of temperature on residual stress distribution as well as depth of compressive residual stress field over material shot peened process at different heat-treating temperatures will be examined. The interaction of induced residual stress and fatigue life will be integrated to realistically evaluate the influence of induced residual stress values in the life of $300 \mathrm{M}$ landing gear components under cyclic stresses. 


\section{CHAPTER 2}

\section{Literature Review and Background}

\subsection{General}

This chapter provides a relevant background on the shot peening process and reviews earlier research works on the thermal stability and its influence on residual stress in steels. Introduction of compressive residual stresses in aircraft landing gears through shot peening and general processing of high strength steel components including heat treatment is also outlined. The literature review consists of shot peening process, contemporary shot peening parameters and material properties affected by shot peening operation.

\subsection{Shot Peening}

Shot peening is a mechanical pre-stressing surface treatment process that substantially improves the strength of metals. It is a cold-work process that has proved to be a powerful and efficient method for enhancing the service life of a wide variety of structural and functional elements. It is one of the most widely used surface enhancing techniques, to improve the material's resistance to fatigue, stress corrosion cracking, fretting, rolling contact fatigue, and corrosion [7]. Since shot peening can be used for a wide variety of structural components irrespective of their shapes and dimensions, shot peening applications are widely demanding in many industrial branches [8]. Figure 2-1 
shows most of the changes of surface characteristics induced by shot peening.

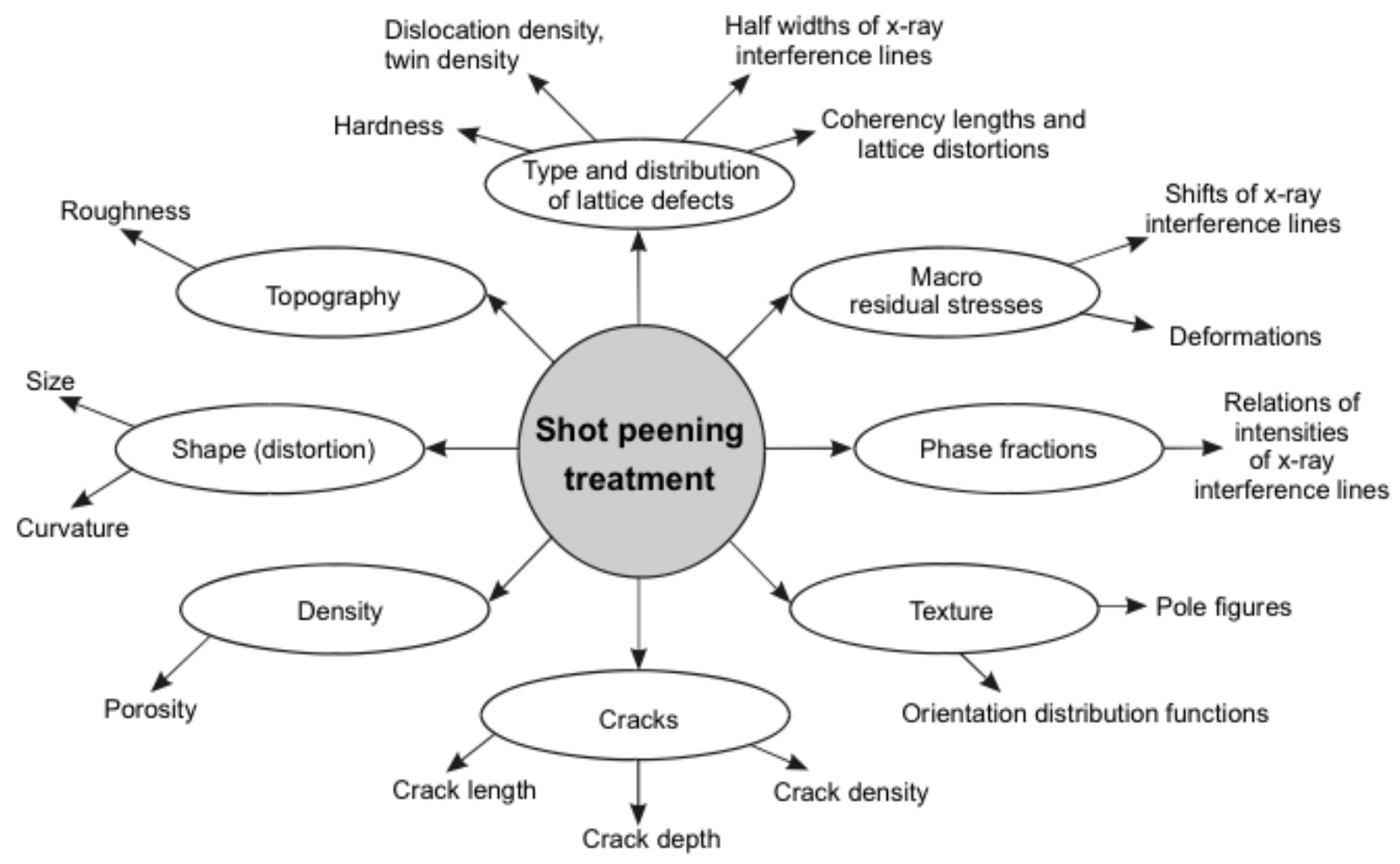

Figure 2-1: Properties of work piece influenced by shot peening [1]

\subsubsection{Shot Peeing Process}

During shot peening, the specimen is bombarded by small and hard media called shots.

Every shot striking the material acts as a tiny peening mallet, imparting to the surface a small indentation or dimple, leading to plastic deformation of a thin surface zone by plastically yielding the surface in tension. This plastically deformed material above elastic material restores the yielded surface to its initial shape, producing residual compressive stress on surface layer [9]. This phenomenon is shown in figure 2-2. 


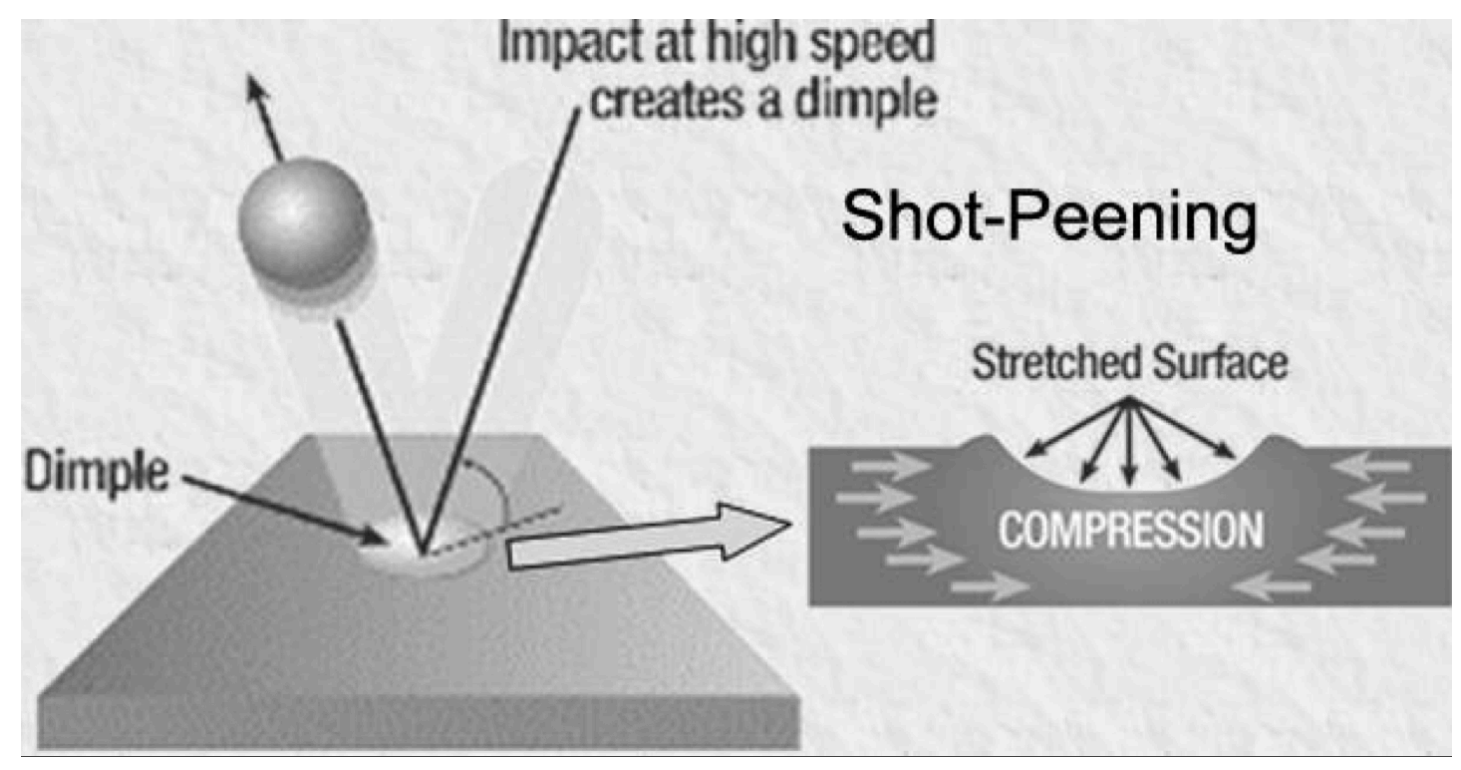

Figure 2-2: Impact of Shot creates compressive stress [8]

Overlapping dimples develop an even layer of metal that is in a state of compression. This cold work-hardening process effectively changes the density of dislocations and interplaner spacing of the crystal lattice [10]. The increase in density of dislocations is proof of work-hardened material, which can also be confirmed by micro hardness readings in the surface zone. The overall higher surface hardness of shot peened piece has also been reported in the literature [11]. The residual compressive stress layer is about $1 \mathrm{~mm}$ deep with maximum value of about one half the yield strength of the material [12]. A typical profile of the changes in residual stress along the depth is shown in figure 2-3.

For the quality evaluation of the shot peened layer, the highest value of the compressive stress at the surface or just below it and the gradient of compressive stress are critical parameters. In practice, the quality of surface layers is mostly determined by various 
destructive testing methods applied to specimens specially prepared for a micro structural analysis, hardness and residual stress measurements [13].

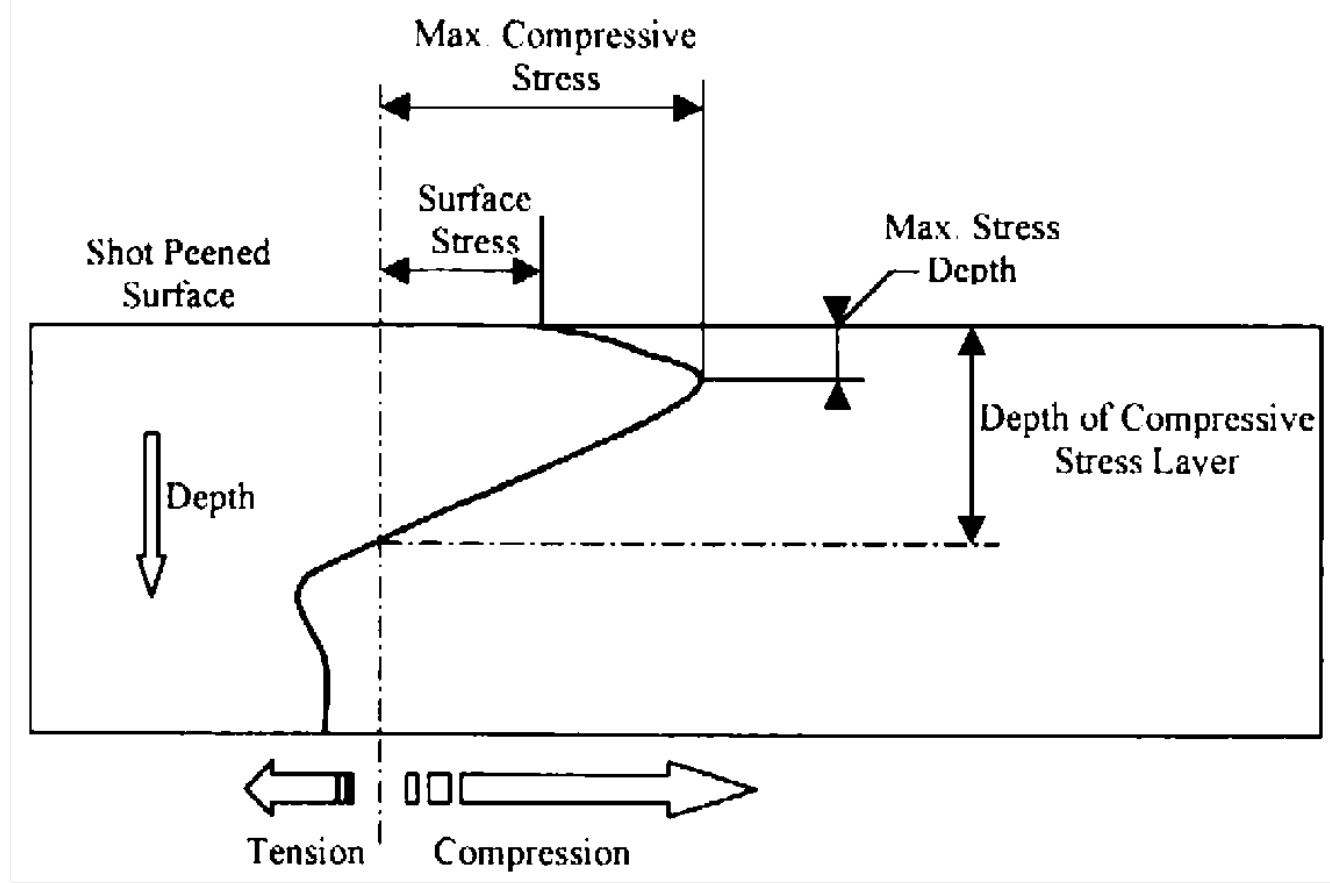

Figure 2-3: Effects of shot peening [14]

\subsubsection{Parameters Affecting Shot Peening Process}

The effectiveness of the shot peening process is dependent upon the uniformity of the induced compressive residual stresses and the energy transfer that occurs during the impact of the shots with the base metal surface [1]. Therefore, shot peen being a mechanical process, the influence of process parameters of the shot peening treatments as well as peening device, the shot and work-piece has to be well known and controlled. The study of the different parameters involved in shot peening applications is essential in order to have better understanding and control of such 
process. Figure 2-4 shows parameters influencing the results of shot peening treatments. In practice, the process efficiency is primarily established by means of coverage, intensity and shot size.

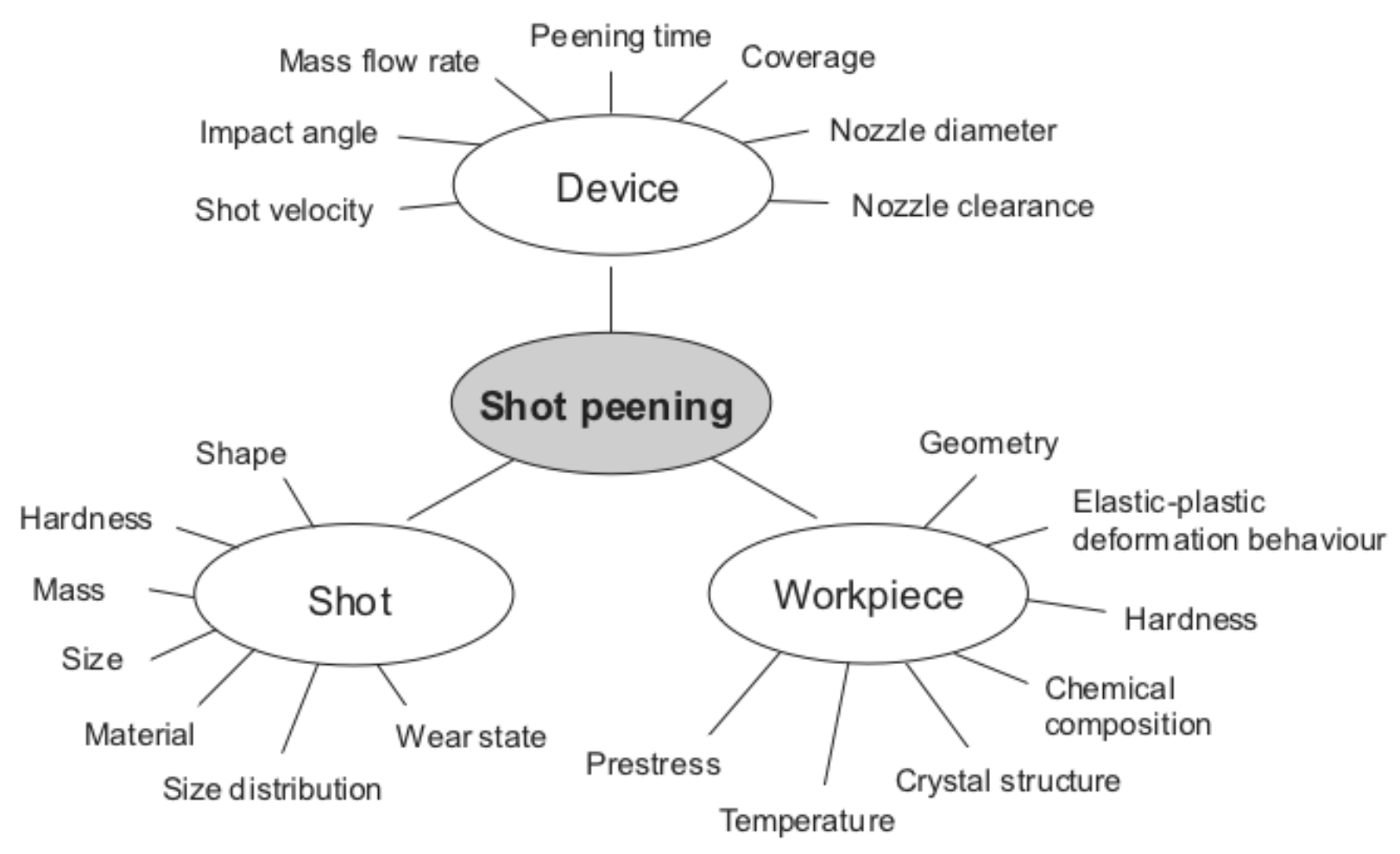

Figure 2-4: Parameters influencing results of shot peening process [1]

Shot peen size and coverage: Since the depth of work hardening of the surface layers is inversely proportional to the hardness of the material undergoing shot peening, this depth is also proportional to the size of balls (shots) until a critical ball diameter is reached where little further hardening is obtained [15]. Nominal shot diameter is expressed in ten-thousands of an inch for cast steel shot and thousands of an inch for cut-wire shot and is identified by shot number or shot size. Hence the shape, hardness, 
mass, material, size and wear state of the shot greatly affects the quality as well as depth of compressive residual stress on surface layer. These parameters are standardized and depend on work piece and comprehensively characterized in AMS 2431 and AMS 2431-1 with testing criteria described in ASTM-E-11.

In shot peening, coverage is defined as a measure of the area fraction of a component surface that has been impacted in a given peening time, and is usually expressed as a percentage. A $100 \%$ or complete visual coverage is reached when the entire surface of a reference area has been indented [1]. At 100\% coverage, the residual stresses are assumed to be uniform in the surface layers of the component. For example, a call out of 2.0 or $200 \%$ coverage requires the part to be exposed to shot blast for a period of time twice that required for the part to have 1.0 or $100 \%$ coverage with required intensity.

During shot peening, the rate of coverage decreases with time because the probability of indentations overlapping increases. Coverage of the reference area can be visual inspected with a magnifying glass, two theoretical models, the Avrami equation and Holdgate model is presented in literature to predict coverage analytically [1].

Intensity of shot peening: Intensity of shot peening is measured as the amount of energy transferred during the impact of a typical shot with the work piece and is related 
to the kinetic energy of the blast stream [16]. Intensity is measured by the Almen strip test, which was originally proposed by Almen, by measuring the arc height of an Almen test strip (in 0.001 inch increments) due to shot peening, for example, $0.009 \mathrm{~A}$ signifies that arc height of a peened Almen "A" test strip is 0.009 inch. Saturation point occurs when $100 \%$ increase in peening time results in an increase of Almen strip intensity of $10 \%$ or less. Intensity is usually increased by increasing the pressure of shot peening machine or by reducing the distance between work piece and shot peening nozzle. Shot peen parameters such as intensity and coverage are usually called out on blueprint for components requiring shot peen whereas general procedures and requirements are described in specifications published by Boeing BAC5730 for aerospace industry.

The use of shot peening to improve component fatigue life has also been standardized [17]. However, shot peening process parameters are still selected by means of empirical considerations or by experience. Although correctly selected shot peening parameters may ensure ideal variations of residual stresses in the layer of material so that the required fatigue life may be achieved. But determining the peening schedules required for optimum shot peening is still a grey area [1]. 


\subsubsection{Shot Peening and Fatigue Response of Materials}

Fatigue fractures of components are often caused by surface defects because the maximum stress occurs on the surfaces in components such as springs and gears. The beneficial effects caused by shot peening have been fundamentally attributed to the surface residual compressive stress. Shot peening was developed to introduce compressive residual stresses close to the surface, thereby delaying failure of components exposed to fatigue loading.

The fatigue life of components is to a large degree controlled by the behavior of its surface zones since most of the cracks tend to initiate at the surface. The compressive residual stresses improve the fatigue properties by increasing the surface resistance to crack initiation as well as reducing the crack propagation rate thereby increasing their fatigue life [11]. Compressive stress formation is only possible with ductile substrates like metals [15]. Studies has shown that compressive residual stresses in the surface region of materials with medium and high hardness values increases the fatigue life and the fatigue limit at cyclic loading compared to material states which are free of residual stresses [18].

Many studies have been carried out to investigate the effects of surface defects on fatigue limit [19]. The crack origin is also either directly at the surface or slightly subsurface within a distance of less than about 25 microns to the surface [20]. Residual compressive stresses play a particularly important role in reducing the stress 
concentrations associated with the presence of surface defects.

Shot peen can be used to great advantage on high strength steels, since many steels with tensile strength of $200 \mathrm{ksi}$ and above experience a reduction in endurance limit with increased strength. Shot peen treatment eliminates the roll-off in endurance limit and a fatigue ratio of 0.5 is extended well beyond an UTS of $200 \mathrm{ksi}$ [12].

Since the tendency of many steels to exhibit cycle-dependent softening, relaxation might occur at lower stresses than expected at monotonic yield stress. Landgraf and Chernenkoff [21] have reported this by assessing residual stresses as mean stresses [21]. Figure 2-5 shows how lowering the mean stress due to shot peening results in increase in fatigue life. Torres and Voorwald [11] also showed that at stress amplitudes above $80 \%$ of the yield strength, shot peening has no positive influence on the fatigue lifetime.

The extent to which shot peening influences the mechanical properties of the material depends on the gradient of residual stresses and depth of the affected layer. Generally, the higher the mechanical characteristics of the base material like fatigue strength, fracture toughness and wear resistance, the thinner is the affected layer and greater the maximum compressive stress [22]. Inversely, the lower the mechanical properties of the substrate material, the greater is the relaxation of residual stresses induced by loading. 


\section{Stress}

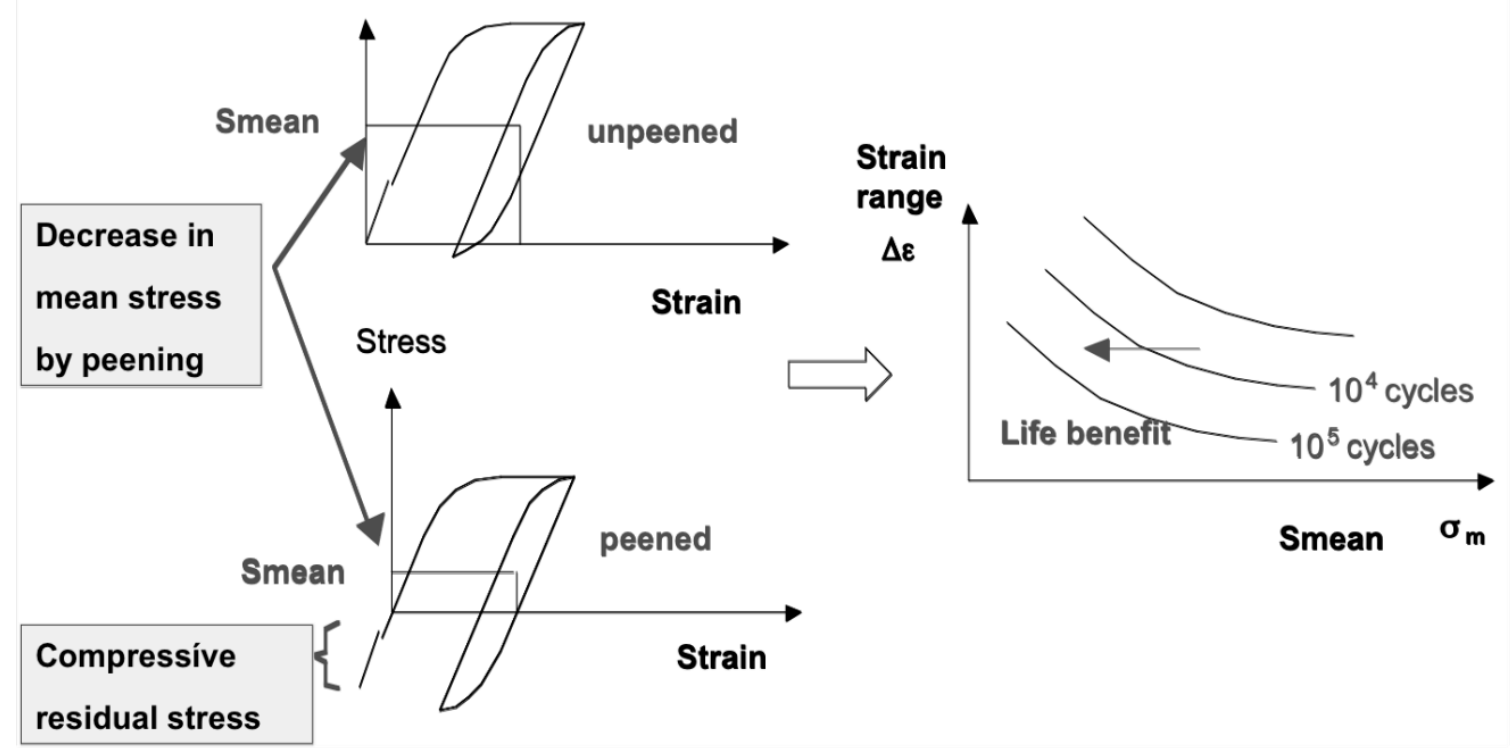

Figure 2-5: Benefit of compressive residual stresses on fatigue life caused by a reduction of the mean stress $S_{\text {mean }}$

The influence of residual stresses and the increase in hardness on the fatigue strength also depends on the initial mechanical characteristics of the treated material. That is why shot peening is normally applied as last treatment to prevent the modification of the residual stresses, which may induce due to machining [1].

Table 2-1 shows components that are treated by shot peeing and their corresponding increase in service life. 
Table 2-1: Examples of applications and results of Shot Peening [22]

\begin{tabular}{|l|l|c|}
\hline \multicolumn{1}{|c|}{ Application } & \multicolumn{1}{|c|}{ Loading/Process } & Increase in service life \% \\
\hline Axles & Flexing & $400-1900$ \\
\hline Shafts & Torsion & 700 \\
\hline Gearbox shafts & Service life tests & 80 \\
\hline Crankshafts & Service life tests & 3000 (variable) \\
\hline Aircraft connecting rods & Torsion \& Compression & 105 \\
\hline Engine connecting rods & Torsion \& Compression & 45 \\
\hline Leaf springs & Dynamic stress & $100-340$ \\
\hline Helical springs & Service life tests & 3500 \\
\hline Torsion Bars & Dynamic stress & $140-600$ \\
\hline Cardan shaft & Flexing & 130 \\
\hline Cogwheel & Service life tests & 1100 \\
\hline Caterpillar tracks for tanks & Service life tests & 700 \\
\hline Valve & Service life tests & 320 \\
\hline Rocker Arm & Service life tests & \\
\hline
\end{tabular}

\subsection{Residual Stresses and Thermal Relaxation}

Residual stress is usually defined as the stress that remains in mechanical parts that are not subjected to any outside stresses. Since the introduction of shot peening, the high cycle fatigue life of critical components has been improved by this surface enhancement to induce a surface layer of compressive residual stress [23]. The compressive layer delays fatigue crack initiation and retards small crack propagation. It can even permit the use of smaller and lighter parts for the same fatigue life. The 
benefits of residual stress are now generally recognized and capitalized on by the aerospace industries.

The total stress on a part is composed of the applied stress and any residual stress that may exists. The level of residual stress can approach or even exceed the strength of the material [24]. Accordingly, residual stress is an important consideration in part performance analysis as well as in parts manufacture.

Residual stresses are also known to reduce yield or elastic collapse loads and may retard corrosion cracking [5]. Residual compressive stresses play a particularly important role in reducing the stress concentrations associated with the presence of surface defects. Residual stresses are always consequence of inhomogeneously distributed dimensional changes due to inhomogeneous plastic deformations, thermo mechanical treatments and phase transformations [5]. When these residual stresses on surface are in tension and are added to maximum tensile stresses due to service loads, there resultant may be substantially greater than the expected stresses, and premature failure may occur at lower loads than expected [25]. In the presence of residual stresses, changes to the effective mean stress experienced during fatigue cycling affects both initiation and growth stages of fatigue cracks. It is known that fatigue failures and other types of brittle failures are always due to tensile stresses. The machined part made of the corresponding specified material will have tensile residual stresses caused by the mechanical and metallurgical processing operations, which 
affects its fatigue strength [26]. Since fatigue cracks originate at regions of maximum tensile stresses and usually at the surface of the member, an intentionally produced thin surface layer of residual compressive stress can greatly increase the fatigue life of the machined component.

For steels, effect of shot peening is very sensitive to initial microstructure and consequently the heat treatment, which controls the microstructure. For $0.5 \%$ medium carbon steel subjected to various heat treatments, it was found that shot peening after oil quenching and tempering produced the largest hardness increase of $1100 \mathrm{Hv}$ close to the surface as compared to core hardness of $200 \mathrm{Hv}$. For annealed and normalized steel, this was limited to $300 \mathrm{Hv}$ only [15]. This shows that shot peening has a greater effect on harder steel than softer steel in increasing the hardness.

\subsubsection{Effect of Temperature}

Temperature greatly affects the shot peen process. For high strength steel alloys, components loose most of the induced residual compressive stress if heated beyond the temperature of $400^{\circ} \mathrm{F}$ [27]. Prevéy [28], shot peened SAE 4340 steel specimens at different coverage and then baked them at 24 hours at $475^{\circ} \mathrm{F}$ to determine if thermally induced relaxation had occurred in residual stresses. The results reveled relaxation in residual stress occurred at depths less than $0.05 \mathrm{~mm}$ with greatest percent changes occurring surface values. Reduction of surface residual stress magnitudes ranged from $20 \%$ to $30 \%$ [28]. The implication from these results shows that cold work from shot 
peening, even at less than $100 \%$ coverage, is sufficient to induce significant residual stress relaxation in surface and near surface layers at modest temperatures. Figure 2-6 shows the residual stresses after and before heat treatment:
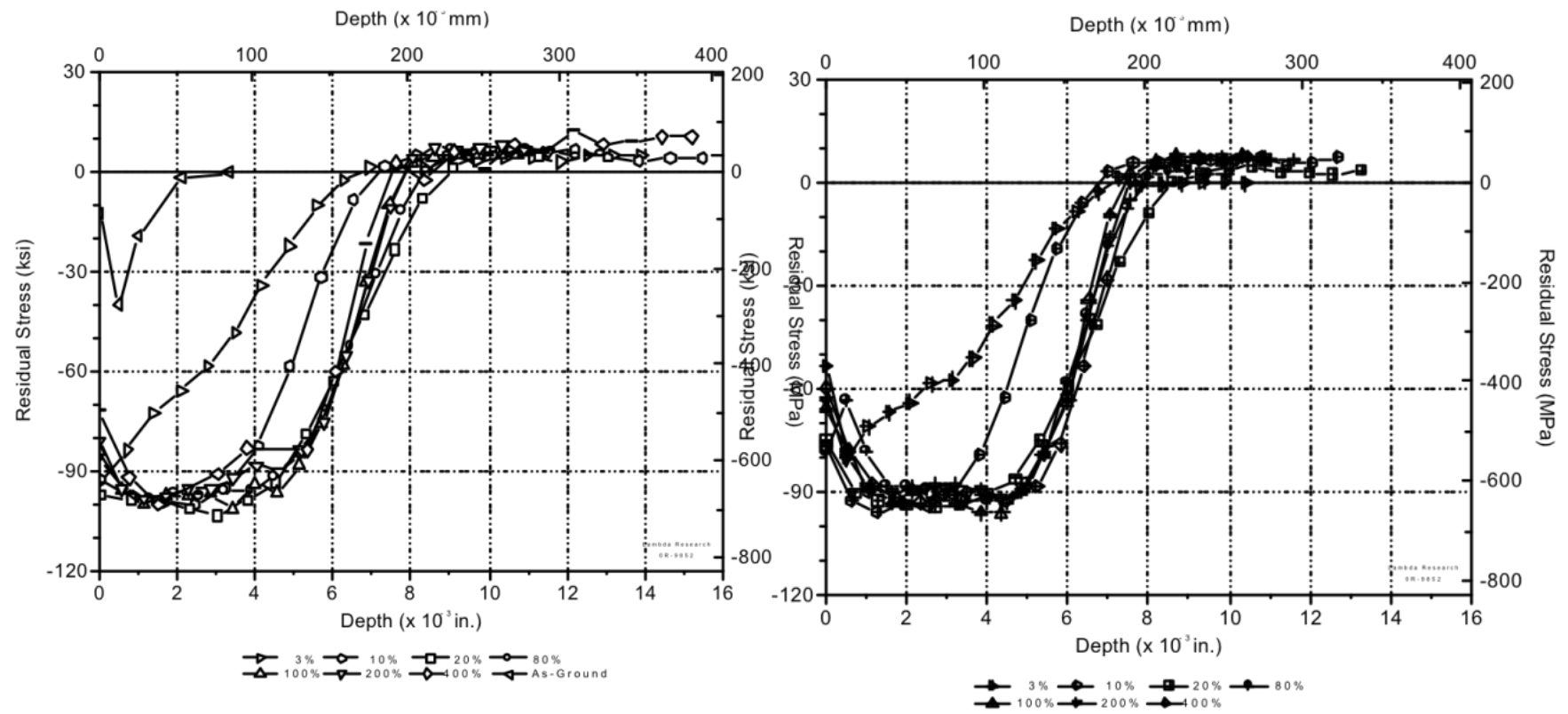

Figure 2-6: Residual Stress-depth distribution for various coverage levels (After and before Shot Peening) [28]

Therefore it becomes very important to monitor the temperature of material after it has been shot peened to avoid any loss of beneficial residual compressive stress. In industry, parts are usually shot peened before electroplating; this requires part to heat treated at $375^{\circ} \mathrm{F}$ to get rid of hydrogen from the microstructure. This temperature should be monitored very properly.

In processing or in-service there are instances when steel parts may be exposed to temperatures where benefits of shot peening may be lost by stress relieve. The relaxation of residual stress here implies the reduction of beneficial effect of shot 
peening on fatigue behavior. Usually the relaxation of residual compressive stress includes mechanical and thermal relaxation processes, they are regarded as independent ones [5].

The process of thermal relaxation is attributed to the reduction of the residual stress causing plastic misfit by diffusive or dislocation movement of atoms driven by the reduction of stored energy. These mechanisms involve the extinction of metastable lattice defects, creep-controlled dislocation rearrangement and recrystallization at higher temperatures [6]. Elastic residual strains $\varepsilon_{\mathrm{e}}$ are related with residual stresses via Hooke's law. These strains are transformed into micro plastic strains $\varepsilon_{\mathrm{p}}$, by shot peening as plastic deformation process[5]. If a surface undergoes permanent plastic deformation by shot peening which in turn results in the underlying material being elastically stretched or compressed, the material plastically deformed by tensile forces is left in elastic compression similarly material plastically deformed by compressive forces is in elastic tension. The mechanics and degree of this deformation on a given material are controlled by dislocation slip, dislocation creep, grain-boundary sliding, or diffusion creep [29]. In heat treatment applications, the best-known technique for inducing residual stress relaxation is by annealing above certain temperatures.

Residual stress relaxation by annealing is brought about by so-called thermally activated processes for which the annealing temperature and annealing time are interchangeable within certain limits [30]. Vohringer has shown that almost total residual 
stress relaxation occurs when a material is annealed at half the melting temperature of that material for several hours[29]. This temperature is usually corresponds to the recrystallization of the ferrous steels therefore complete relaxation of macro residual stresses is expected at this temperature.

In an experiment conducted by Vohringer [5] showing characteristic and material specific stress-temperature curves confirms the macro residual stress relaxation after annealing for 1 hour. It is postulated that residual stresses produced by hardening are relaxed at lower temperatures, machining residual stresses at medium temperatures, and deformation residual stresses at higher temperatures.

\subsubsection{Previous Studies on Thermal Relaxation of Residual Stress}

The thermal stability of shot peened residual stresses is mainly dependent on several critical peening parameters, including coverage, intensity and the resulting cold work. Numerous researchers have investigated thermal stability in steel alloys. Schulze reported results for AISI 4140 steel at temperatures ranging from $482^{\circ} \mathrm{F}$ through $842^{\circ} \mathrm{F}$ and exposure times up to 100 hours where surface compressive residual stresses relaxed from $15 \%$ to $85 \%$ with increasing temperature [31]. Hoffmann also reported similar results for surface relaxation where he considered three different heat treatments

of a $0.45 \% \mathrm{C}$ plain carbon steel at exposure temperatures ranging from $392^{\circ} \mathrm{F}$ to $1022^{\circ} \mathrm{F}$ and exposure times up to 1000 minutes [29]. He showed that relaxation of surface residual stresses was a strong function of temperature. In all of the above cases 
the compressive residual stress was induced by shot peening with constant shot peening parameters and results were compared with non-heat treated samples.

However, Prevey and Cammett [28] studied thermal relaxation at different shot peening coverages as well as different depths in high strength steel (AISI 4340 steel) at $475^{\circ} \mathrm{F}$ for 24 hours. They found that surface and near-surface relaxation was minimal about $10 \%$ to $30 \%$ and residual stresses are generally stable below a depth of about 0.004 in. In a study conducted by Tufft, it was found that only minor changes in compressive residual stresses for Marage 250 steel after 16 hours at $250^{\circ} \mathrm{F}, 400^{\circ} \mathrm{F}$ and $600^{\circ} \mathrm{F}$ [32]. Childs also observed substantial decreases in residual stresses induced by shot peening in 403 stainless steel in times as short as 1 hour at temperatures as low as $300^{\circ} \mathrm{F}$, with similar or larger decreases at longer times and temperatures up to $1100^{\circ} \mathrm{F}$ [33]. This also shows that thermally activation for residual stress relaxation takes place at earlier times in stress relieve process and relaxation is not linear relative to depth.

\subsection{Residual Stress in Aircraft Landing Gears}

A landing gear is one of the main structures of an aircraft, which is subject to cyclic loading during its operation. A typical aircraft has a tricycle landing gear configuration, which includes two main landing gears (MLG) and nose landing gear (NLG). The main landing gears normally carry $90 \%$ of the aircraft static weight. The primary purpose of the landing gear is to facilitate movement of aircraft easily on ground while taxiing, carry the aircraft weight during take off until it is transferred to the wings and to absorb the 
shock while landing. The major load bearing structures of landing gear includes outer cylinder, piston/inner cylinder, truck beam containing two axles also known as axle beam assembly and drag braces. Figure 2-7 shows typical main landing gear components. The outer cylinder and piston forms the shock strut assembly of the landing gear, which is connected to axle beam assembly. The shock strut assembly is also connected to airframe structure via trunnion pins. Hydraulic actuators control the retraction and extension of landing gears.

Landing gears are made of variety of materials, with major load bearing structures made of low alloy high strength steels as well as some aluminum and titanium alloys. High strength steel such as $4340 \mathrm{M}$, a variant of 4340 -alloy steel provides excellent strength to weigh ratio required for this aerospace application. It exhibits good fatigue resistant. In landing gear manufacturing, high strength steel is processed to size by machining to generate close tolerance surfaces such as attachment holes, bearing journals lug face etc. Particular care is taken to ensure that adequate and smooth radii, etc. are always present and that drill scores in bores, deep machining scratches, etc. are avoided [34]. A nital etch inspection is then performed to detect any hardened alloy due to machining or grinding abuse which is followed by a stress relief at $525^{\circ} \mathrm{F}$. Components are than magnetic particle inspected (MPI) to detect any cracks, shot peened to create a compressive residual stress layer for enhanced fatigue resistance. Chrome plating is applied on wear surfaces followed by another necessary hydrogen embrittlement relief heat treatment at $375^{\circ} \mathrm{F}$. Cadmium plating is applied on non-functional surfaces for 
corrosion protection with paint and bushing completing the final process before assembly.

Aircraft landing gear structures have safe life components meaning parts should be overhauled or scrapped depending on condition after every 8 to 10 years or depending on number of landing cycles. During the overhaul process, entire landing gear (main and nose including door mechanisms and actuators) is removed from aircraft and then disassembled followed by in-depth inspection.

Some landing gears are also subjected to incident related landings for example hard landing or flight test gears, which are regarded as incident related gears. Because of this, stresses are formed inside major components of the gear, specifically in round parts for example outer cylinders which house the shock strut and piston assembly and truck beam containing axles. It becomes important to remove the gear from service right away and do complete stress analyses on the gear and to remove any residual stresses, reprocess them including shot peening of entire surface and put back to service. Failure to do so could start a fatigue crack, which could propagate and can lead to catastrophic failure of the whole landing gear system. 


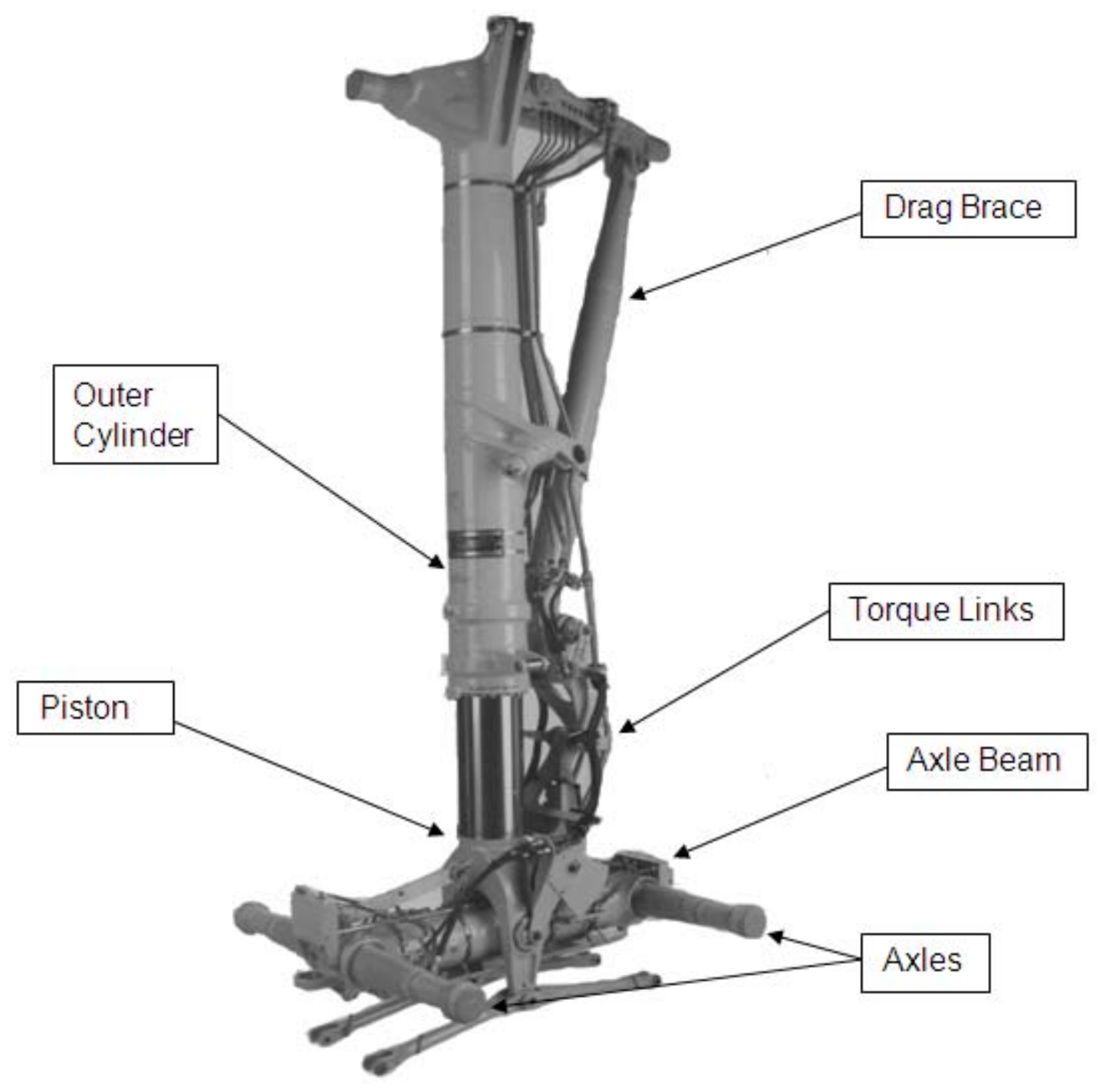

Figure 2-7: A typical Main Landing Gear

For the duration of the service, landing gear components are subjected to very high stress during repetitive landings and takeoff in different environments. The stress incurred during landings is of detrimental nature on landing gear components since this gives rise to fatigue. Resistance to crack-initiation and sub-critical crack-growth rate become more important criteria and ideally this rate should be slow enough to ensure that a crack will not grow to the critical size between two overhaul periods and could 
therefore be detected before complete failure took place [34]. Therefore after the fabrication of landing gear components, it becomes important to introduce compressive residual stress in all structural components to delay crack initiation hence delay fatigue failure.

It is seen from the study conducted by Parmeswaran and Mate [4] that during the processes of exploitation of aircraft, the stress critical zones of main landing gear strut undergo fatigue damage and micro cracks develop on the surface. It is also seen that the depth to which the micro crack develop is proportional to the number of landings. Usually, fatigue cracks nucleate and propagate from the surface due to the surface texture and defects like scratches. The compressive residual stress field induced by cold working such as shot peening treatment, indicate that such stresses act as a barrier to crack propagation [35]. Landing gears are often subjected to certain types of heavy loads applied a relatively small number of times and which therefore may contribute appreciably to the total fatigue damage. Low-cycle high-stress data (close to and exceeding the yield) under reverse-loading conditions are therefore required [34].

\subsubsection{Landing Gear Components Processing}

To increase the fatigue life of alloy steel parts manufactured from high strength steel material are routinely shot peened. Because of the complex geometries of landing gear components, the shot peening application as cold working processes is applicable in inducing residual stress. This shot peening imparts compressive stresses in the surface 
of steel. However, in processing and in service and overhaul of low alloy high strength steel parts there are instances in which the part may be exposed to elevated temperatures in excess to $400^{\circ} \mathrm{F}$. In such a case, the compressive stresses induced in the surface of the part may be relieved by exposure to these high temperatures. Since, landing gears are being overhauled once in 8-10 years according to the maintenance instructions of the manufacturer as well as to maintain continuous airworthiness. A typical landing gear overhaul process includes:

1) Sand cleaning to remove paint and rust.

2) Stress relief heat treatment to remove residual tensile and compressive stresses induced during service.

3) Use of non-destructive testing (NDT) to detect any cracks, nicks, tool marks.

4) Removal of any corrosion, cracks, tool marks from holes, bores, lugs and threads by machining, deburring or polishing.

5) Shot peening to introduce residual compressive stress.

6) Chromium or Nickel plating of the machined areas followed by heat treatment for hydrogen release per applicable standard and specifications.

7) Grinding of plated areas to restore to design dimensions and surface finish per applicable specifications.

8) Cadmium plating of entire surface followed by heat treatment for hydrogen release.

9) Installation of bushings and paint. 
Non-destructive testing (NDT) is done to verify the structural integrity of a component without compromising its ability to perform its service. As per grinding specifications (MIL-STD-866), which establishes the requirements for grinding of martensitic high strength steel heat-treated to 180,000 pounds per square inch (psi), ultimate tensile strength (UTS) and above, and the grinding of chromium plating applied to such high strength steel components, when such parts are intended for use in components for man- rated flight hardware.

In above process, the components are heat-treated and grinded few times after the shot peening process due to subsequent required plating processes. Since, in an overhaul process the component could require a chrome, nickel and cadmium plating, the subsequent heat treatment times could add up to 60-90 hours. Although electroplating by chrome, nickel or cadmium provides excellent benefit to the component in terms of wear and corrosion protection but it is detrimental to base material. It induces tensile residual stress because of the procedure, which diffuses hydrogen in substrate microstructure hence making the material brittle; this process is also called hydrogen embrittlement. As per plating specification parts are baked for minimum of 23 hours at $375^{\circ} \pm 25^{\circ} \mathrm{C}$ for release of hydrogen which is diffused after plating process where the maximum plating time before the start of the hydrogen bake out is 24 hours from start of the plating operation or 10 hours after the end of the plating operation, whichever occurs first. This process greatly affects the properties induced by shot peening. Electroplating alone is known to reduce compressive stress in steels by as much as 
$50 \%$; added this to subsequent heat treatment processes for hydrogen embrittlement relief, the effect of shot peeing could decrease even more.

Grinding operations which are performed after chrome plating, if done abusively could also lead to thermal damage by local overheating of base material leading to further decrease or even complete removal of induced residual stress in local areas hence making component very susceptible to increased fatigue damage during service. This kind of thermal damage to material is usually hard to detect because of lack of nital etch inspection processes in overhaul operation after final plating has been applied. Improper overhaul practices can lead to unscheduled maintenance or surface damage that can cause crack initiation. Several in-service fractures have been attributed to improper electroplating technique, poor-quality plating, and base metal damage caused by poor blending or grinding control [36].

Overheating conditions could also occur in-service for example during brake overheating or heavy landings, in this case uncontrolled temperature increase could eliminate the effects of induced compressive residual stress required for safe operation of landing gear system. That is why it becomes important to know the relaxation behavior and stability of induced compressive stress due to shot peening on 300M high strength steels. 


\section{CHAPTER 3}

\section{Material Characteristics and Modeling}

\subsection{General}

This chapter presents the Zener-Wert-Avrami model to calculate residual stress relaxation due to heat treatment as well as thermal stability of residual stress induced by shot peening. The experimental parameters required to form this function will be discussed in details. Information of materials used in landing gears, especially high strength steel is provided. Evaluation of fatigue life model and effect of residual stress is also discussed.

\subsection{Landing Gear Materials}

Most of modern aerospace structural components are designed from low alloy high strength steels; materials strong and tough enough to meet or exceed minimum application requirements. Low-alloy steels, quenched and tempered to tensile strength levels up to $300 \mathrm{ksi}$ are employed in a number of structural components. To achieve this strength level, the alloys contain about $0.4 \%$ carbon with other elements added to obtain hardenability and tempering resistance. The strength levels of these low alloyed steels are higher than virtually any other structural alloy, with approximately $40 \%$ strength to weight advantage over 7000 aluminum series, and superior mechanical properties compared to most titanium alloys. 300M ultra high strength steel (UHSS) was 
introduced around 1965 and is now almost the universal choice in the U.S.A. and the U.K. [34], it has been widely used for over forty years as a structural material in aerospace applications where a high strength is required [37].

Major components of landing gear system are made of high strength-low alloy steel, therefore for this purposes $4340 \mathrm{M}$ or $300 \mathrm{M}$ steel with UTS $300 \mathrm{ksi}$ is used. $300 \mathrm{M}$ is a modified version of AISI-4340 steel with silicon, vanadium and slightly greater carbon and molybdenum content. Alloy steels containing chromium or high percentages of silicon have also somewhat better oxidation resistance than the carbon or other alloy steels. The $300 \mathrm{M}$ alloy contains $1.5 \%$ to $1.89 \%$ silicon and $0.1 \%$ vanadium, whereas the silicon content of 4340 is $0.2 \%$ to $0.35 \%$ and vanadium is not added. The silicon is added to increase the tempering resistance, thereby allowing a higher tempering temperature than with 4340 and so providing a greater degree of stress relief. These modifications also provided a higher strength level than could be guaranteed with 4340 [38][39]. The elevated-temperature strength for the alloy steels is also higher than that of corresponding carbon steels.

$300 \mathrm{M}$ is heat treatable in thicker sections and exhibits higher strength levels than AISI 4140. They are much more difficult to weld. It is known for its toughness and capability of developing high strength in the heat-treated condition while retaining good fatigue strength. This grade of steel is produced by vacuum arc remelted process. In addition to a higher degree of consistency in fracture-toughness and fatigue, the principle 
advantage gained from vacuum melting is an improvement in transverse ductility at these high strength levels [34].

The chemical composition of $4340 \mathrm{M}$ steel is given in table $3-1$ which is certified to Aerospace Material Standard (AMS) 6419 and 6257 standards. As per AMS 6419, composition conforms to the percentages by weight as shown determined by wet chemical methods in accordance with ASTM E 350:

Table 3-1: Composition of 300M steel bars by weight percentage

\begin{tabular}{|c|c|c|}
\hline Element & Minimum \% & Maximum \% \\
\hline Carbon & 0.40 & 0.45 \\
\hline Manganese & 0.60 & 0.90 \\
\hline Silicon & 1.45 & 1.80 \\
\hline Phosphorus & - & 0.010 \\
\hline Sulfur & - & 0.010 \\
\hline Chromium & 0.70 & 0.95 \\
\hline Nickel & 1.65 & 2.00 \\
\hline Molybdenum & 0.30 & 0.50 \\
\hline Vanadium & 0.05 & 0.10 \\
\hline Copper & - & 0.35 \\
\hline
\end{tabular}


These steels are available in a variety of finish conditions, ranging from hot- or coldrolled to quenched and tempered. They are generally heat treated before use to develop the desired properties. Some steels in this group are carburized, and then heattreated to produce a combination of high surface hardness and good core toughness. These properties were obtained by normalizing by heating to $1700{ }^{\circ} \mathrm{F}$, holding at heat for 60 minutes, and cooling at a rate equivalent to air cooling, hardened by heating to $1600^{\circ} \mathrm{F}$, holding at heat for 60 minutes, and quenching in oil, and double tempered by heating to, holding at heat for 2 hours, cooling in air to room temperature, reheating to $575^{\circ} \mathrm{F}$, holding at heat for 2 hours, and cooling in air.

The resulting microstructure consists of a martensitic matrix with a variety of carbides distributed within or at the martensite boundaries [37]. Maximum hardness in these steels is obtained in the as-quenched condition, but toughness and ductility in this condition are comparatively low. By means of tempering, their toughness is improved, usually accompanied by a decrease in strength and hardness [40]. Following table 3-2 provides full design mechanical and physical properties (minimum required) of $300 \mathrm{M}$ steel with thickness of less than or equal to 5.00 inch for quenching in oil at a flow rate of $200 \mathrm{feet} / \mathrm{min}$. [40] 
Table 3-2: Mechanical properties of 300M steel [40]

\begin{tabular}{|l|l|}
\hline Property & Value \\
\hline Ultimate Tensile Strength $\mathbf{F}_{\text {tu }}$ & $280 \mathrm{ksi}$ \\
\hline Tensile Yield Strength $\mathbf{F}_{\text {ty }}$ & $230 \mathrm{ksi}$ \\
\hline Compressive Yield Strength $\mathbf{F}_{\text {cy }}$ & $247 \mathrm{ksi}$ \\
\hline Ultimate Shear Strength $\mathbf{F}_{\text {su }}$ & $168 \mathrm{ksi}$ \\
\hline Modulus of elasticity E, & $29.0 \times 10^{3} \mathrm{ksi}$ \\
\hline Shear Modulus G, & $11.0 \times 10^{3} \mathrm{ksi}$ \\
\hline Poisson's ratio, $\mathbf{v}$ & 0.32 \\
\hline Density, & $0.283 \mathrm{lb} / \mathrm{in}^{3}$ \\
\hline Elongation & $7 \%$ \\
\hline
\end{tabular}

The stress strain curves for $300 \mathrm{M}$ high strength steel is also provided in figure $3-1$ including curves at low temperature.

In general, tempering temperatures to achieve very high strength should be avoided when toughness is an important consideration especially in case of landing gear applications. In addition, these steels may be embrittled by tempering or by prolonged exposure under stress within the "blue brittle" range of approximately 500 to $700^{\circ} \mathrm{F}$. Strength levels that necessitate tempering within this range should be avoided [40]. 


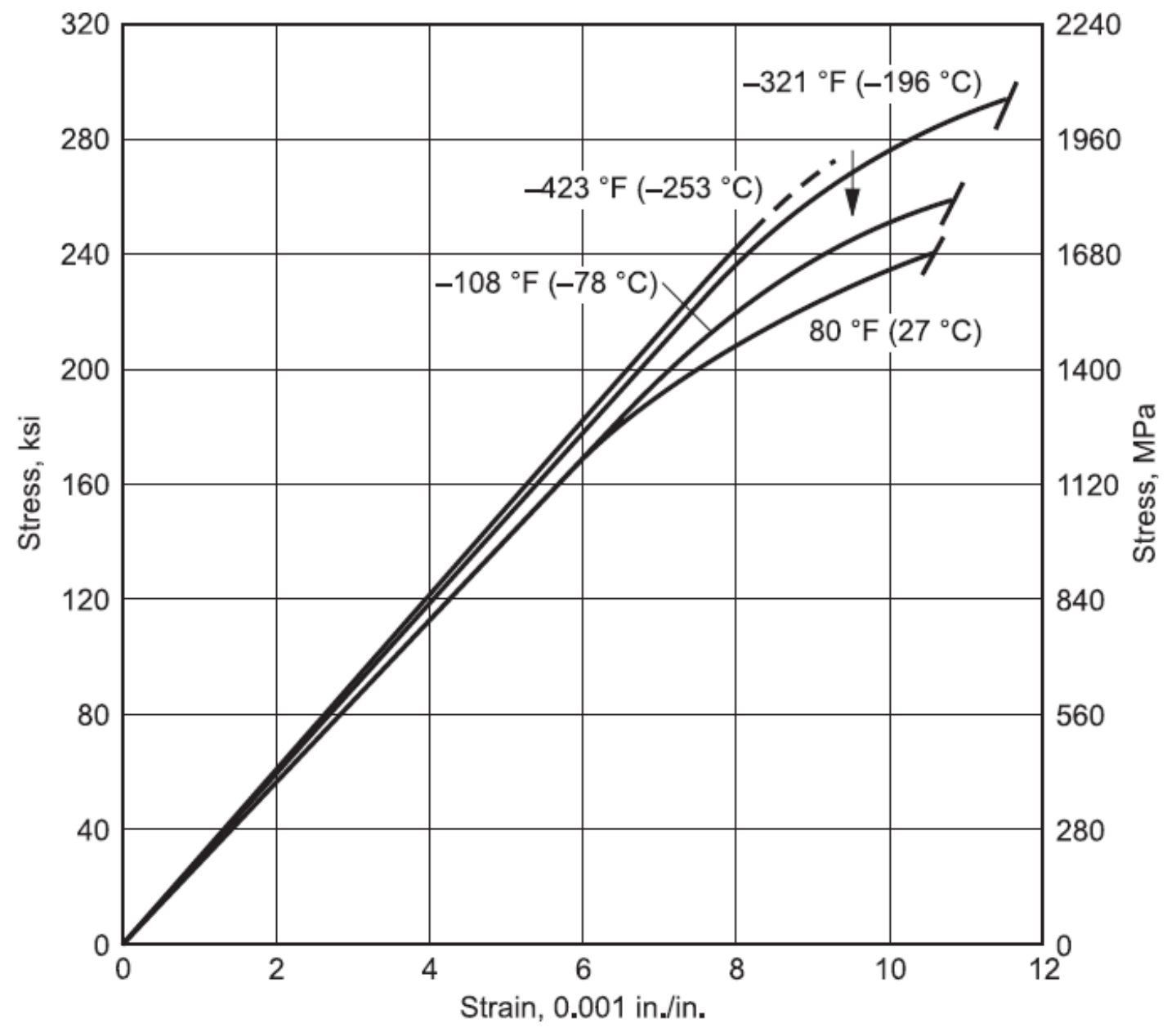

Figure 3-1: Stress-Strain curve of 300M alloy steel at room and low temperatures [40]

The mechanical properties of all alloy steels in the heat-treated condition are affected by extended exposure to temperatures near or above the temperature at which they were tempered. Hence, following charts provide elevated temperature curves for heat-treated AISI low-alloy steels exposed at these temperatures up to 1/2 hour. Best fit S-N curves for $300 \mathrm{M}$ steel at unnotched condition is also presented in figure 3-5. 


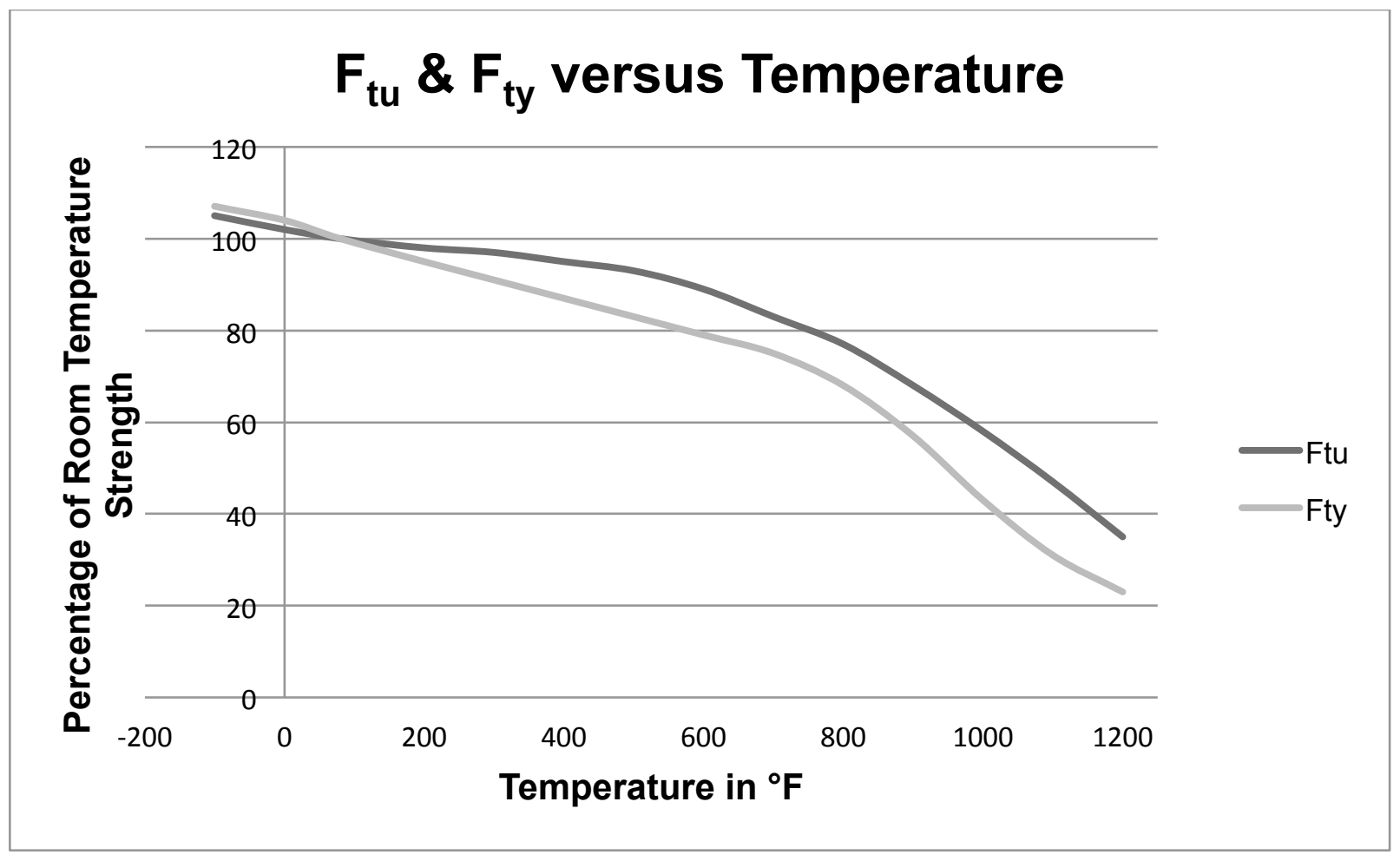

Figure 3-2: Effect of temperature in ultimate tensile strength and tensile yield strength of low alloy steel [40]

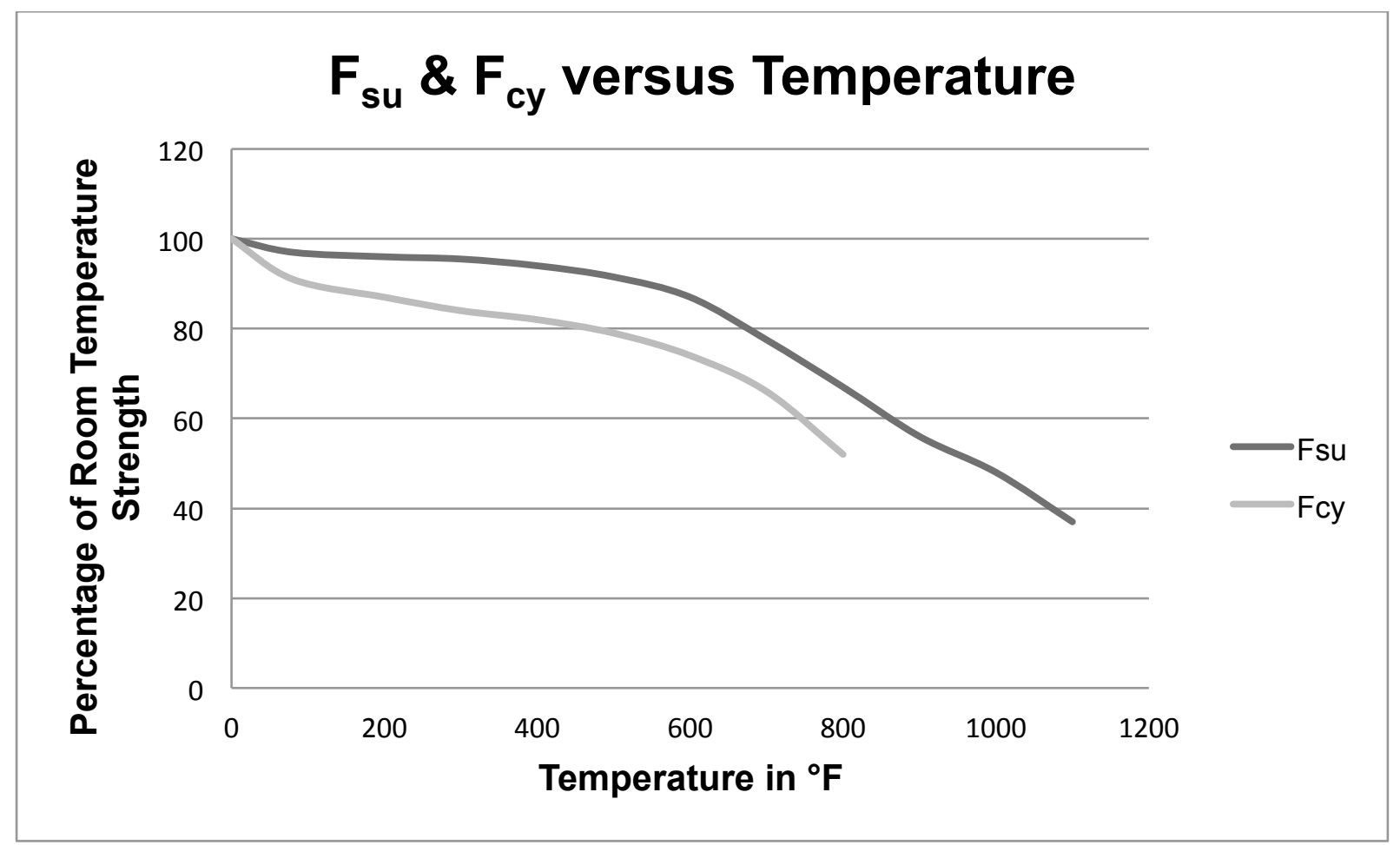

Figure 3-3: Effect of temperature on compressive yield strength and shear ultimate strength on AISI low alloy steels [40] 


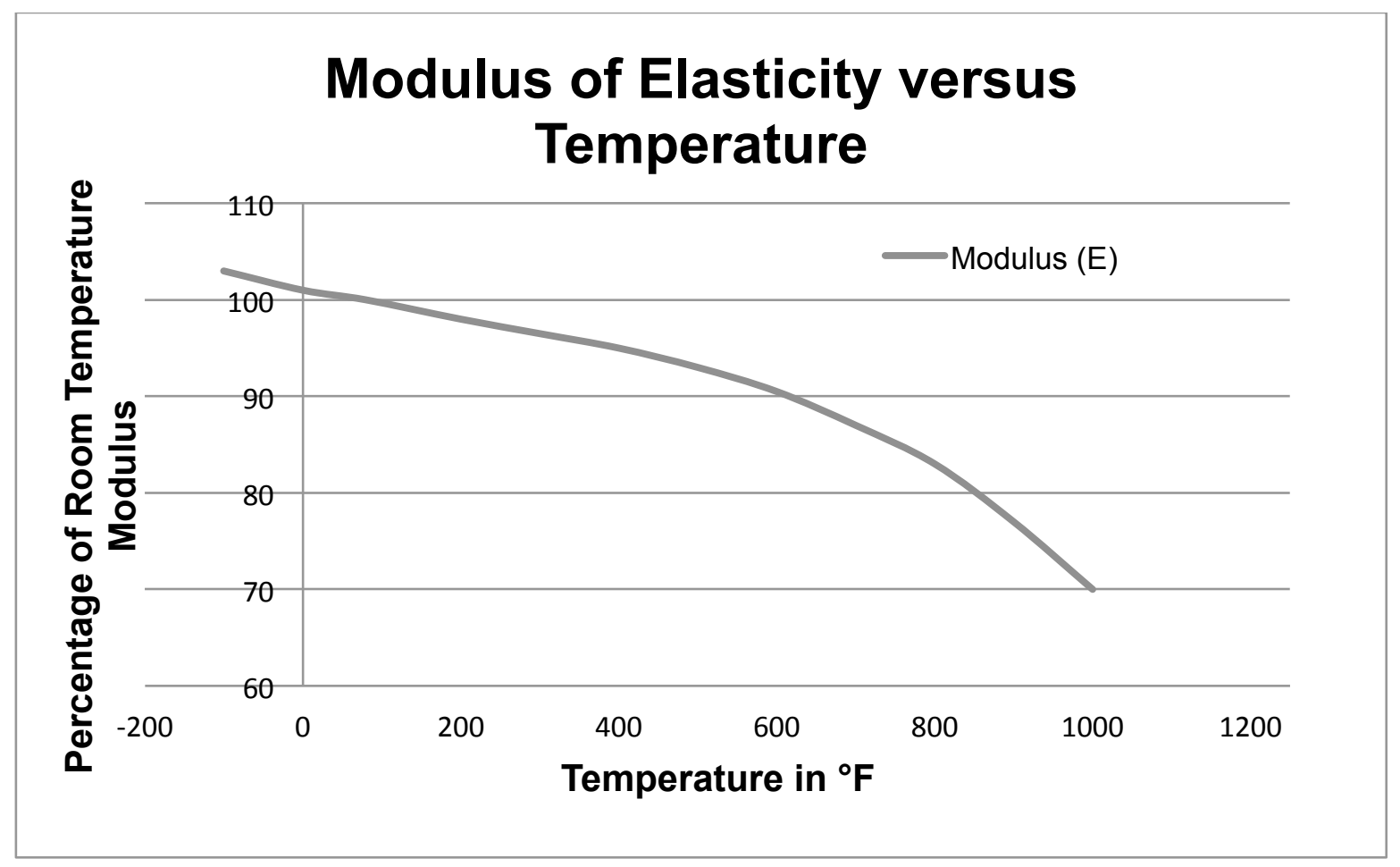

Figure 3-4: Effect of temperature on modulus of elasticity of low-alloy steels [40]

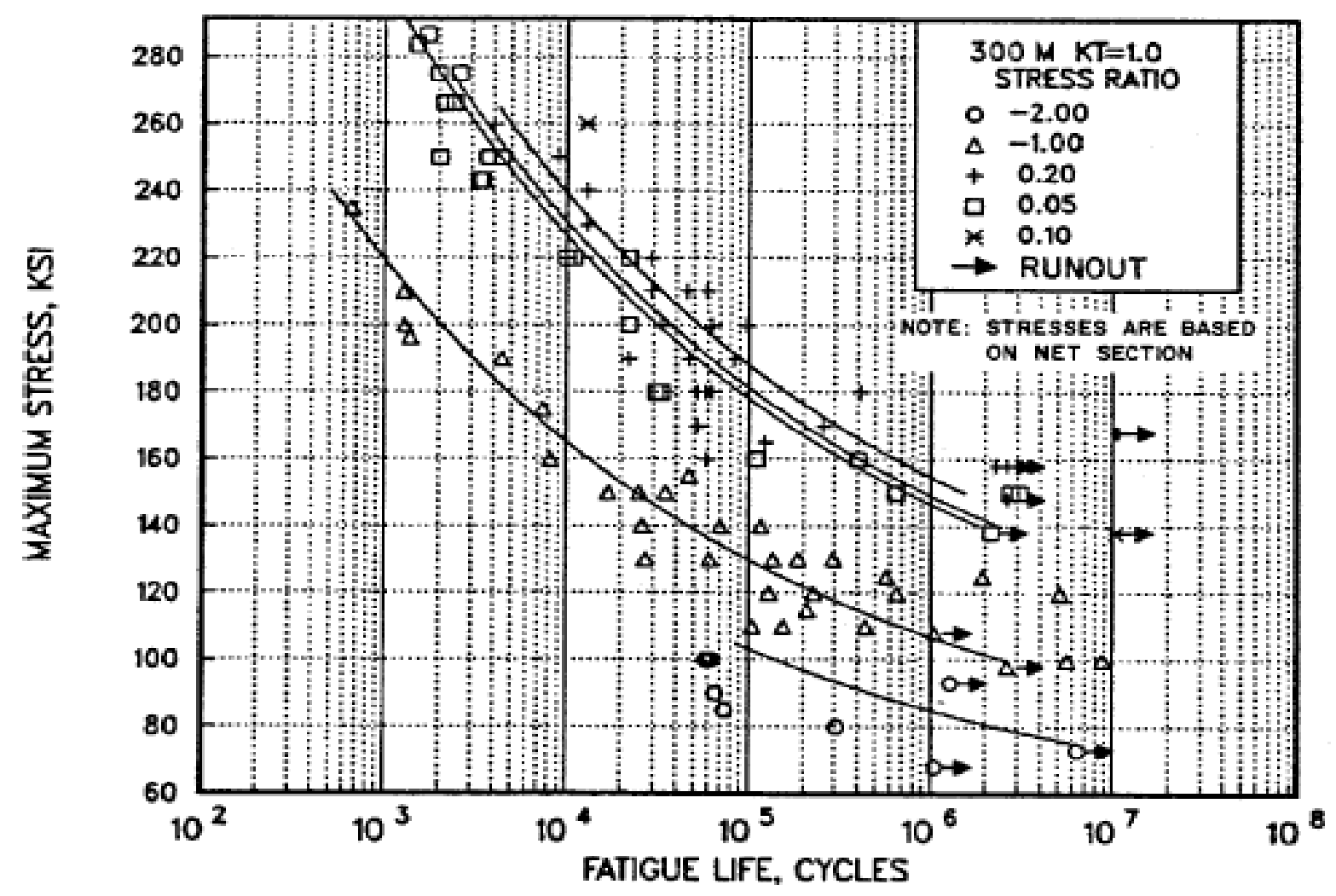

Figure 3-5: S-N curves for unnotched 300M alloy steel forging [40] 


\subsection{Zener-Wert-Avrami function of Residual Stress Relaxation}

The involvement of temperature to the relief of residual stresses can be mainly treated as a stress relaxation process, in which elastic strains are transformed into plastic strains. To analyze this thermally activated process, the influence of stress relieve time and temperature must be known. It is known that Vohringer and his colleagues [29] at the University of Karlsruhe in Germany have widely used a so-called Zener-WertAvrami function of the general form. If time and temperature ranges are in such a way that the ratio of residual stress at stress relieve temperature $\sigma_{r s}^{T}$ and residual stress at shot-peened and non-heat treated material $\sigma_{\mathrm{o}}$ stays constant then stress relieve time $\mathrm{t}$ is expressed as:

$$
t=t_{o} \exp (Q / k T)
$$

where $Q$ is the activation energy, $k$ is the Boltzmann's constant, taken as $8.6173 \times 10^{-5}$ $\mathrm{eV} \mathrm{K}^{-1}$ and $T$ is stress relieve temperature

When effect of stress relieve time $t$ on residual stress relaxation is linearized with the help of a Zener-Wert-Avrami function, following equation is obtained:

$$
\sigma_{r s}^{T} \sigma_{\sigma_{o}}=\exp \left[-(A t)^{m}\right]
$$

where $m$ is a numerical term dependent on dominant relaxation mechanism and $A$ is a material-dependent function, which is affected by temperature::

$$
A=B \exp (-Q / k T)
$$

Coefficient $B$ is a constant prefactor. 
Through a logarithmic transformation, equation 3-2 is rewritten as:

$$
\log \ln \left(\sigma_{\mathrm{o}} / \sigma_{\mathrm{rs}}^{\mathrm{T}}\right)=m \log t+m \log A
$$

Constant $m$ corresponds to the slope of curves of $\log \ln \left(\sigma_{\mathrm{o}} / \sigma_{\mathrm{rs}}^{\mathrm{T}}\right)$ versus $\log t$ as shown on figure 3-6. The straight lines obtained at different heat-treating temperatures possess identical slopes. As the magnitude of heat treat temperatures increases, the increasing $y$-intercept of these lines increases.

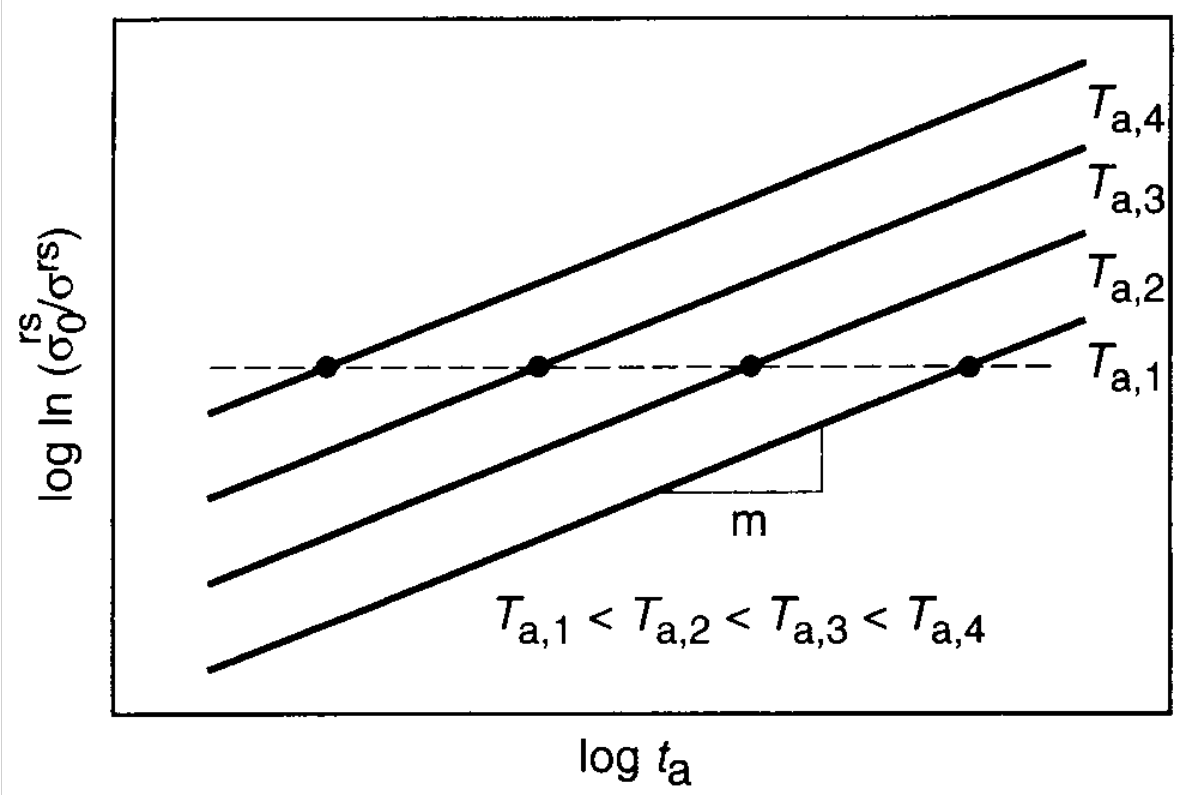

Figure 3-6: Determination of $m$ as slope [5]

The slope and equation of lines are very important in determining the activation energy required for thermal relaxation. Similarly with $\log t$ versus $1 / k T$ plot as shown in figure 3-7, corresponding stress relieve time and temperature for $\left(\sigma_{r s}^{T} / \sigma_{o}\right)=$ constant can be derived. The activation energy for residual stress relaxation is expressed as : 


$$
\log t=\text { constant }+\frac{Q}{(\ln 10 . k T)}
$$

The percentage relaxation of residual stresses for a given material is obtained from equations (3-2) and (3-3) as:

Percent relaxation $=\left[\exp \left\{-B t e^{\frac{c}{T}}\right\}^{m}\right] \times 100 \%$

where, constant $C=\frac{-Q}{k}$ is determined experimentally from equation 3-5 and material specific constants $m$ and $Q$ are determined experimentally by creating plots similar to figures 3-6 and 3-7 using measured residual stress relaxation at different temperatures and heat treat times. Value of constant prefactor $B$ is calculated by rearranging equations 3-2 and 3-3 and using recorded relaxation ratios at constant time and different temperature. In this study, method described by Roth [30], was applied.

Equation (3-6) is limited for temperature magnitudes below the half melting point $(T<$ $0.5 \mathrm{~T}_{\mathrm{m}}$ ) since at $\mathrm{T}=\mathrm{T}_{\mathrm{m}}, 100 \%$ relaxation is expected. 


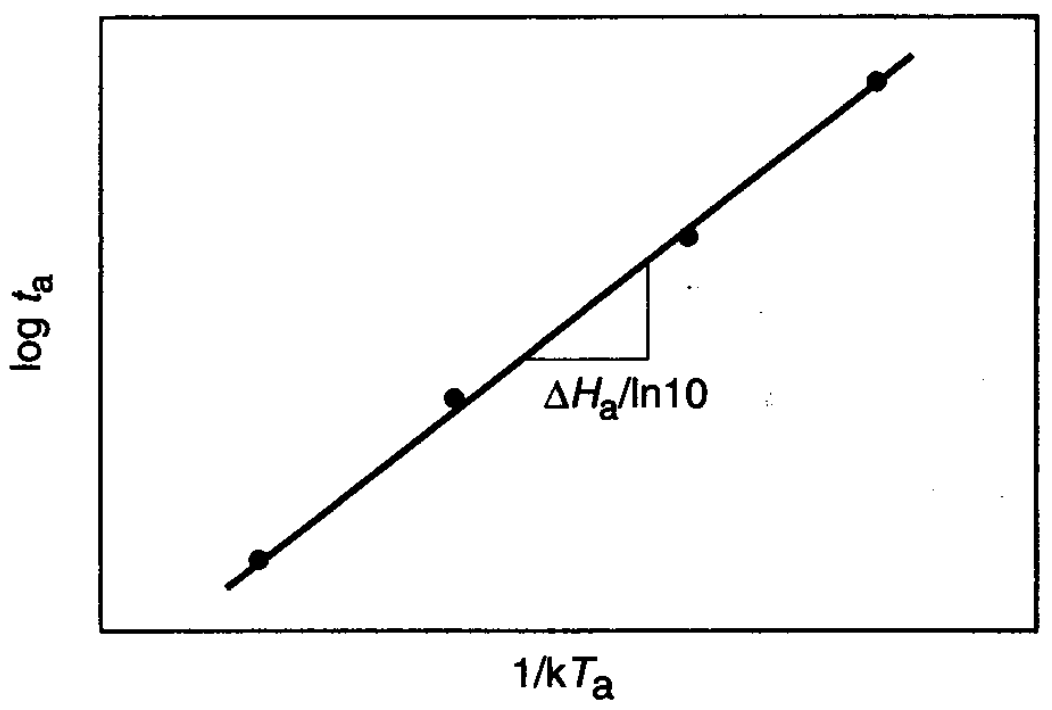

Figure 3-7: Determination of activation energy $Q\left(\Delta H_{a}=Q\right)$ [5]

The slope of the each line in figure 3-7 is obtained for percent relaxation interval, hence parallel lines are formed with same slope at any given percent relaxation value. A main advantage of using this model is that this technique looks at ratio between initial residual stress and final residual after heat treatment; therefore it is not required to have identical values of initial residual stress in a material as long as any initial value is known. That is why this model can be applied easily to residual stress obtained by shot peening, which is based on empirical techniques. To experimentally obtain values for $m$ and $Q$, slopes in figures 3-6 and 3-7 are required, which can determined by measuring values of compressive residual stress induced by shot-peening before and after heat treatment at corresponding known time intervals.

An experimental verification of this theoretical model was obtained with the SAE 1045 steel, which had been deformed in tension or hardened to produce residual stresses[5]. 
In an extensive study Vohringer [5] conducted by shot peening on AISI 4140 steel by measuring macro residual stress before and after relaxation by X-ray diffraction. It was conformed in his experiments that volume diffusion controlled dislocation creep in the residual stress field is dominated by climbing of edge dislocations which is rate controlling process for the relaxation of shot peening residual stresses [29].

In case of steels, it was found that the activation energy $Q$ depends on the state of the material and lies in the range of 1.1 to $2.6 \mathrm{eV}$ where $Q$ the lowest for relaxation of residual stresses due to hardening and is the highest for those due to deformation in soft annealed states [5].

Vohringer [5] further reported that an increase in the dislocation density and a change in the dislocation arrangement occur during hardening of steels. The concentration of solute interstitial atoms differs from equilibrium value and along with dislocations and greatly affects on residual stress fields. Vohringer and his colleagues recognized that in addition to temperature and exposure time, the state of the material microstructure is itself is another parameter that affects relaxation rate of residual stresses. It was postulated that relaxation rate determining process, with exception of early stages in stress relieving is due to thermally activated climb of edge dislocations [41]. In case of extremely high density of dislocation in hardened steels, residual stress relaxation is expected to involve diffusion-controlled climb by edge dislocations. 
In a similar experiment conducted by Roth [30] on $12 \%$ chromium steel shot peened and stress relieved at different temperatures and time, it was observed that at temperatures above $300^{\circ} \mathrm{C}$ the activation energy becomes $3.5 \mathrm{eV}$, and below $300^{\circ} \mathrm{C}$ it is $1.4 \mathrm{eV}$ as shown in figure 3-8 where a plot similar to figure 3-7 is displayed with different stress relieve percentages. The higher value of activation energy was found comparable to the activation energy required for self-diffusion of pure iron, which was $2.8 \mathrm{eV}$. This lead to conclusion that from $300^{\circ} \mathrm{C}$ to $600^{\circ} \mathrm{C}$ the residual stresses were reduced by deformation processes based on diffusion controlled dislocation movement.

Accordingly this thesis intended to choose stress relieve temperatures of $375^{\circ} \mathrm{F}, 450^{\circ} \mathrm{F}$, $525^{\circ} \mathrm{F}, 650^{\circ} \mathrm{F}$, and $875^{\circ} \mathrm{F}$ as previous studies well documented that at temperatures above $400^{\circ} \mathrm{F}$, the beneficial effects of shot peening for steel alloys have been rapidly disappeared.

It is also to be noticed that at stress relieving temperatures lower than half of melting temperature of material, the mechanical properties like hardness and yield strength are not significantly altered. If however stress relieving temperature is above half of material's melting temperature than recrystallization of material structure occurs and dislocation density rapidly takes very small values as result of growth of new grains, which leads to complete removal of residual stresses but also results in changes in hardness and yield strength of the material [5]. This highlights how important is the correctly chosen stress relieve temperature and time to rescind any recrystallization of 
material structure. It was seen in the study that the dependence of macro residual stresses after different stress relieving times on distance from surface can be described quantitively using the surface material properties, which is very useful aspect in fatigue life of materials.

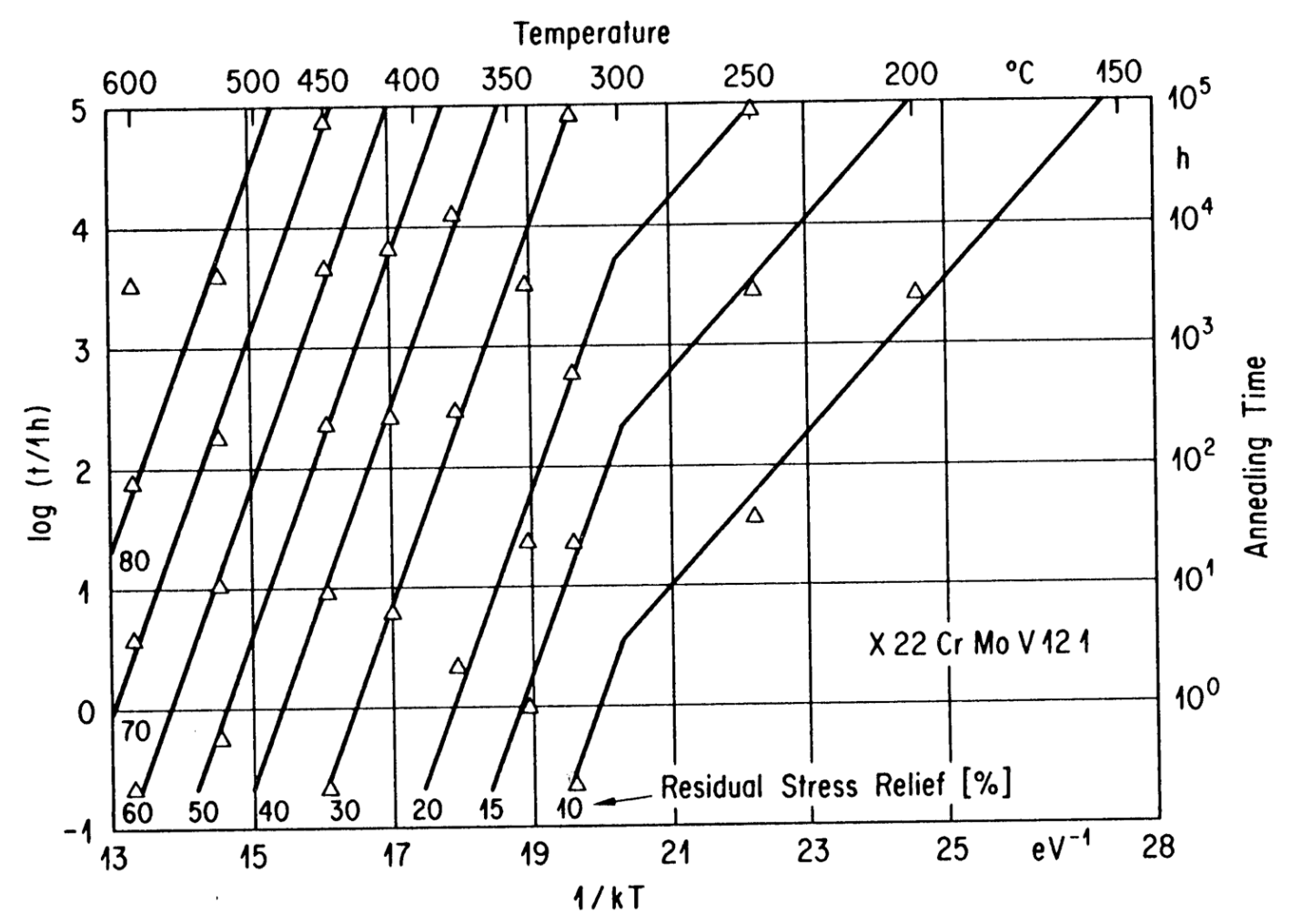

Figure 3-8: Plot showing determination of activation energy from slopes of straight lines for $12 \%$ chromium steel [30]

Materials used in landing gear major structural components, such as $4340 \mathrm{M}$ are susceptible to fatigue failure due cracks arising from surface nicks, corrosion or their inner surface impurities which might have been induced during manufacturing processes. Hence, subsurface information about the residual stress in these materials is very important in relation to fatigue. 


\subsection{Effect of Residual Stress in Fatigue-life Calculations}

Several calculation methods linking residual compressive stress levels and fatigue life have been proposed. Generally, when a part is subjected to a field of residual stresses and is superimposed on a field of service stresses, the real stress on the part is characterized as addition of two stress fields [42]. If the residual stresses are added to the service stresses, in case of tensile residual stress, the part is locally overloaded due to residual stress. After shot peening, to introduce the compressive residual stress, the part is relieved of some of the load locally and the mechanical performance of the materials is increased a result, figure 3-9 shows how superimposed residual stresses on service stress affects the stress distribution in a bending fatigue test.

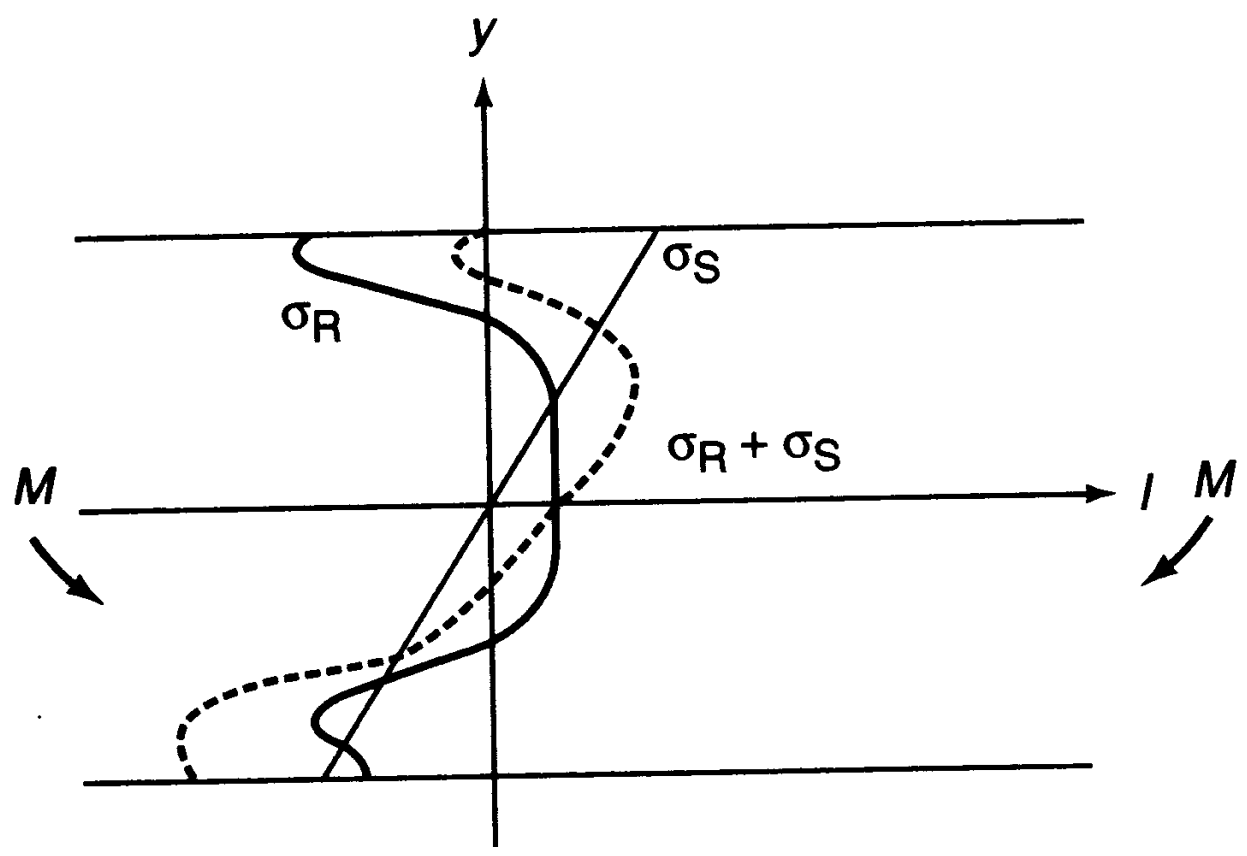

Figure 3-9: Superimposing of residual stress and service stress [42] 
Residual stress plays an extremely important role with respect to fatigue strength of the materials. They can be considered to be mean or static stress superimposed on the cyclic stress [42]. As the mean stress increases, the fatigue strength decreases. If residual compressive stress introduced by shot peening is known, Haigh or Goodman diagrams can be used to illustrate the mean stress and applied alternate stress relationship for stress-life estimations [43]. Equation 3-7 has been modified to include the residual stress $\sigma_{R S}$ :

$$
\sigma_{a}=\sigma_{D}-\sigma_{D} / S_{U}\left(\sigma_{m}+\sigma_{R S}\right)
$$

where, $\sigma_{a}$ is the critical alternating applied stress, $\sigma_{m}$ is the mean stress, $\sigma_{D}$ is reverse tensile fatigue limit or fatigue strength at zero mean stress and $S_{u}$ tensile strength of the material. It can be clearly seen from the equation that residual stresses are taken into account with mean stresses. In case of notches, when the load is fully reversed, the residual stress at the root where fatigue cracks initiate has the same effect as an externally applied compressive mean stress of equal magnitude. Hence, compressive mean stress will increase the life at given alternating stress level [44]. 


\section{CHAPTER 4}

\section{Experimental Procedure}

\subsection{General}

The current chapter presents the experimental procedure used to measure residual stress using two different methods. Some background information is also provided on measurement techniques and its principles. Several number of readings were required to create the model to measure residual stress relaxation. The present chapter provides details about material selection and sample preparation as well as shot peening parameters and procedure followed by heat treatment technique used when measuring residual stress using deflection method. The second method of measuring residual stress using X-ray diffraction was applied as it provides residual stress measurements at different depths of material. Material preparation, shot peening and stress relive processes for material used in measuring residual stress at different depth using X-ray diffraction method are described in details as well.

\subsection{Residual Stress Measurement Methods}

There are variety of methods developed to measure residual stress, which are qualitative and quantitative in nature as well as destructive and non-destructive techniques. Nearly all the residual stress measurement methods measure elastic strain, not stress and the residual stress are calculated from strain values. The destructive 
methods involve destruction of state of equilibrium of the residual stress in a mechanical component, hence residual stress can be determined by measuring strain changes due to stress relaxation as a consequence of material removal [45]. These techniques include hole drilling method, ring core technique, the bending deflection method and the sectioning method. Generally, strain is measured by mechanical or electrical resistance strain gauges, optical gages and birefringent methods. These methods involve material rendering process, which makes the material unusable after measurements.

On the other hand non-destructive methods are based on the relationship between the physical or crystallographic parameters and the residual stress [46]. These methods include X-ray diffraction method, the neutron method, the ultrasonic method and the magnetic methods. Whenever a mechanical force, resulting in the stress that is less than the yield strength is placed on a solid metal component, that component distorts and strains elastically. The elastic strain results in a change in the atomic lattice dimension, and this dimension or change is measured by the non-destructive stress measurement procedure [45] in case of X-ray diffraction.

Usually, non-destructive methods are very costly to implement and required expensive and sophisticated equipment. In the present thesis, both methods of destructive and non-destructive, deflection and X-ray diffraction were employed to measure residual stress to create and calculate stress relaxation model. 


\subsection{Deflection Method to Determine Residual stress}

When a plane thin part that contains residual stresses is deformed in such a way as to maintain the static equilibrium of internal moment and forces, the deflection along its major axis is produced [45]. This deflection naturally depends on the type and magnitude of residual stresses involved.

It is expected that when a flat piece of steel strip is secured to a solid block (the test strip holder) and then exposed to a stream of shots, it will be curved upon removal from the block. The curvature is due to residual compressive stresses induced by the shot impacts, causing the peened face to be convex as shown in figure 4-1. Deflection of the strip occurs in order to relieve some of the high surface compressive stress [45]. The curvature serves as a mean of measuring the effect of the shot peening. The degree of the curvature depends upon the properties of the shot stream, which is shot velocity, shot size, the properties and mounting of the test strip, and the exposure condition [45].

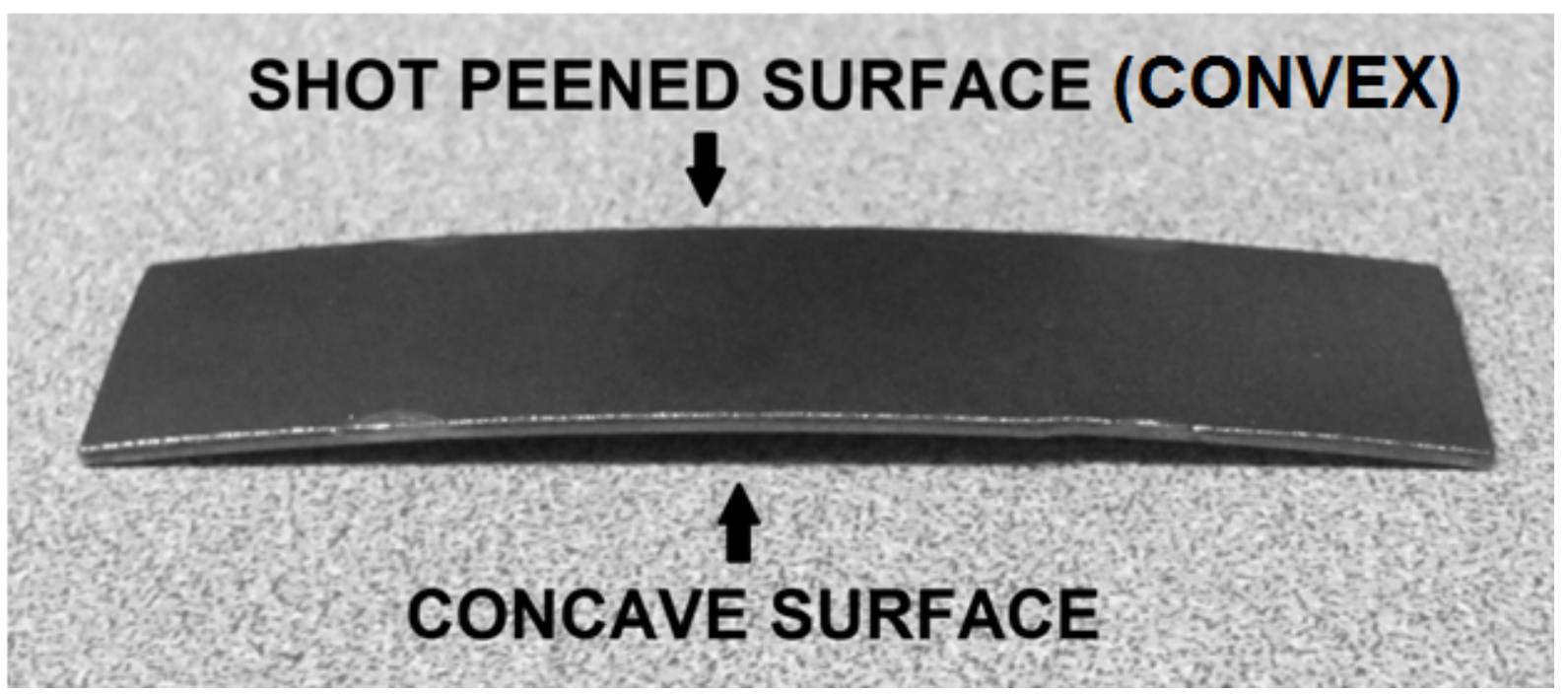

Figure 4-1: Effect of shot peening on thin plate 
The lift height is proportional to the level of compressive stress developed in the peened surface during peening. Peening is continued until the material has reached saturation; that is, when the lift height increases by no significant amount and the compressive stress in the surface layers corresponds closely to the elastic limit of the steel strip.

The magnitude of curvature is restricted by the restraint of the remainder of the material, and equilibrium is reached when the remaining compressive stress is in balance with the elastic compressive stress developed in the un-peened surface. Therefore, the depth and intensity of the compressive layer is proportional to the lift height at saturation. The magnitude of estimated residual stress values should be in the range of 200 psi - 5000 psi. Equation 4-1 can be applied to estimate residual stress in the test specimen.

$$
\sigma_{R S}=\frac{E d u}{2 L^{2}}
$$

where, $E$ is Young's Modulus for steels, $t$ is thickness of specimen, $d$ is measured deflection and $L$ is length of test sample

Since, this model is constructed in way that only ratio between residual stresses before and after heat treatment is significant, the derivation of this equation is not considered part of this study. At deflection $d=0$, the residual stress is also zero, hence larger the deflection is, the residual stress value becomes higher in magnitude. 


\subsubsection{Specimen Preparation for Deflection Method}

Deflection method very much depends on a precise measurement of material deflection and the induced residual stress. Test strips made of $300 \mathrm{M}$ high strength steel of size similar to Almen strips were obtained from manufacturer Intercontal Inc., except with thickness of 0.045 inch. Detailed dimensions are shown in figure 4-2. The hardness of material ranged between 56 to $57 \mathrm{HRC}$. These test strips were made of same material used in aircraft landing gears which conforms to all commercial and military material specification of major aircraft manufacturer enterprises.

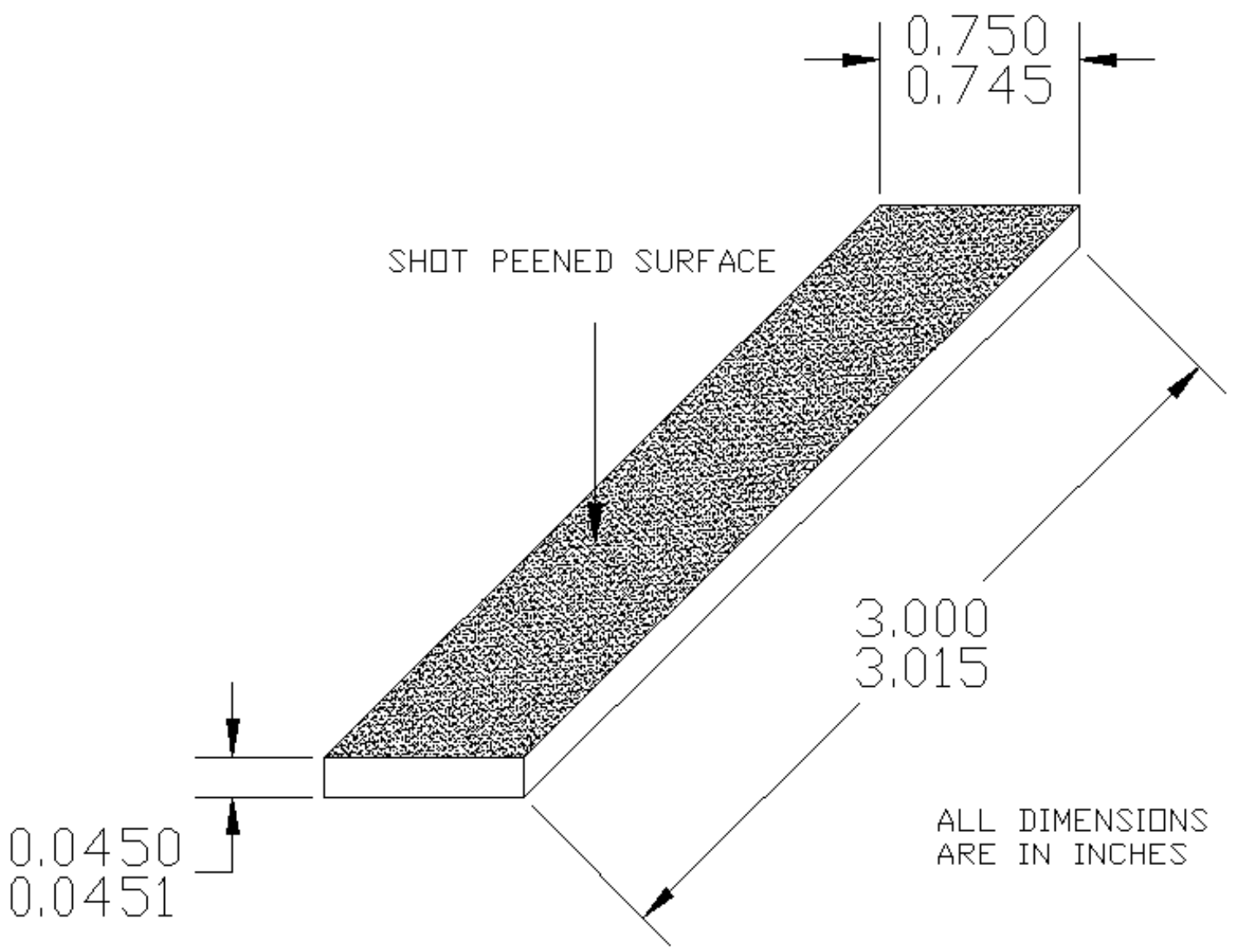

Figure 4-2: Dimensions of 300M steel strip 
Strips made of $300 \mathrm{M}$ material were fabricated by vacuum arc remelted process, rough turned, normalized for 2 hours at $926^{\circ} \mathrm{C}$; air cooled and followed by tempered at $676^{\circ} \mathrm{C}$ for 4 hours to obtain hardness of 55-57 HRC. The strips were cut at $3 \times 0.75$ inches using milling machine with a thickness of $0.045 \pm 0.0005$. An image of a $300 \mathrm{M}$ steel strip and an Almen strip is shown in figure 4-3.

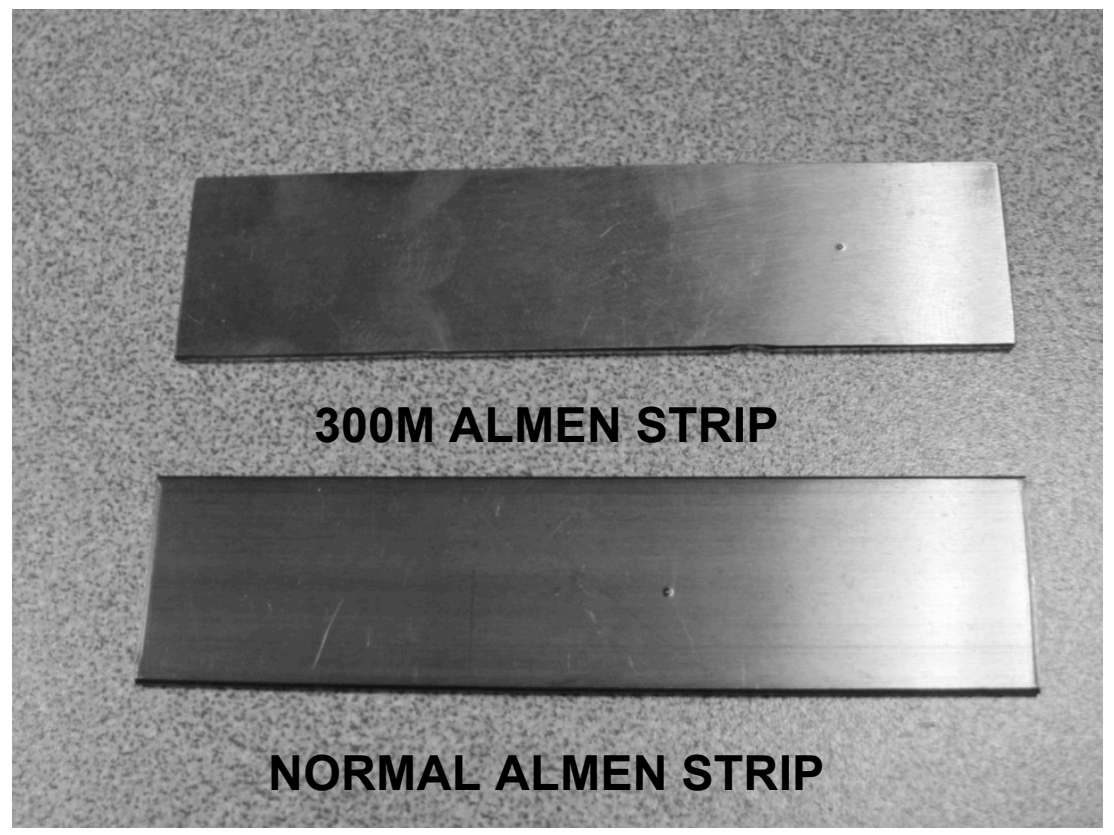

Figure 4-3: Image of 300M steel strip with same dimensions as Almen Strip

For statistical purposes, total of fifteen (15) specimens were required for residual stress measurement test at which six stress relieve time experiments were performed each at 5 stress reliving temperatures. The strips were checked for pre-straightness using the Almen gauge, all strips were than vibro-engraved with strip number to control the experiment as shown in figure 4-4. 


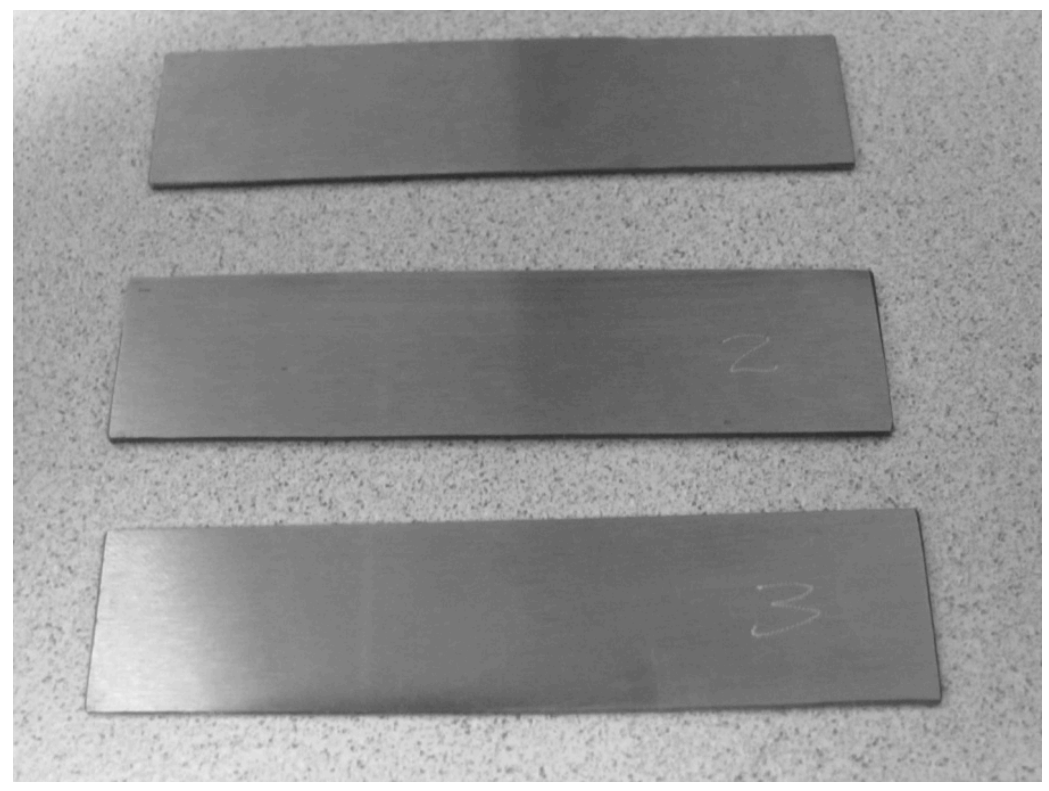

Figure 4-4: Vibro-engraved strip identification

\subsubsection{Material Specifications and Properties}

The material is controlled by many national and commercial standards: Aerospace Material Specification (AMS) 6417, AMS6419, AMS6257, AMS2300, Boeing DMS 1935 (Boeing Military), Boeing BMS 7-26 (Type 1) (Boeing Commercial) Bendix CE-0896, Grumman GM1012, MIL-S-83135, MIL-S-8844 Class 3, SAE AMS-STD-2154 Type 2, Class A, Lockheed C-05-1190.

The actual composition of $300 \mathrm{M}(4340 \mathrm{M})$ conforms to the percentages by weight shown in table $4-1$, while the mechanical properties of $300 \mathrm{M}$ steel are given in the table $4-2$. 
Table 4-1: Composition of 300M steel strips by weight percentage

\begin{tabular}{|l|l|}
\hline Element & Weight \% \\
\hline Carbon (C) & 0.420 \\
\hline Silicon (Si) & 1.65 \\
\hline Manganese (Mn) & 0.78 \\
\hline Phosphorous (P) & 0.004 \\
\hline Sulfur (S) & 0.0006 \\
\hline Chromium (Cr) & 0.79 \\
\hline Molybdenum (Mo) & 0.39 \\
\hline Nickel (Ni) & 1.79 \\
\hline Copper (Cu) & 0.04 \\
\hline Vanadium (V) & 0.065 \\
\hline Iron (Fe) & Remainder \\
\hline
\end{tabular}

Table 4-2: Mechanical Properties of 300M steel strip

\begin{tabular}{|l|l|}
\hline Poisson's Ratio & 0.32 \\
\hline Elastic Modulus & $29,000 \mathrm{ksi}$ \\
\hline Ultimate Tensile Strength & $300 \mathrm{ksi}$ (average) \\
\hline Yield Strength & $245 \mathrm{ksi}$ (average) \\
\hline Elongation & $12 \%$ \\
\hline Reduction in Area & $42 \%$ \\
\hline Hardness (average) & $57.6 \mathrm{HRC}$ \\
\hline
\end{tabular}




\subsubsection{Shot Peening Procedure for 300M Steel Strips}

All specimens were shot peened at Goodrich Landing Gear Services at Burlington, Ontario facility through following procedures. $300 \mathrm{M}$ steel strips were securely attached in test strip holder. The surface flatness of test strip holder was also verified and found to be within acceptable limit of \pm 0.0002 . Dimensions of test strip holder are given in figure 4-5 and figure 4-6,

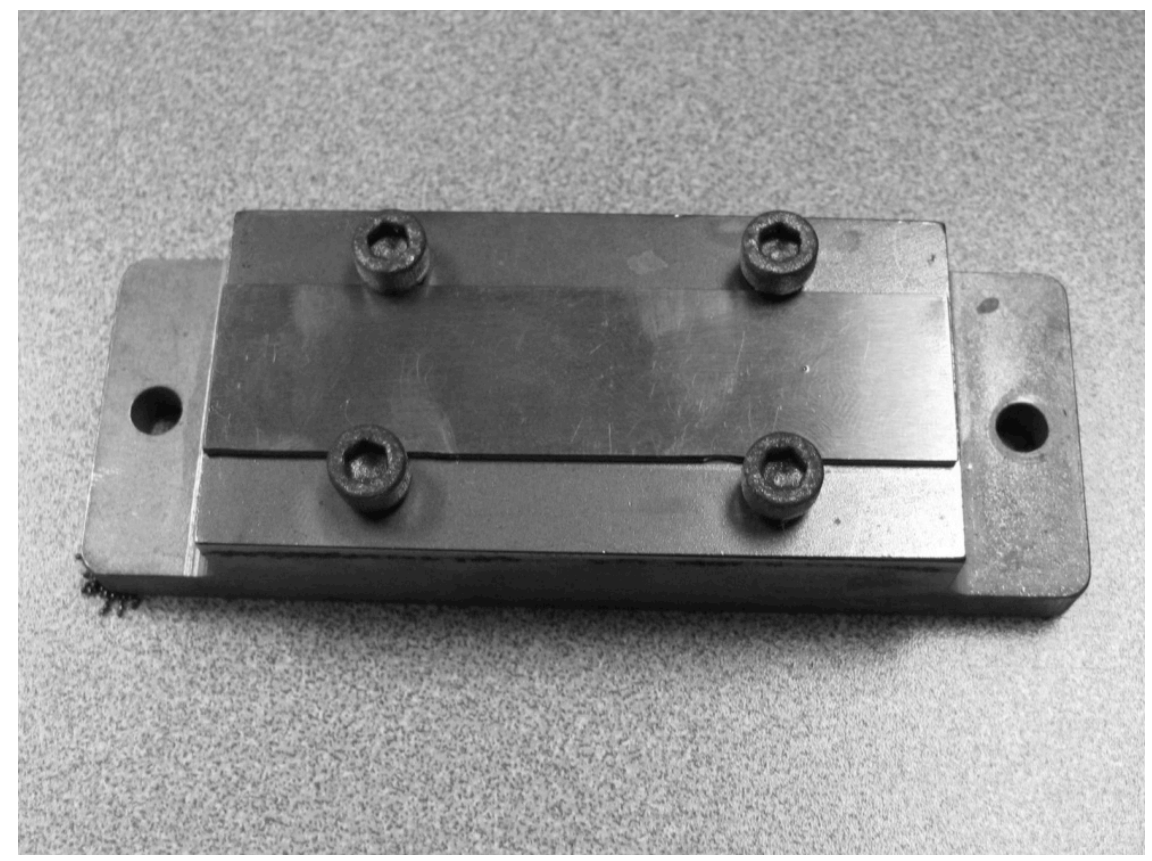

Figure 4-5: Image of Test specimen holder or Almen block

The test holder is made of harder carbon steel that was also used during the stress relieve process. Later, these test strip holders were attached to a 'turtle fixture' as shown in figure 4-7 which is a heavy jig that can hold 9 test strip holders at different locations. The fixture ensures that strips don't fly off as they are being shot peened and results in a maximum surface area of strip exposed on one side only. 


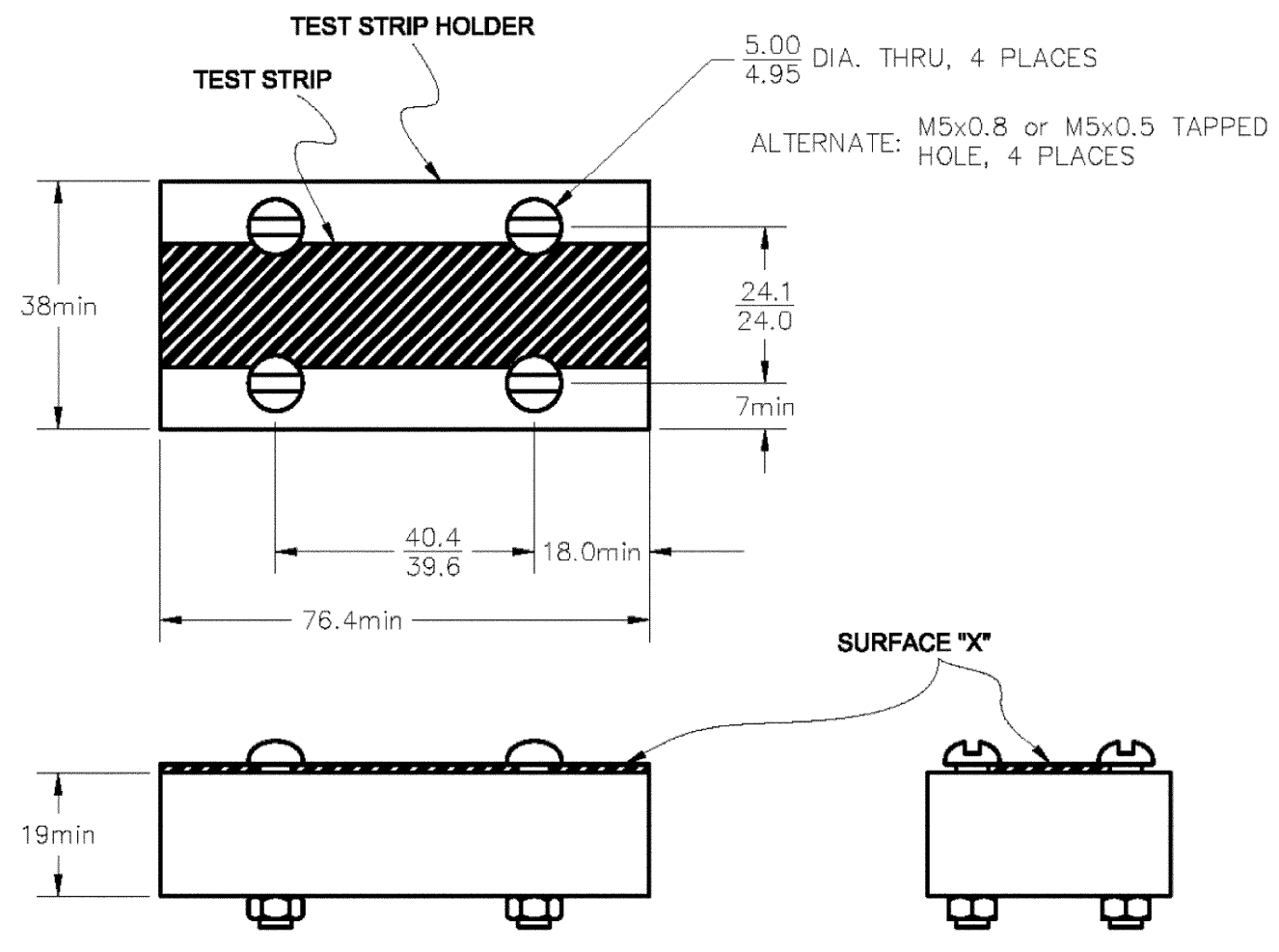

Figure 4-6: Dimensions of Almen Strip test holder [46]

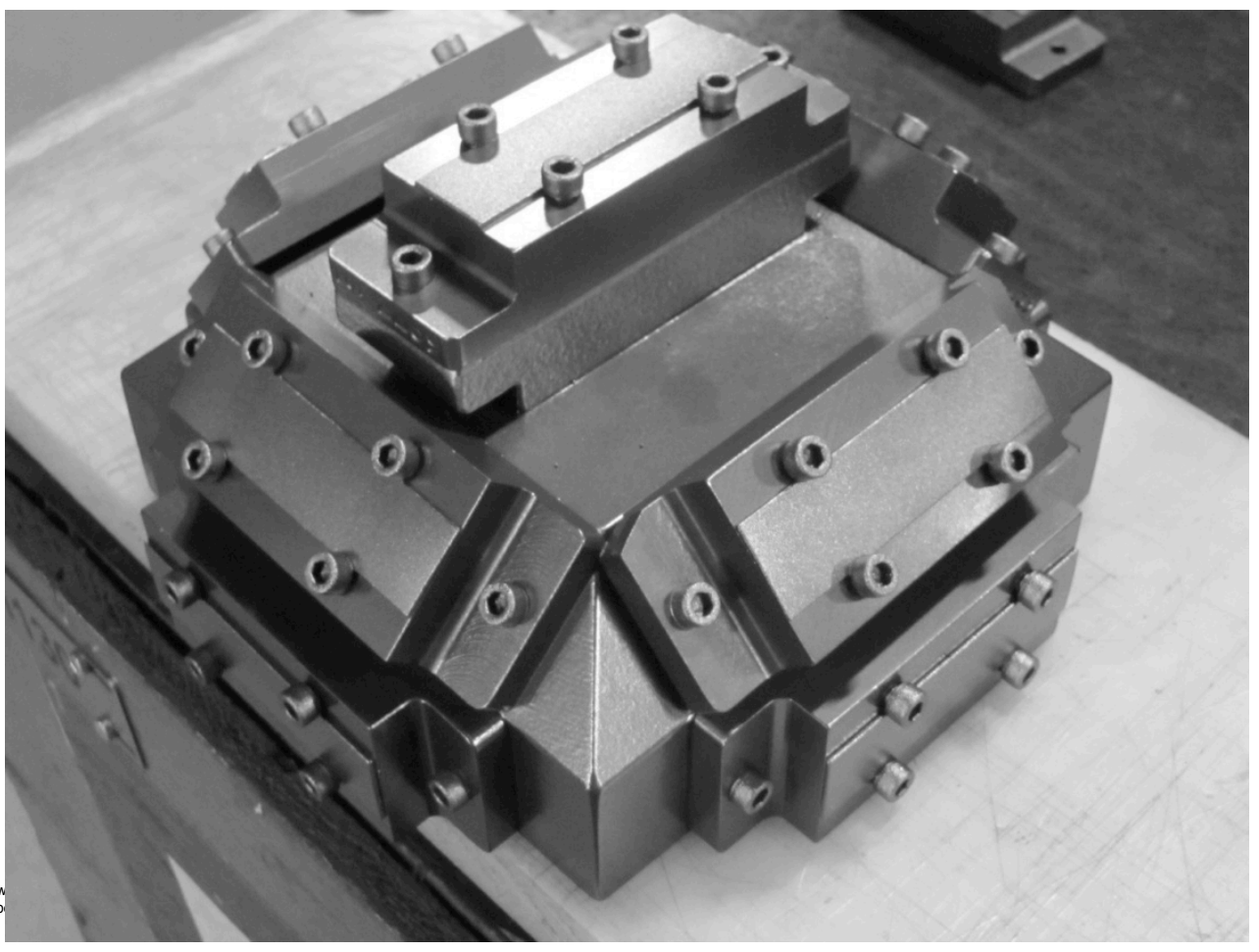

Figure 4-7: "Turtle fixture" holding Almen strip blocks 
Before shot peening $300 \mathrm{M}$ steel strips, it was important to achieve selected shot peening parameters on Almen strips, which is currently used in industries to determine intensity and coverage provided by the machine at particular location and orientation of the specimen. Since shot peening is an empirical process, based on an experienced operator, the Almen strips were placed in identical fixture as $300 \mathrm{M}$ steel strips at particular location inside the machine and then subjected to the uniform controlled blast stream for pre-determined periods of time to get saturation curve to derive intensity. The saturation curve is developed from arc height data points obtained by peening a series of Almen strips while varying exposure times [46]. After each period of exposure, the Almen strip was removed from the holder and the degree of curvature of the strip was measured using an Almen gauge as shown on figure 4-8.

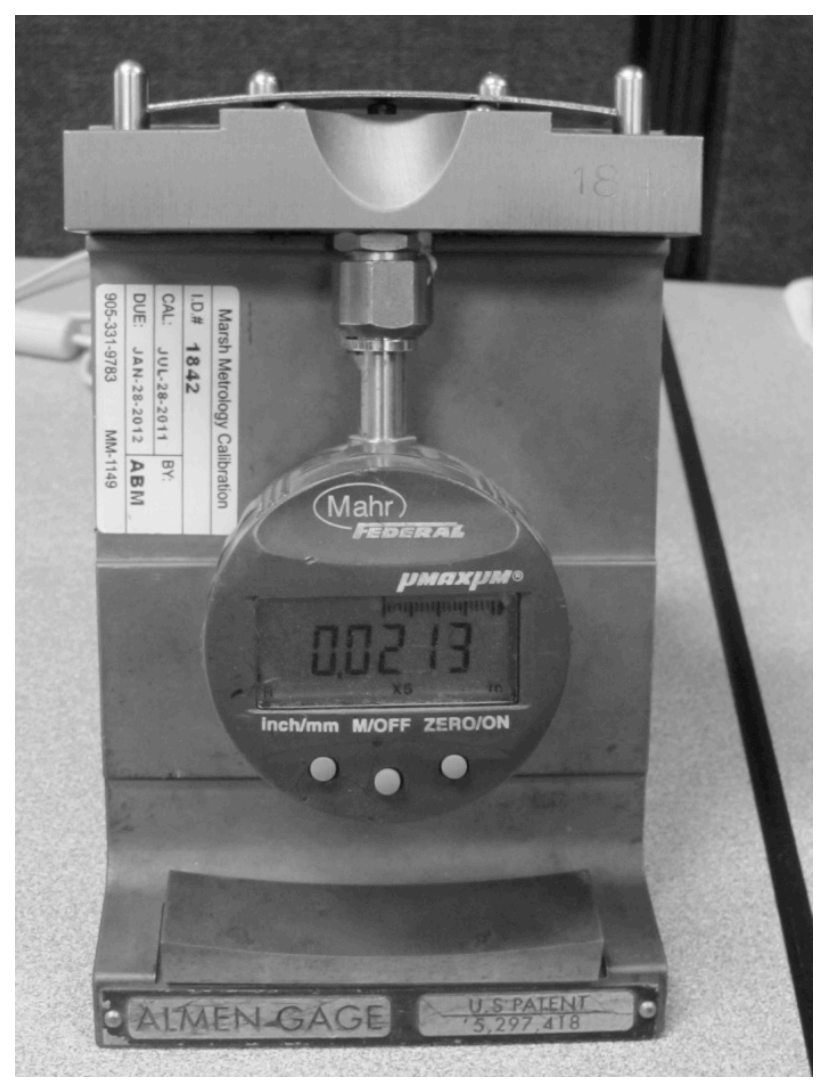

Figure 4-8: Almen Gauge for measuring curvature of Almen strips 
Almen strip arc height/curvature was determined by a measurement of the height of the combined longitudinal and transverse arc across standard chords. This arc height is obtained by measuring the displacement of a central point on the non-peened surface from the plane of four balls forming the corners of a particular rectangle [46]. The Almen strip was located on the Almen gauge so that the indicator spindle bears against the center of the non-peened surface, one long edge of the strip bearing against the two back stops. The Almen strip is then centered by placing the ends even with the edges of the base, or by resting the ends against built-in end stops [46], as shown in figure 4-9.

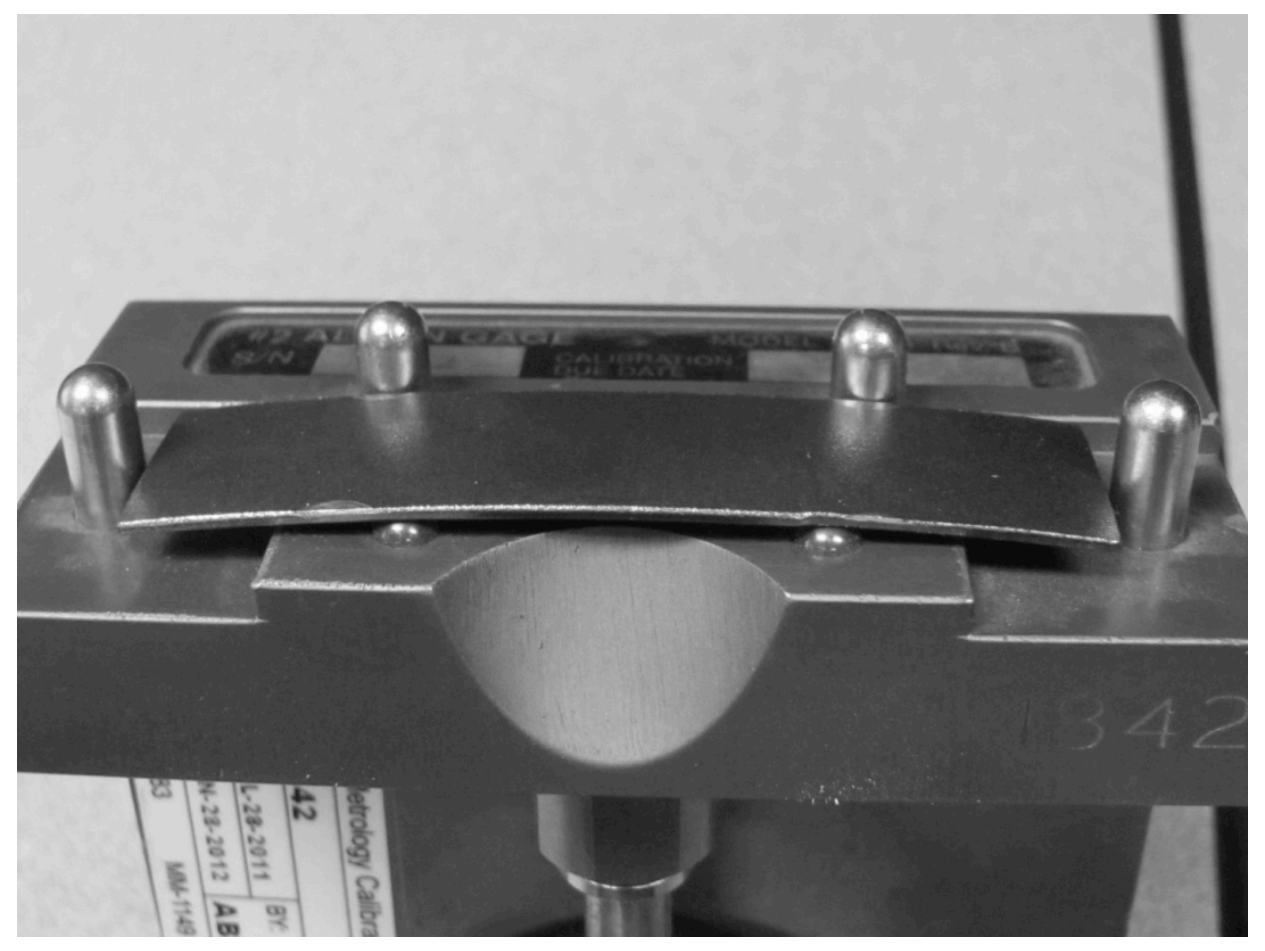

Figure 4-9: Almen Gauge with Almen strip between 4 spindles

The curvature of the strip is result of the layer of compressive stress as it begins to accumulate on the strip. Therefore based on results from Almen strips, following shot 
peening parameters were established, which are consistent with current industry requirements for shot peening high strength steels:

- Coverage: $200 \%$

- Intensity: $0.014 \mathrm{~A}-0.018 \mathrm{~A}$ (' $\mathrm{A}$ ' indicates type of strip used)

- Shot Size: S230 or diameter 0.0234 inches per AMS2431

(Cast Steel shot 55-62 HRC)

An intensity range was selected since it is extremely hard to obtain uniform intensity on all strips in given orientation. Since, in this experiment model, the focus of study is on ratio of relaxation of residual stress from a known stress value, having uniform intensity in all strips is not important.

Almen strips were peened to get $100 \%$ coverage and saturation. Saturation is defined as a point at which a 100 percent increase in peening time, results in an increase of Almen strip intensity of 10 percent or less. It is important to know saturation point since continued peening will yield little additional benefit.

The Almen gauge instrument has an accuracy of \pm 0.0001 inch and can be calibrated quickly with calibration block. A reading between 0.014 to 0.018 inch on A-type of Almen strip indicates desired intensity level. Shot peening time is determined in a way that all Almen strips in the fixture are peened at or beyond saturation and fall within 
given intensity range, peening is longer of (1) the time required for $100 \%$ Specimen coverage or (2) the time required for Almen strip saturation. Shot peening coverage on Almen strips was also verified using $30 \mathrm{X}$ microscope to get $100 \%$ coverage. This process was repeated with few Almen strips, until desired intensity was achieved and exposure time was multiplied by 2 to achieve $200 \%$ coverage on Almen strips.

The recoded parameters by shot peening computer software were then repeated on $300 \mathrm{M}$ steel strips attached to identical fixture as Almen strips and placed at same location, so required intensity and coverage can be achieved and controlled. Figure 410 is a photo of the shot-peeing machine control software operating at provided shot flow rate and wheel RPM.

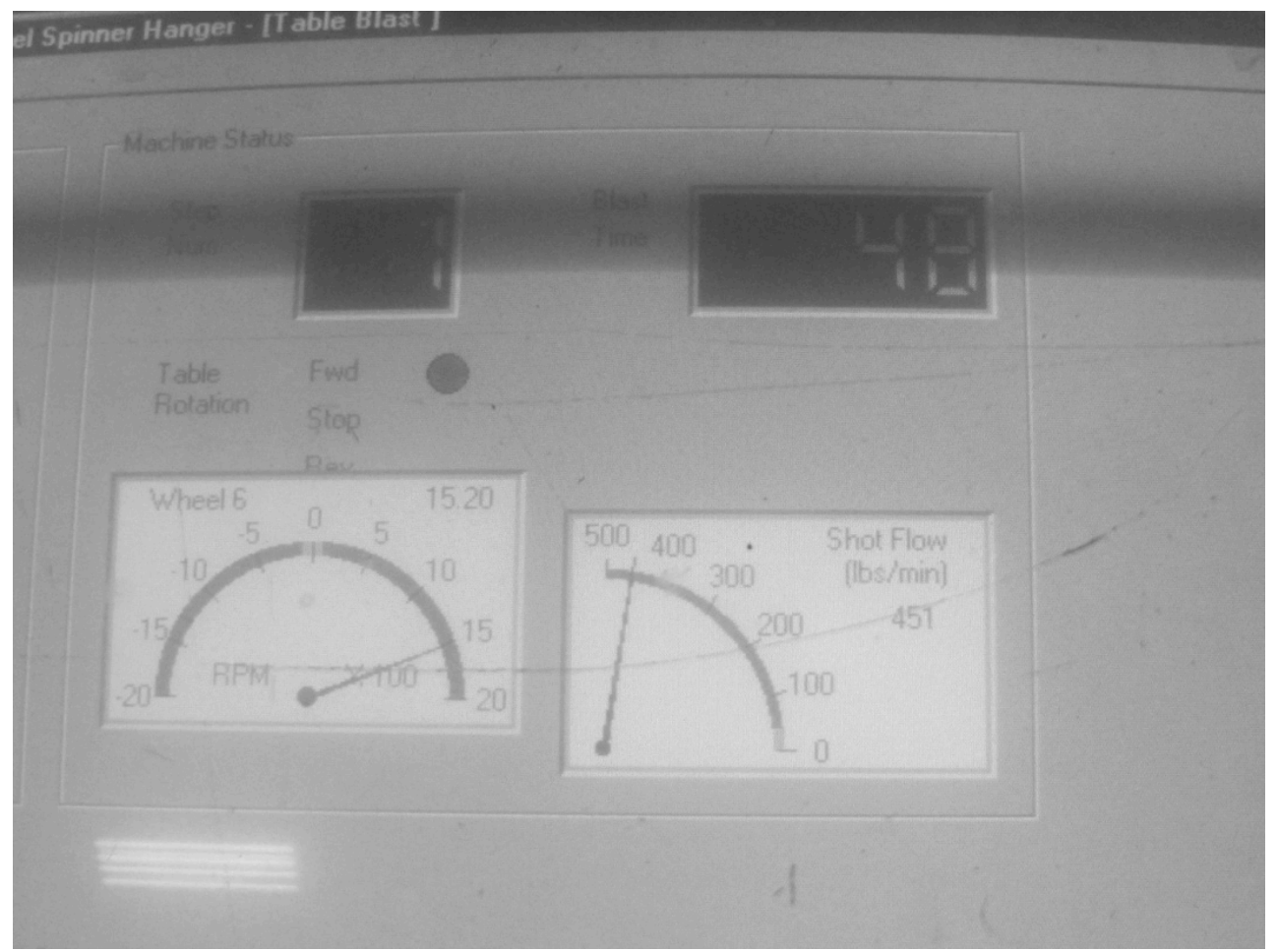

Figure 4-10: Screen shot of Shot Peening software screen operating at 1500 RPM 
- Machine: Wheelbrator 7000 O.D.

- Number of wheels: 4

- Almen strip peening time: 300 seconds $\mathrm{x} 2$ for $200 \%$ coverage

- Shot outflow rate for wheel: $450 \mathrm{lb} / \mathrm{min}$

- Wheel speed: $1500 \mathrm{rpm}$

- Distance from wheel: $2 \mathrm{ft}$

- Direction of wheel relative to specimen: Perpendicular

All shot peened 300M steel strip specimens were measured for deflection using Almen gauge and listed in table 4-3.

Table 4-3: Deflection Measurements after shot peening

\begin{tabular}{|c|c|}
\hline Strip Number & $\begin{array}{c}\text { Deflection } \\
\text { Measurement } \\
\text { (inches) }\end{array}$ \\
\hline $\mathbf{1}$ & 0.0235 \\
\hline $\mathbf{2}$ & 0.0284 \\
\hline $\mathbf{3}$ & 0.0285 \\
\hline $\mathbf{4}$ & 0.0177 \\
\hline $\mathbf{5}$ & 0.0186 \\
\hline $\mathbf{6}$ & 0.0157 \\
\hline $\mathbf{7}$ & 0.0252 \\
\hline $\mathbf{8}$ & 0.0241 \\
\hline
\end{tabular}

\begin{tabular}{|c|c|}
\hline Strip Number & $\begin{array}{c}\text { Deflection } \\
\text { Measurement } \\
\text { (inches) }\end{array}$ \\
\hline $\mathbf{9}$ & 0.0262 \\
\hline $\mathbf{1 0}$ & 0.0270 \\
\hline $\mathbf{1 1}$ & 0.0299 \\
\hline $\mathbf{1 2}$ & 0.0295 \\
\hline $\mathbf{1 3}$ & 0.0306 \\
\hline $\mathbf{1 4}$ & 0.0261 \\
\hline $\mathbf{1 5}$ & 0.0325 \\
\hline
\end{tabular}




\subsubsection{Stress Relieve of 300M Steel Strips}

The vibro-engraved specimens were divided into four groups of 3 specimens each, one for $375^{\circ} \mathrm{F}$ stress relieve temperature, for $450^{\circ} \mathrm{F}$ stress relieve, for $525^{\circ} \mathrm{F}$ stress relieve, for $650^{\circ} \mathrm{F}$ stress relieve and for $875^{\circ} \mathrm{F}$ stress relieve temperature. All specimens were heat treated at known time intervals for total of 54 hours and deflection was measured after each time interval. The stress relieving time intervals chosen for this experiment model were 1 hour, 3 hours, 7 hours, 15 hours, 30 hours, and 54 hours at each temperature. For stress relieve process, the specimens were again affixed to test strip holder as shown in figure $4-11$, in order to eliminate the elastic deflection of $300 \mathrm{M}$ steel strips.

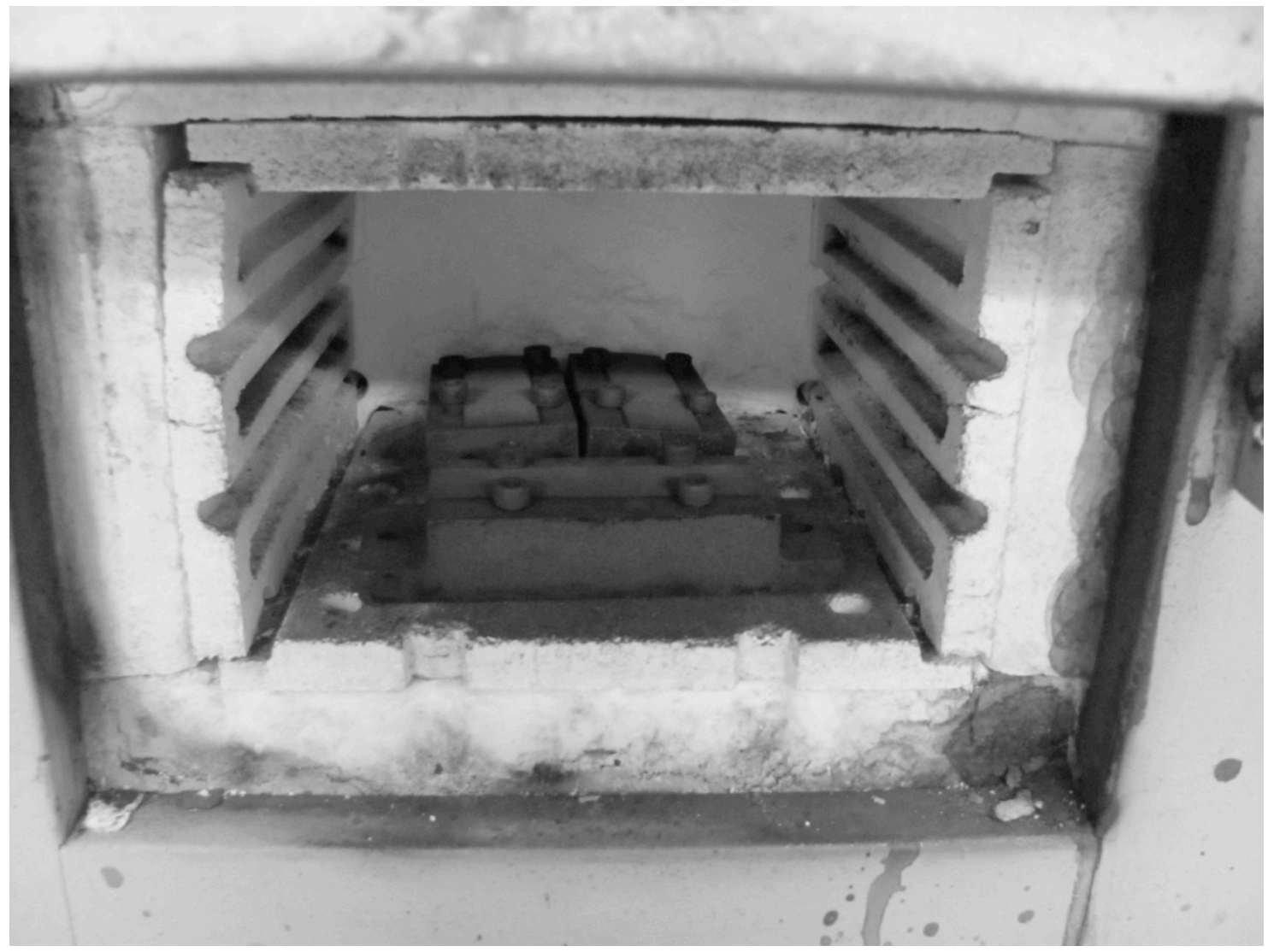

Figure 4-11: 300M steel Almen strips clamped to Almen block during stress relieve 
All specimens were placed in an industrial filament oven as shown in figure 4-12 according to their temperature and time group. The specimens were stress relived per AMS2759/11 standard procedures [3]. The temperature was closely monitored for any changes, a standard tolerance limit of $\pm 10^{\circ} \mathrm{F}$ was observed. After the bake process, the specimens were air cooled at room temperature.

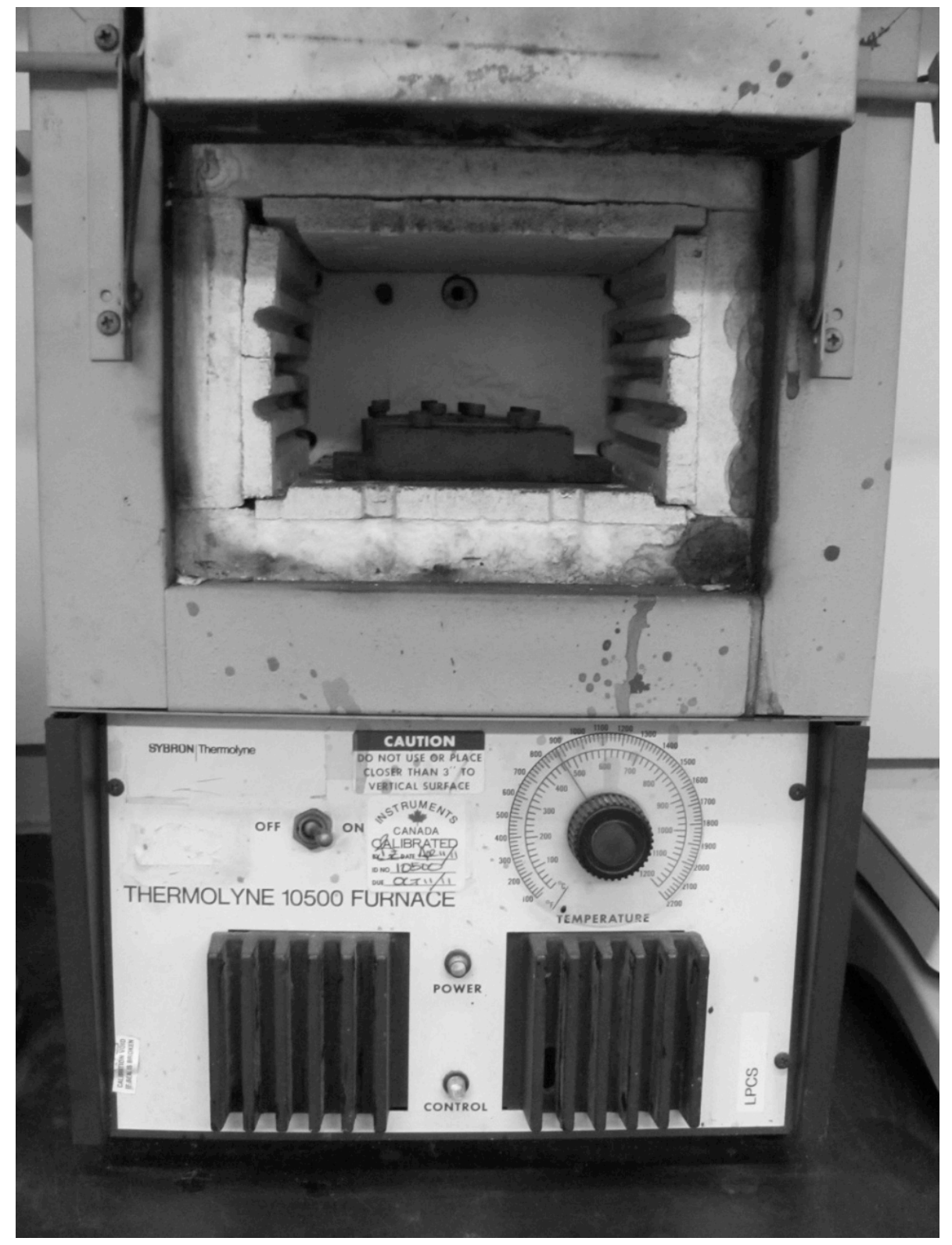

Figure 4-12: Industrial Oven with 300M steel Almen Strips 


\subsubsection{Deflection Measurements}

After each stress relieve time interval, 300M steel strip's arc height/curvature was measured using Almen gauge for any changes due to stress relieve. Deflection measurements were recorded in Appendix A Table A4 for each specimen number after each time interval according to their temperature groups.

The measured deflection difference along with other material properties and dimensions is later used to estimate values of residual stressed induced in the specimens.

\subsection{X-Ray Diffraction Method to Determine Residual stress}

X-ray diffraction method is quantitative technique to measure stress in a material by measuring strain in crystal lattice structure of the material. The residual stress producing the strain is calculated by assuming a linear elastic distortion of the crystal lattice. X-ray diffraction residual stress measurement is applicable to materials that are crystalline, relatively fine grained, and produces diffraction for any orientation of the sample surface. The method employs the knowledge of X-ray wavelength, the change in Bragg's angle and changes in interplaner spacing to calculate elastic strain [45].

This technique measures residual stress using the distance between crystallographic planes, i.e., d-spacing, as a strain gage as shown in figure $4-13$. When the metal is deformed plastically, the lattice planes usually become distorted in such a way that spacings of any particular $\{\mathrm{hkl}\}$ set varies from one grain to another or form one part of 
the grain to another [48]. This leads to broadening of d-spacings causing change in diffraction.

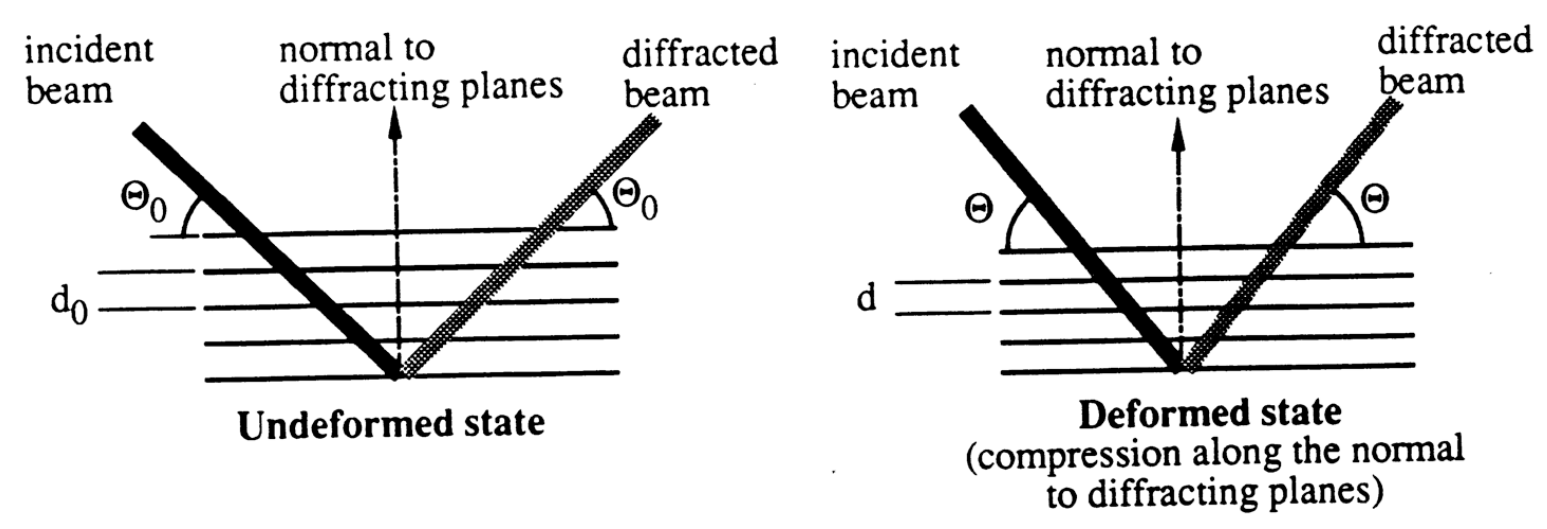

Figure 4-13: Measurement of change in $d$-spacings by X-ray diffraction [45]

Metallic materials are composed of atoms arranged in a regular three dimensional array to form crystal, which create many tiny grains and are randomly oriented with respect to their crystalline arrangement and fused together to make a bulk solid [49]. When these materials are under tension loads, their d-spacing increases and, upon compression their $d$-spacing decreases. Stresses can be determined either by calculation involving the mechanically measured elastic constants of the material, or by a calibration procedure involving measurement of the strain produced by known stresses. 


\subsubsection{Measuring Residual Stress using X-ray Diffraction Method}

The $300 \mathrm{M}$ high strength steel specimens required for this procedure were supplied by Goodrich Aerospace Canada in Oakville, Ontario, from same material used on Airbus A380 landing gear.

\subsubsection{Material Properties}

The specimens used were cut out from an Airbus A380 test axle and rough machined. Material properties available for this component were well agreed with specification and standards of $300 \mathrm{M}$ steel and certified to Aerospace Material Standard (AMS) 6419 standard. Hence, material properties listed in Table 2-2 from Chapter 2 are used for this specimen. AMS 6419 ensures that quality of the steel is premium aircraft-quality conforming to AMS2300. This grade of steel is produced by vacuum arc remelted process.

\subsubsection{Specimen preparation}

For statistical purposes, total of nine specimens were required for this experiment, since residual stresses at various depths were measured for shot-peened and heat treated at two different temperatures: three for shot peened condition only, three for shot peened and stress relieved at $375^{\circ} \mathrm{F}$ and three shot peened and stress relieved at $525^{\circ} \mathrm{F}$ were obtained.

The obtained specimens were initially media blasted at $60 \mathrm{psi}$, to remove any foreign object debris and any rust from the surface. The rough-cut machined specimens were of 
variable thickness; hence it was important for the experiment that all specimens are of the same thickness. The nine pieces were than machined to achieve fine finish of $20 \mathrm{RA}$ average, as well as thickness of 0.5 inch $(1.27 \mathrm{~cm})$. Figure $4-14$ presents specimen geometry and its dimensions.

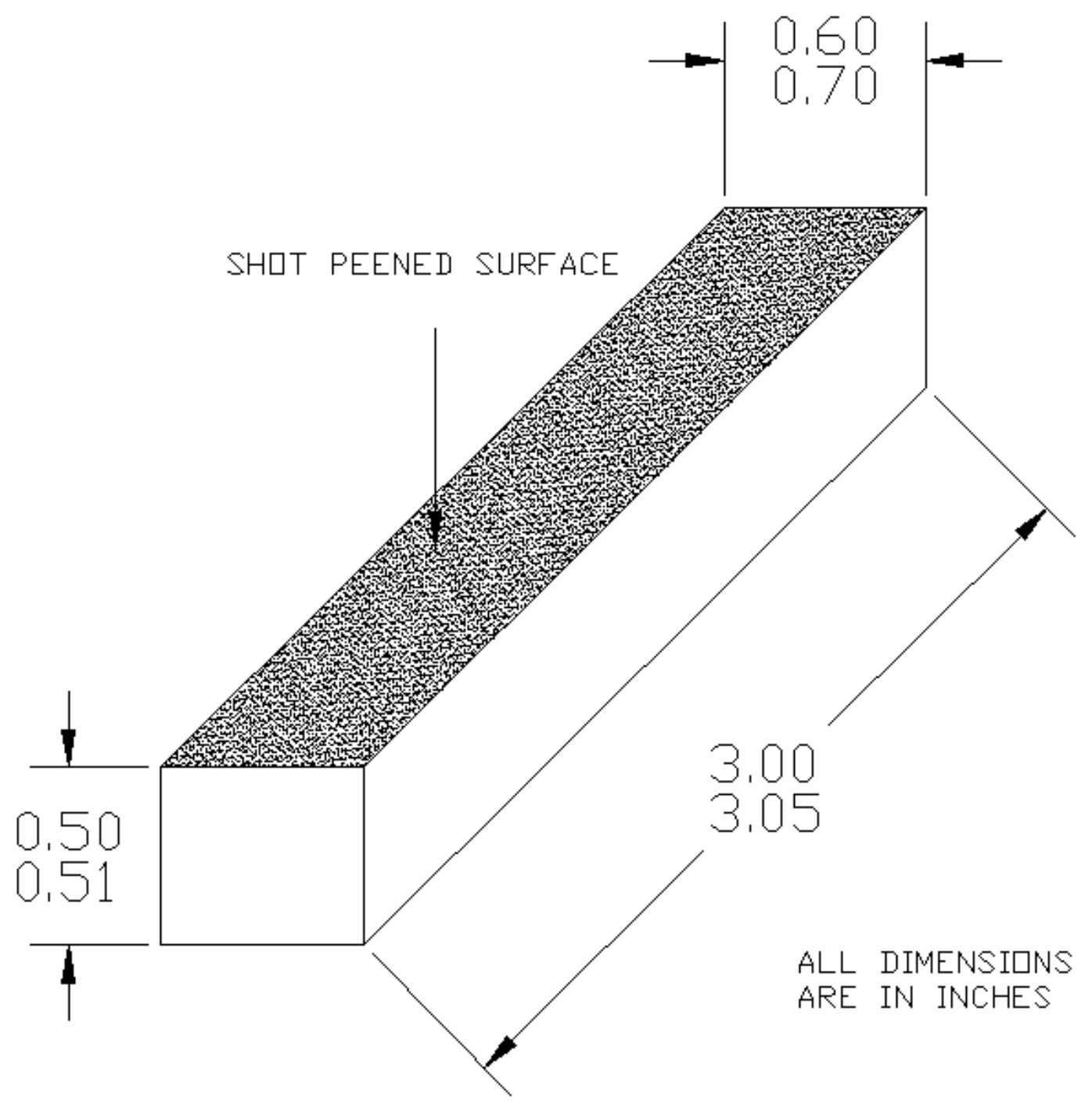

Figure 4-14: 300M steel specimen bar design and dimensions 
These specimens were then stress relieved for 24 hours at $525^{\circ} \mathrm{F}$ to remove any residual stress induced by machining and cutting operations. This is a common industrial practice to process and to stress relieve the high strength steel at $525^{\circ} \mathrm{F}$ after any machining operations. The specimens were also non-destructively tested for any cracks and nicks by magnetic particle inspection technique, per ASTM-E-1444, at which all samples passed the test. Figure 4-15 shows the digital picture before shot peening and after initial stress relieve.

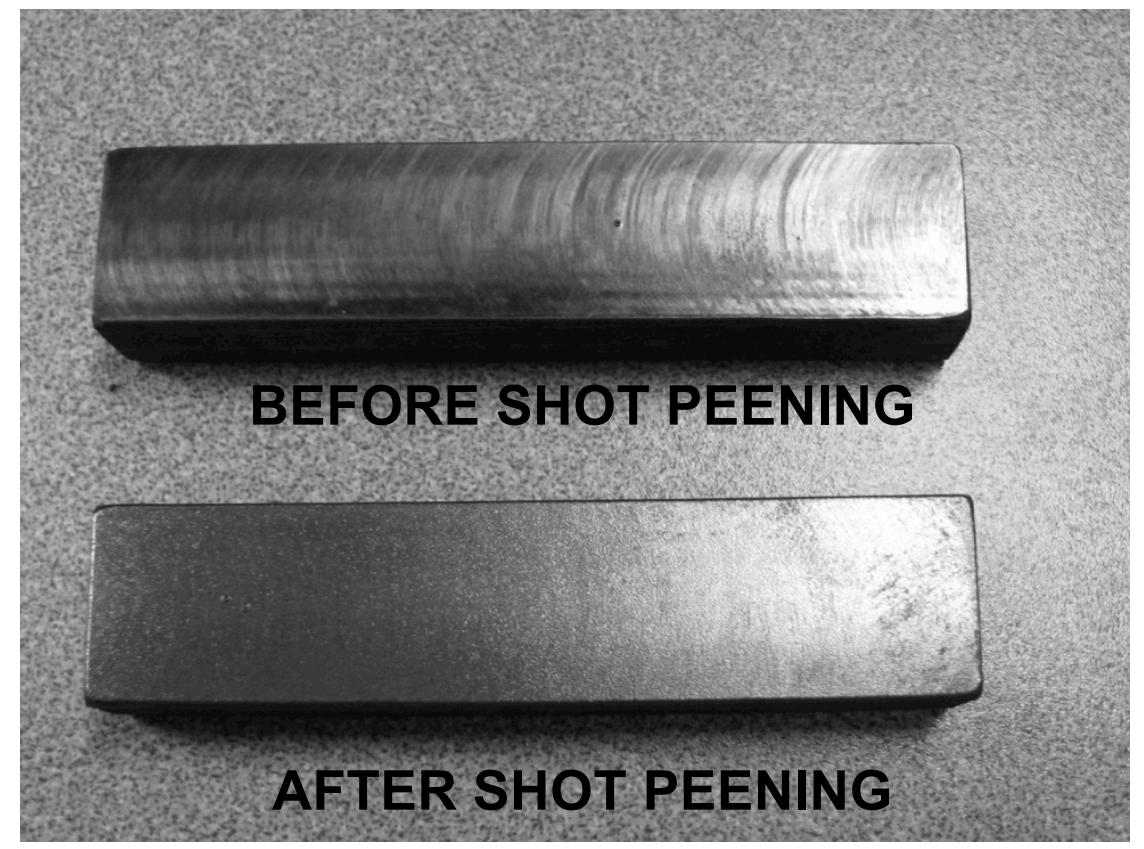

Figure 4-15: Specimens - Before and after shot peening

Surface hardness was measured using a digital hardness gauge, and was found with an average value ranging between $55-56 \mathrm{HRC}$. This value was used to average ultimate tensile strength of material to be $303-312 \mathrm{ksi}$. Figure $4-16$ shows equipment and technique used for surface hardness measurement. 


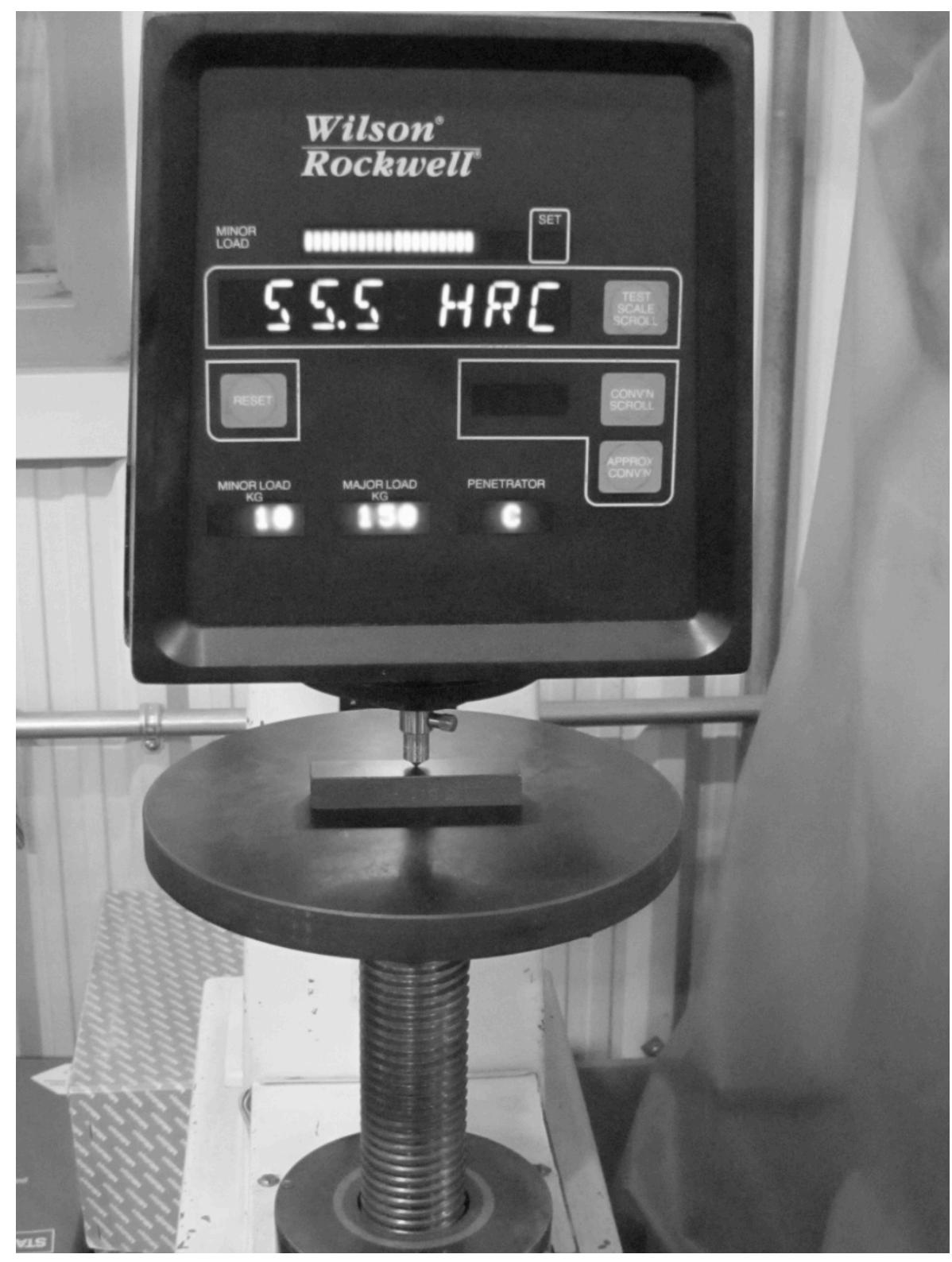

Figure 4-16: Hardness testing machine with specimen

\subsubsection{Shot peening of $300 \mathrm{M}$ steel bars}

Specimens free of any residual stress were now ready to be shot peened. Since it was important to shot peen only one side of the specimen, all specimens were masked from 5 sides and assembled in a jig where a uniform shot peening can be performed as shown in figure 4-17: 


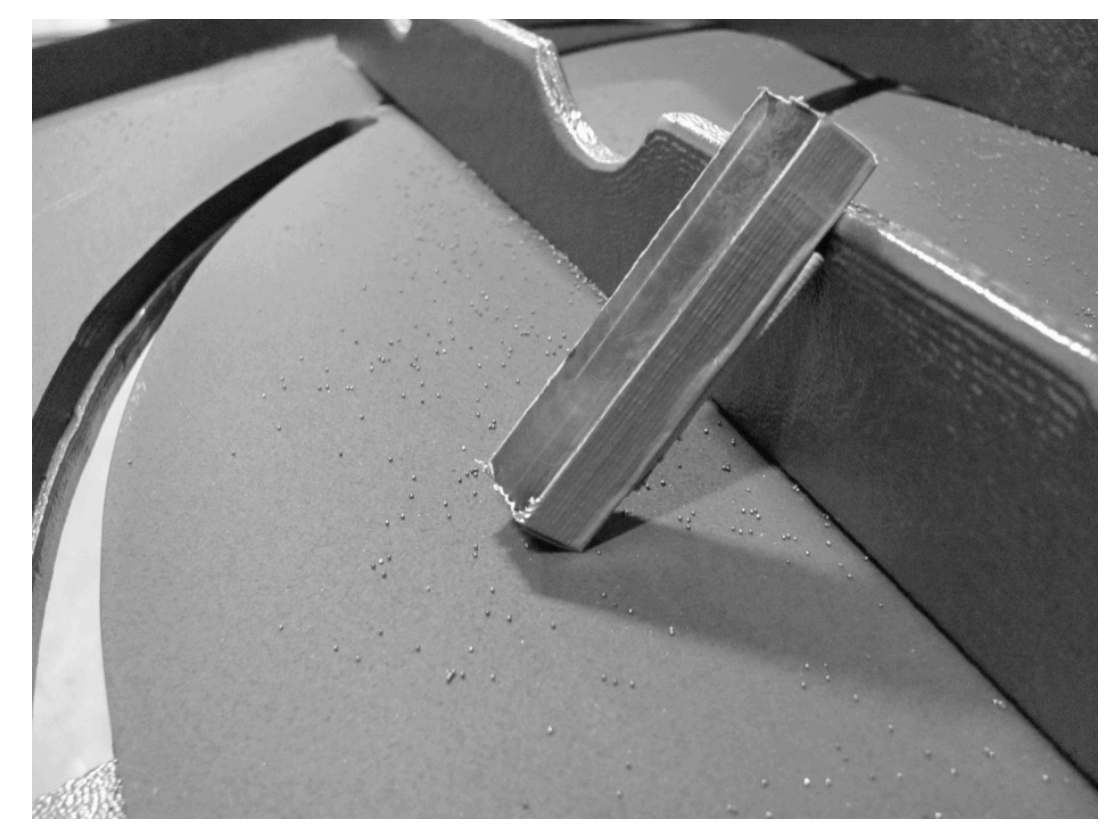

Figure 4-17: Masked Specimen ready for shot peening

Similar shot peening parameters from previous experiment using $300 \mathrm{M}$ strips were selected, which were consistent with current industry requirements for shot peening 300M high strength steel.

Shot peening machine parameters recorded by computer were repeated on actual specimens; except placement was different and only one wheel was used because of smaller area and orientation of specimens.

The total peening time required for specimens were calculated using following formula:

Total specimen area $\times$ Almen strip peening time / 2.25 (surface area of Almen Strip) $=$ Peening time for specimen $\mathrm{x}$ coverage required $=$ Total peening time

Since the exposed areas of specimen were comparable to Almen strip surface area, the shot peening time was same as that of Almen strips. All specimens were automated 
shot peened using swing table machine with above noted machine settings according to standard MIL-S-13165.

Almen strips were also placed near the shot peened specimens to check for its intensity as well as coverage, which were verified using optical microscope with $30 \mathrm{X}$ magnification. Since all specimens were shot peened concurrently, each specimen resulted in same shot peening properties and intensity of $0.016 \mathrm{~A}$.

\subsubsection{Stress Relieve of 300M steel bars}

For identification purposes all specimens were vibro-engraved on the side and identified with following nomenclature (see figure 4-18 for identification example):

Shot-peened only specimens: 0251, 0252, 0253.

Shot-peened and stress relieved at $375^{\circ} \mathrm{F}: 3751,3752$, and 3753 .

Shot-peened and stress relieved at $525^{\circ} \mathrm{F}: 5251,5252,5253$.

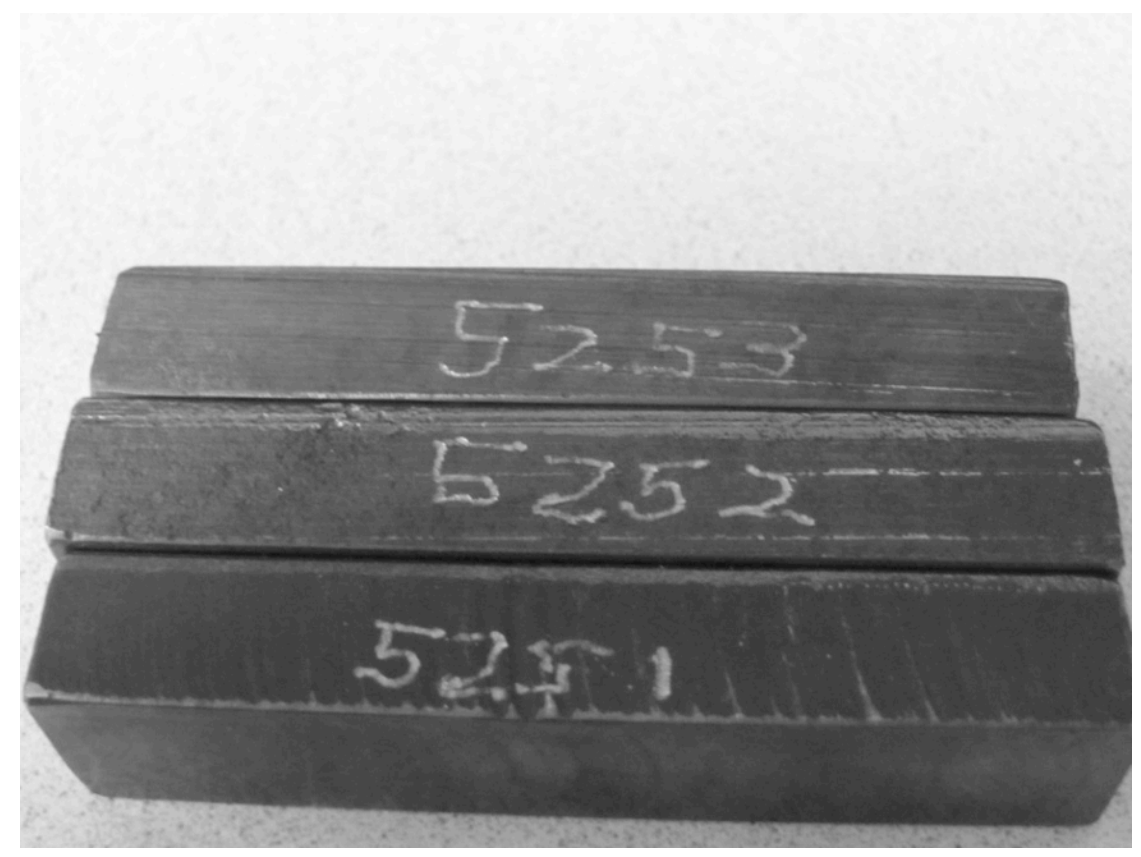

Figure 4-18: Example of vibro-engraving on specimen 
After vibro-engraving, the $375^{\circ} \mathrm{F}$ stress relieve group was placed in a industrial $1.5 \mathrm{ft} \mathrm{x}$ $1.5 \mathrm{ft} \times 2.5 \mathrm{ft}$ oven as shown in figure $4-19$ and heat treated for 4 hours at $375^{\circ} \mathrm{F}$ and similarly $525^{\circ} \mathrm{F}$ stress relieve group was heat treated for 4 hours at $525^{\circ} \mathrm{F}$. The specimens were cooled at room temperature.

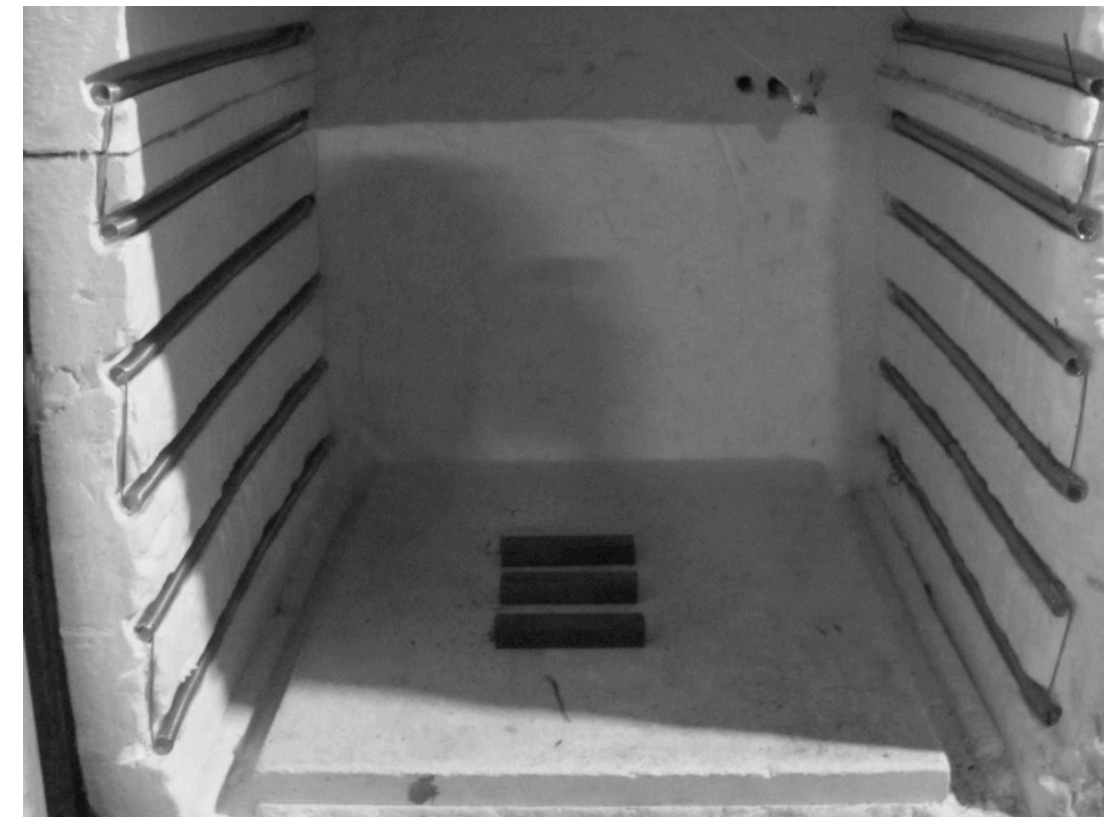

Figure 4-19:Inside the Industrial Oven with specimens

\subsubsection{Residual Stress Measurement using X-ray Diffraction Principles}

There are few industry standards controlling the residual stress measurement methods using X-ray diffraction techniques, Society of Automotive Engineers manual outlined in SAE J784a "Residual Stress Measurement by X-ray diffraction" [50] as well as ASTM E915-90 "Standard Test Method for Verifying the Alignment of X-ray Diffraction Instrumentation for Residual Stress" are standard specification used for industries and laboratory equipment. 


\subsubsection{Principles of X-ray Diffraction}

When an X-ray beam irradiates the surface of a crystalline material, it is constructively scattered only if it meets lattice planes oriented to fulfill Bragg's law. Because only the elastic strain changes the mean lattice spacing, only elastic strains are measured using $\mathrm{x}$-ray diffraction [49]. For a stress free material, the lattice spacings, $d_{o}$ for a given plane family does not vary with orientation of planes as shown in figure 4-20.

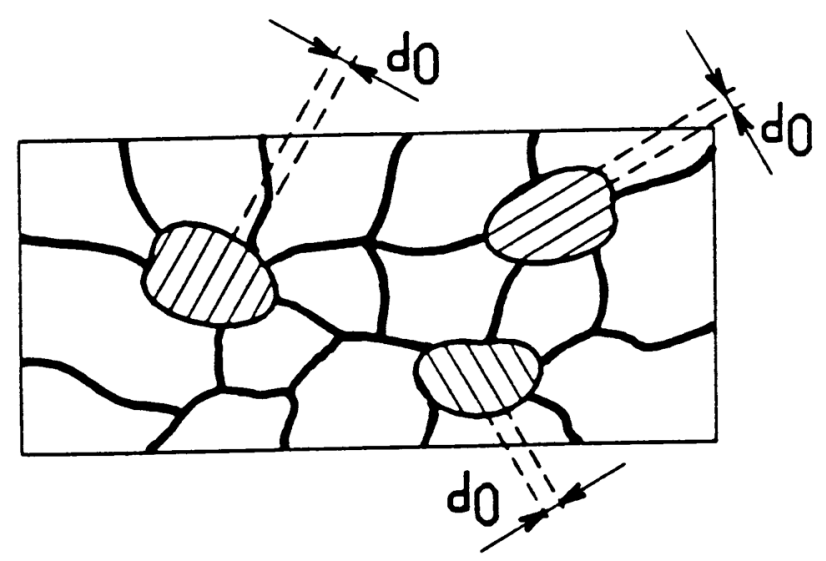

Figure 4-20: Inter-atomic d-spacings in unstressed material grains [51]

When the material is stressed due to deformation, the lattice spacings vary according to orientation of planes relatively to the stress direction. When stress is applied, the lattice spacings increase for planes perpendicular to stress directions and decreases in parallel to stress direction upon tensile stressing [45]. This enables to measure strain from this variation in lattice spacing $d_{f}-d_{o}$ by position of diffraction peak by Bragg's law. 
In this method, a monochromatic X-ray beam, usually means the strong $K \alpha$ characteristic component of the a radiation from $\mathrm{x}$-ray tube of sufficient intensity is made incident on the atomic planes [51] as shown in figure 3-7 at high diffraction angle $2 \theta$ from the surface of sample.

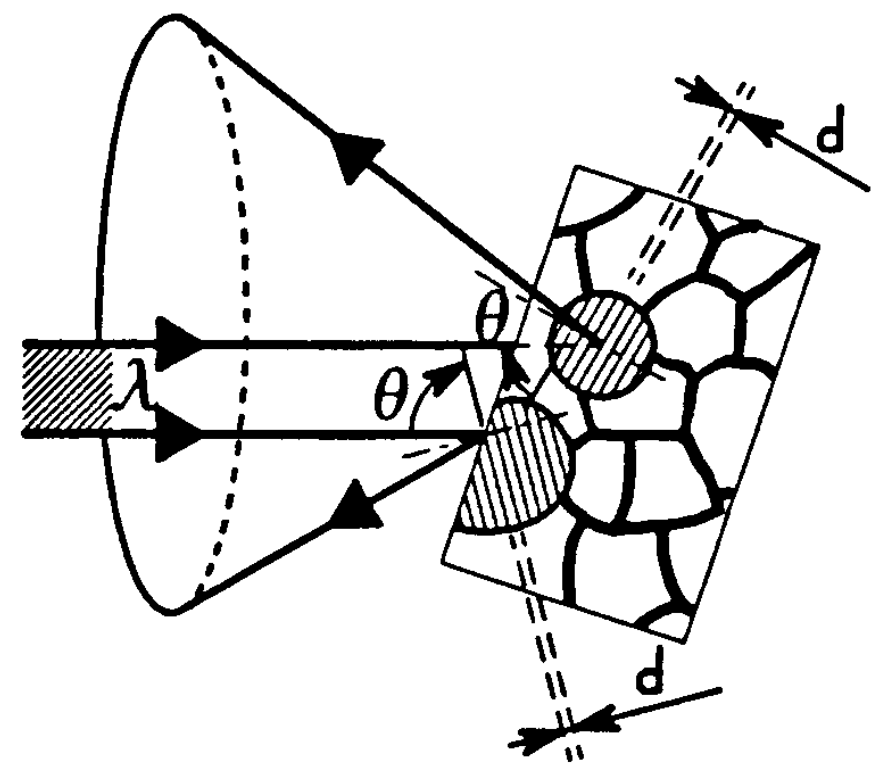

Figure 4-21: Reflection of $X$-ray beam from stressed material grain [51]

The reflected beams from successive planes of atoms are observed, where Bragg's law defines the condition for diffraction through the following equation:

$$
n \lambda=2 d_{f} \sin \theta
$$

where $n$ is an integer denoting the order of diffraction, $\lambda$ is the x-ray wavelength, $d_{f}$ is final lattice spacing of crystal planes, and $\theta$ is the diffraction angle. 
The choice of a diffraction peak selected for residual stress measurement impacts significantly on the precision of the method. The higher the diffraction angle, the greater the precision. Practical techniques generally require diffraction angles, $2 \theta$, greater than $120^{\circ}$. To obtain the largest peak shift for a given lattice deformation, the diffraction peak is chosen at highest angle possible depending on diffracting plane material [51]. For steels or ferrous materials with plane orientations $\{\mathrm{hkl}\}=\{211\}$, a wavelength of $\lambda=2.911 \AA$ is used. This wavelength is provided by standard chromium anode $(\mathrm{CrK \alpha}) \mathrm{X}-$ ray tubes.

\subsubsection{Equipment and Settings}

The residual stress measurement using X-ray diffraction technique is normally carried out on flat surface of specimen. The specimen surface should be clean and smooth with no major changes in texture. Surface roughness should be strictly avoided because the high points in a rough surface are not stresses in the same way as the bulk of specimen but they contribute most to diffraction pattern [51]. Residual stress produced by shot peening is usually $0.010-0.015$ inch deep at specimen surface, if material removal is required, it must be done by the process which does not itself produces residual [50]. Acid etching is also known to alter some state of stress on material surface as well affects surface roughness.

In this experiment, the residual stress was measured directly using X-ray diffraction machine. The measurements were performed in Proto Manufacturing Inc. Laboratory at 
Windsor, Ontario. The X-ray diffraction machine model "LXRD" (Laboratory NonDestructive Residual Stress Measurement System) was used in their facility as shown in figure 4-22. This X-ray diffraction machine was connected and controlled by computer with custom software called XRDWin 2.0 designed for data collection and stress analysis.

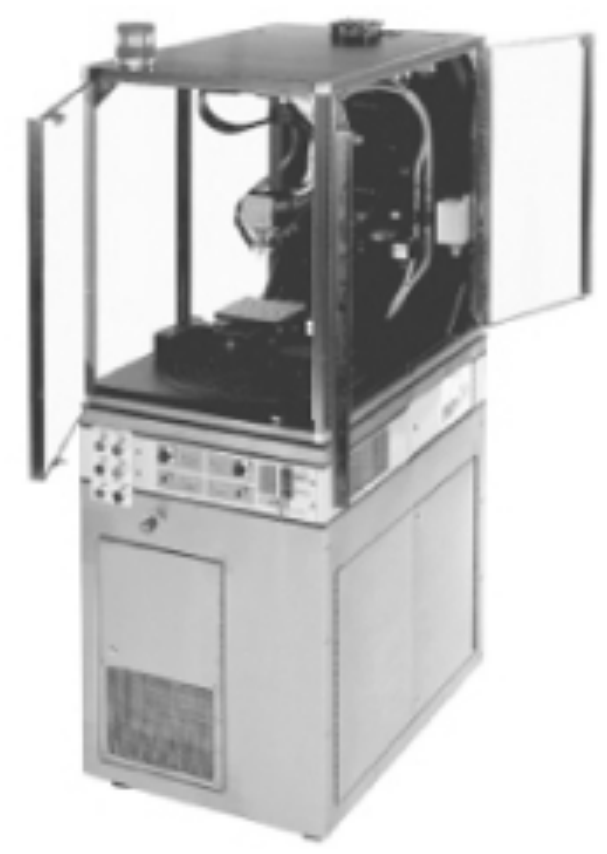

Figure 4-22: X-ray diffraction machine used to measure residual stress (LXRD) [49]

The X-ray diffraction machine was verified for alignment based on ASTM E915. Therefore, before measuring residual stress on specimens, the LXRD machine was calibrated by measuring residual stress of known calibration block of zero stress as well as of $44 \mathrm{ksi}$. After machine displayed corrected values for known samples, the set up parameters for steel alloys were loaded on the software and the machine was ready to measure the stress in prepared 300M steel specimens. 
The proper sample position was established by using a focusing needle as shown in figure 4-23, so that the surface of specimen was positioned at $\theta$ axes within the focal distance range. Hence, shot peened specimens were placed inside the enclosure as shown in figure 4-24 one by one, so stress can be measured in longitudinal direction at the center of specimen.

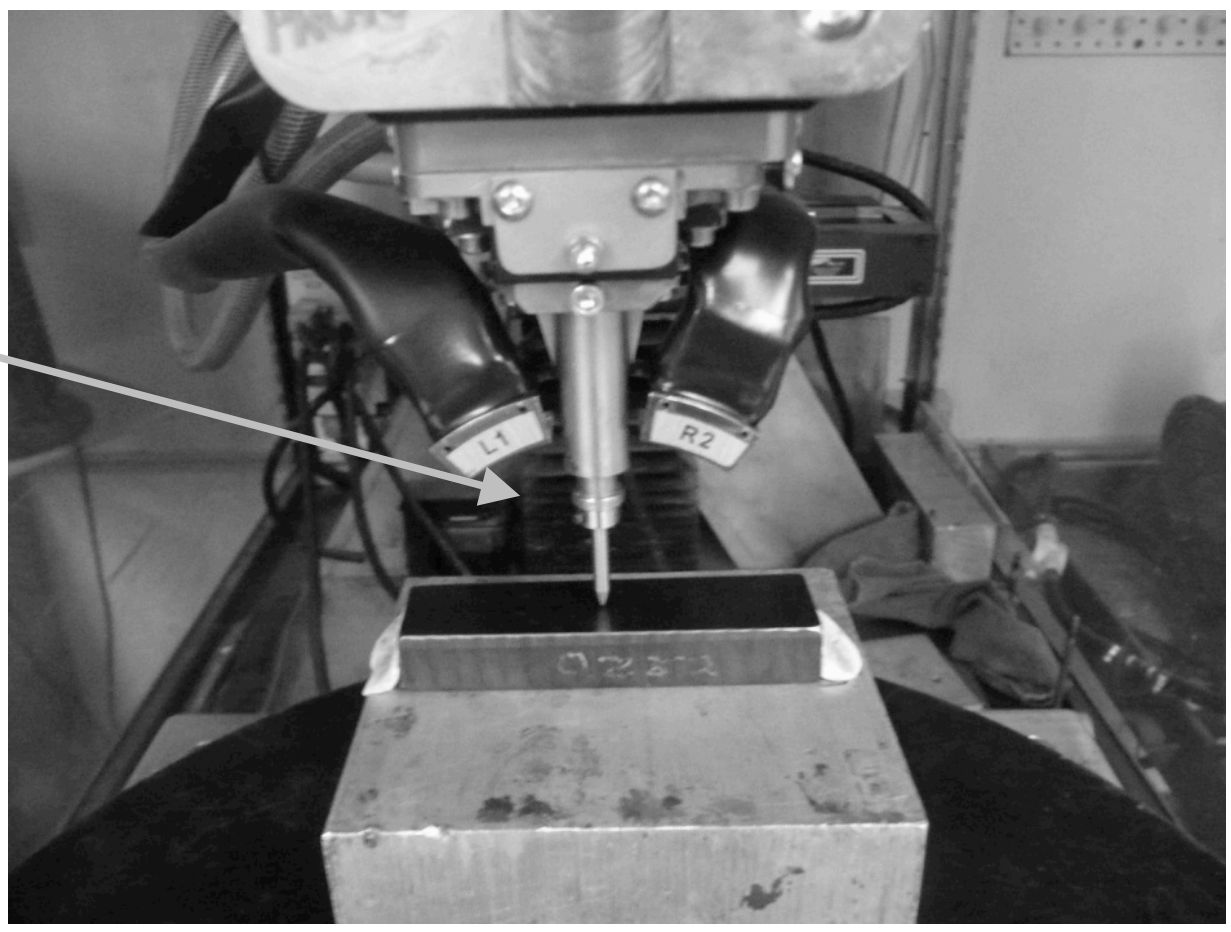

Figure 4-23: Sample positioning and focusing

X-ray peak selection was made at the highest diffraction angle of $156.4^{\circ}$ which was consistent with the peak intensity. Set-up parameters used to determine residual stress are shown in table 4-4. 
Table 4-4: X-ray Diffraction machine Set-up parameters

\begin{tabular}{|c|c|}
\hline Target Wavelength: & $\mathrm{Cr}\left(\mathrm{Ka}_{\mathrm{avg}} 2.29100\right.$ Angstroms $)$ \\
\hline Target Power: & $30.00 \mathrm{kv}, 25.00 \mathrm{~mA}$ \\
\hline Gain Material: & Titanium - Beta \\
\hline Gain Power: & $18.00 \mathrm{kV}, 25.00 \mathrm{~mA}$ \\
\hline Material: & 4340M steel \\
\hline X-Ray Elastic Constant: & $24,500.00 \mathrm{ksi}$ \\
\hline Crystallographic Plane: & $\{211\}$ \\
\hline Diffraction Angle (20): & $156.4^{\circ}$ \\
\hline Aperture: & $1.0 \mathrm{~mm}$ round \\
\hline Psi Tilts: & 11 \\
\hline Tilts (degrees) & $0, \pm 25.00, \pm 20.6, \pm 15.85, \pm 3.74$ \\
\hline Oscillations: & Beta $3.00^{\circ}$ \\
\hline Collection Time: & 0.50 seconds $\times 20$ exp's \\
\hline Total Collection Time: & 5 minutes 30 seconds \\
\hline Peak Fit: & Gaussian 85\% \\
\hline Background Subtraction: & Linear \\
\hline Peak Shift Method: & Absolute Peak \\
\hline Instrument: & LXRD 1 \\
\hline Software Version: & 2.0 Build 71 \\
\hline Goniometer Configuration: & Psi \\
\hline
\end{tabular}




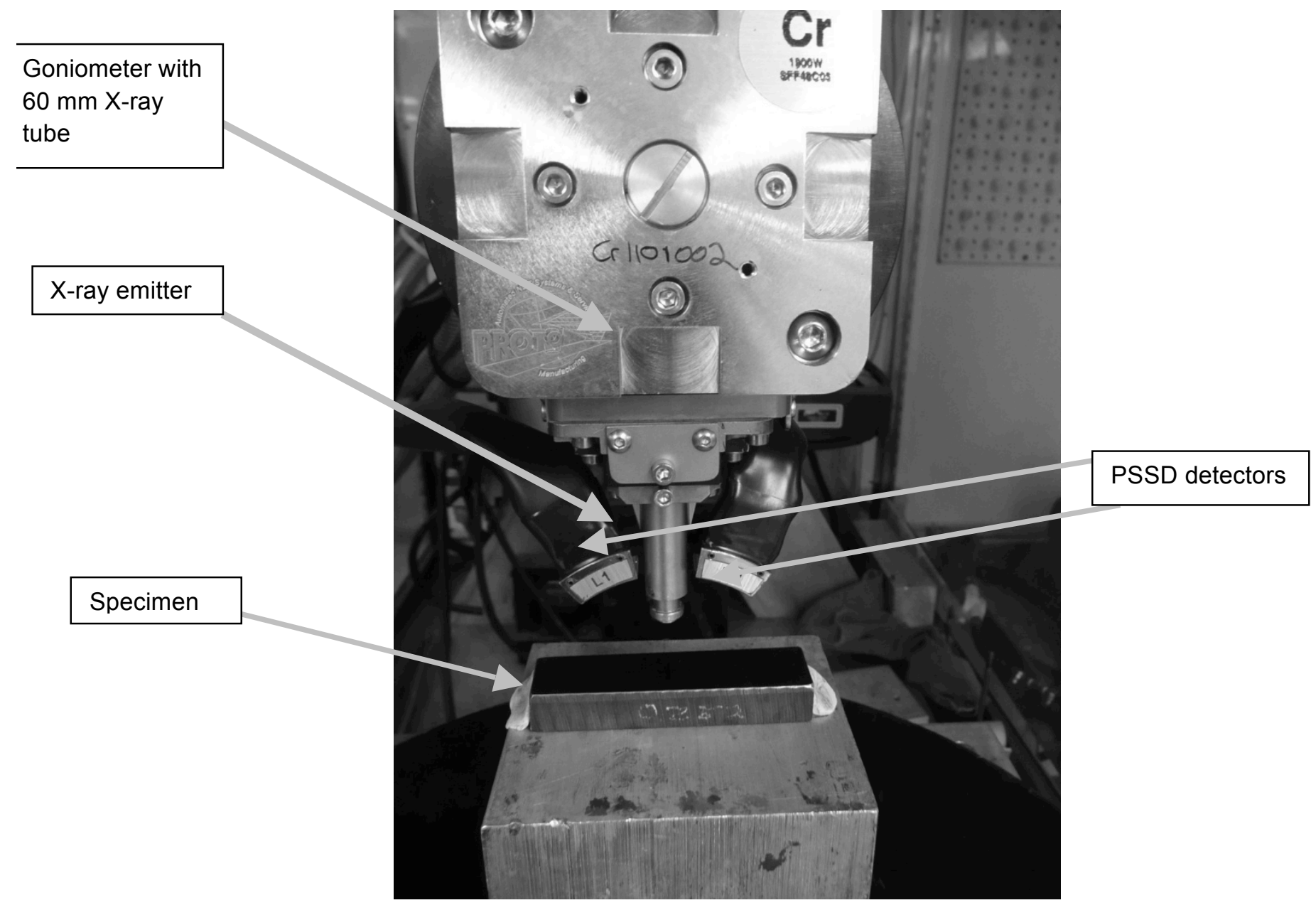

Figure 4-24: X-ray diffraction machine

The main objective of performing residual stress measurements using X-ray diffraction was to measure residual stress at different depths of the material, so effect of stress relieved can be quantified at sub-surface level as well as to measure maximum residual stress induced by shot peening on $300 \mathrm{M}$ steel. Therefore, 4 different depths were chosen to get a residual stress measurement curves at sub-surface level. To measure residual stress using X-ray diffraction at different depths, a surface layer removal process of electro-polishing was used. 


\subsubsection{Electro-polishing Layer Removal}

Measuring residual stress distribution as a function of depth into the sample surface requires removing material to expose new stressed surface. The most common method of removing material for residual stress measurement using X-ray diffraction is electro polishing. Electro polishing is preferred for layer removal because no residual stresses are induced, and if properly performed, preferential etching of the grain boundaries also is skipped [50]. Most extensively used solutions for electrolytic material removal are based on phosphoric or per-chloric acids, a detailed chemical solution formula for electrolyte can be found in [50]. Different types of electrical circuits are used in the equipment based on material and electrical current required.

Electro-polishing removes a very small layer of material from metallic surface without affecting or inducing any residual stress in the surface unlike grinding or machining. Since, the chosen depths are 0.002 inches, 0.004 inches, 0.006 inches and 0.009 inches below the specimen surface, electro-polishing was found capable of removing very small amount of material from the surface.

Electro polishing process in this experiment was done per ASTM-E-1558 by immersing the small portion of specimen as shown in figure 4-25 in a temperature controlled bath of electrolyte solution acting as an anode and negative terminal being attached to specimen itself as the cathode. 


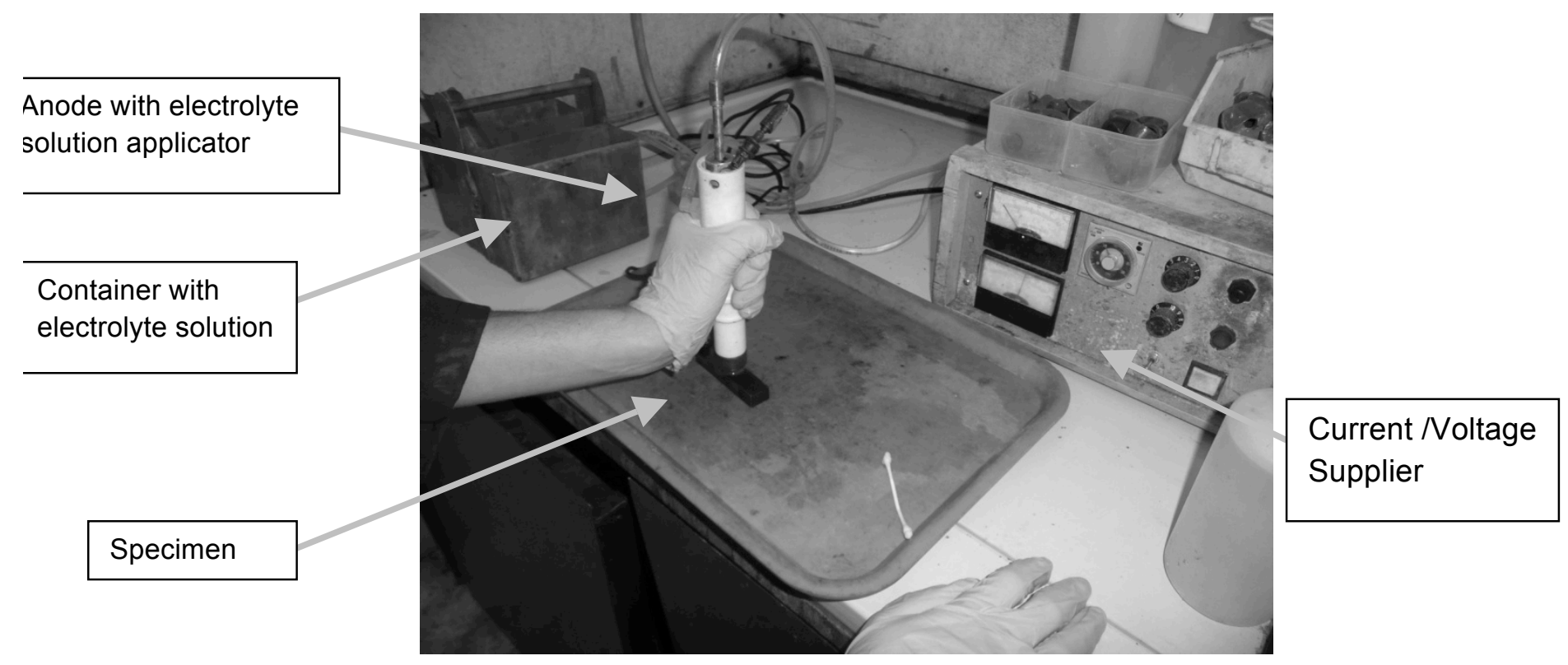

Figure 4-25: Electropolishing Process

After solution preparation, a current applicator was used with special nipple where the material removal can be concentrated at given location of the specimen. After few experiments, it was noticed that after applying current for 2 minutes, 0.001 inches of material could be removed. Therefore, to get 0.002 inches depth, the process was conducted for 4 minutes.

This depth was very carefully measured using digital contour tracing equipment by Mitutoyo, CV-2000 Contracer, connected with a computer, with very high accuracy as shown in figure 4-26. Figure 4-28 presents the profile of the depth generated using the computer controlled instrument. 


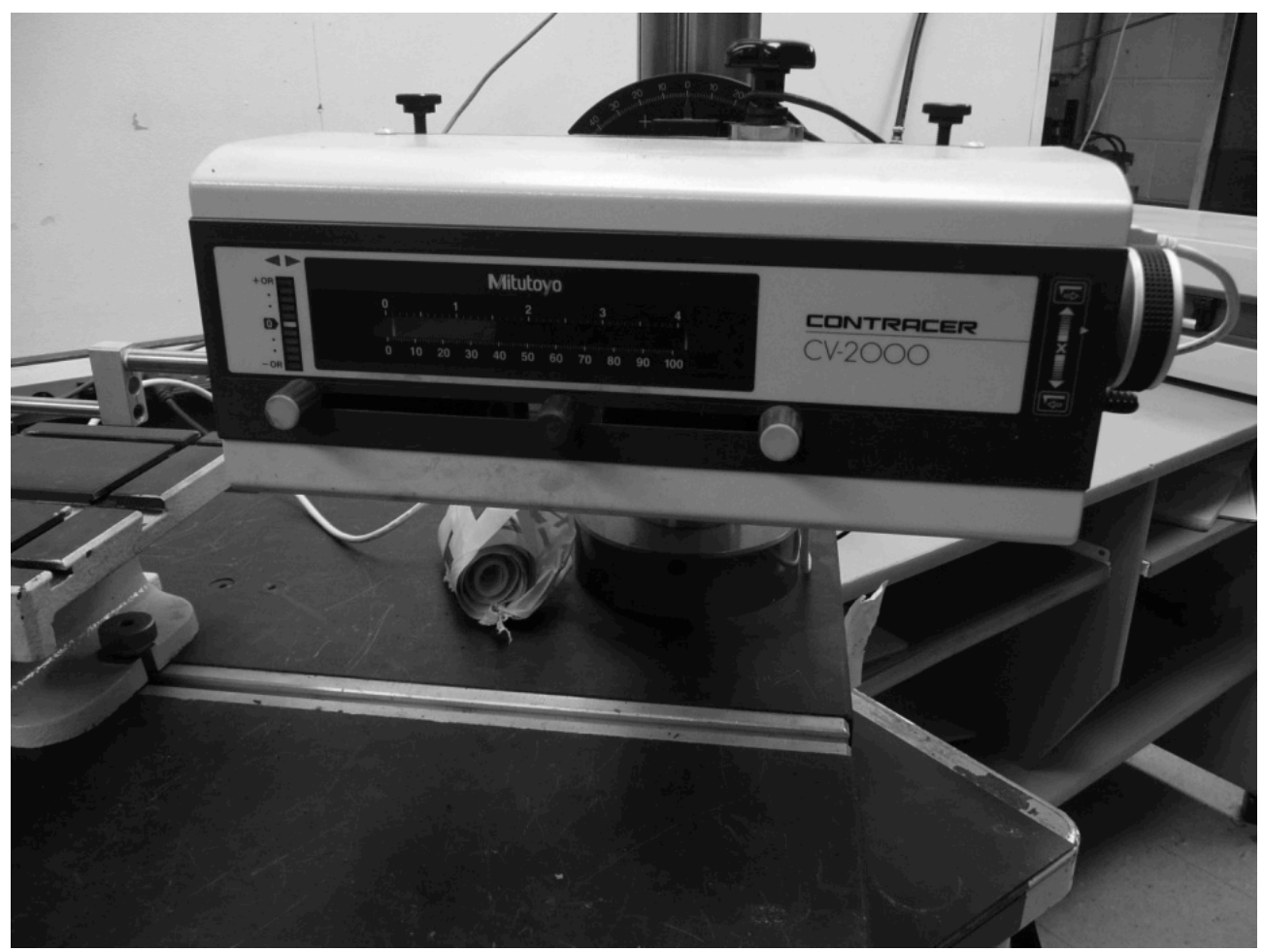

Figure 4-26: Instrument used for measuring depth accurately

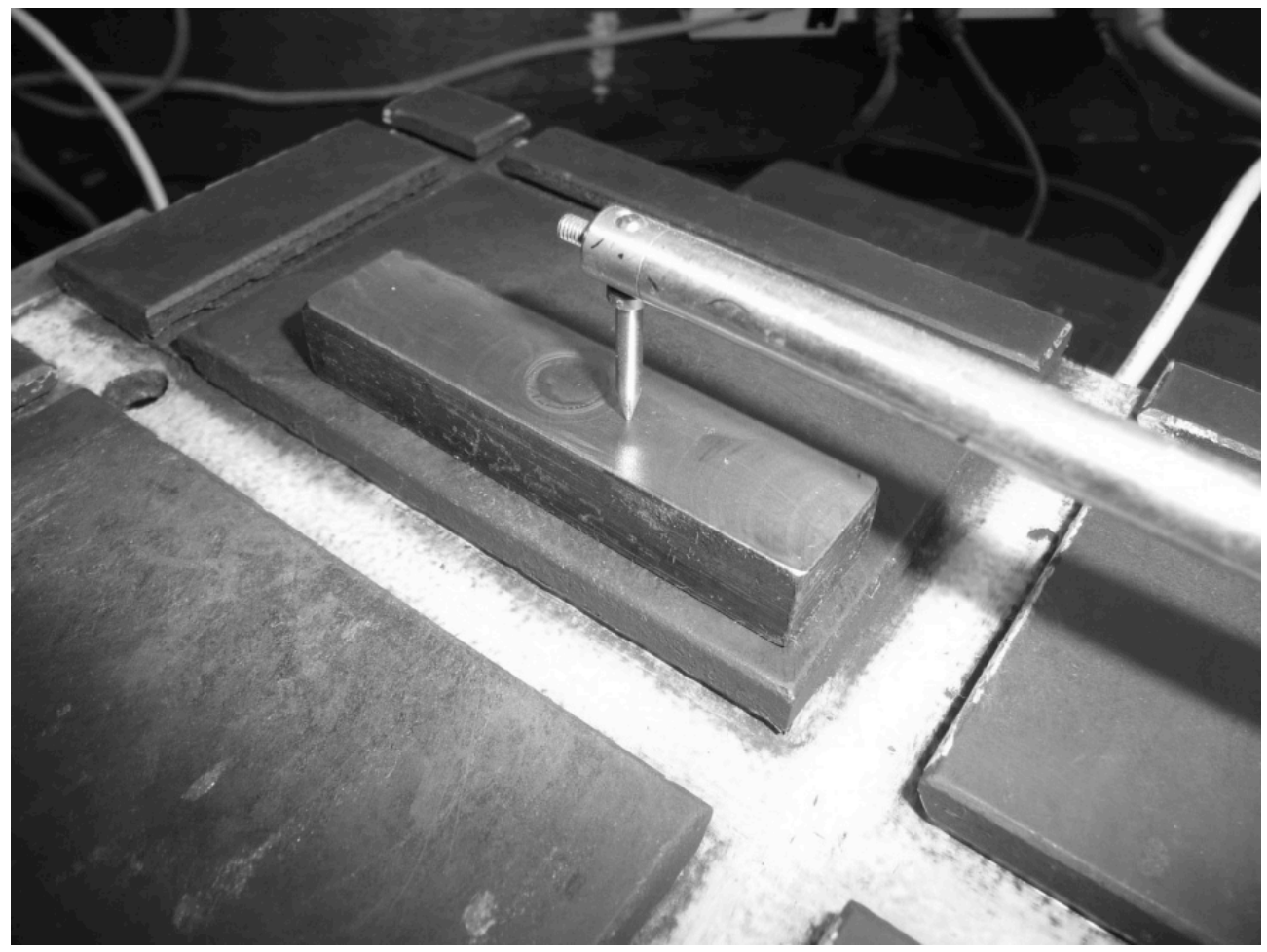

Figure 4-27: Accurate measurement and mapping of depth 
After determining the exact depth, the specimen was cleaned and placed again in LXRD machine enclosure, to measure the residual stress at required depth.

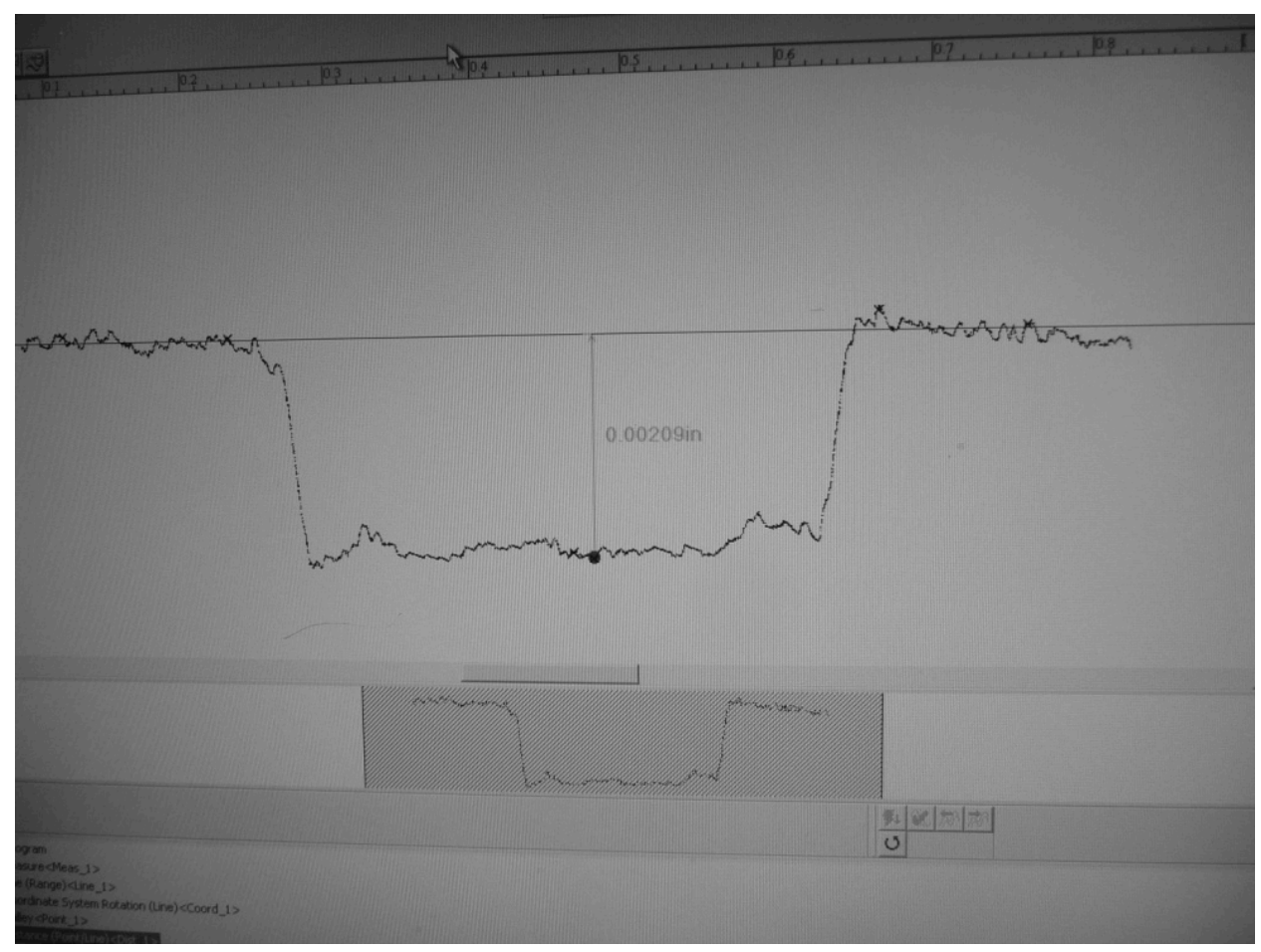

Figure 4-28: Determination of accurate depth using computer controlled instrument

Figure 4-27 shows the image of specimen after removing 0.002 inch of material under measurement. These steps were repeated for different depths for all nine samples, and data were recorded, corrected for material removals by the software.

The recorded results are shown in Appendix Tables A1 to A3 for each sample at different depths with standard deviation of $\pm 0.2 \mathrm{ksi}$. The results are also plotted in Appendix figures A1-A3 to better illustrate the observations. 


\section{CHAPTER 5}

\section{Results and Discussions}

\subsection{General}

This chapter provides all results and analysis obtained using deflection method and Xray diffraction of residual stress measurements. Fatigue analyses are also performed from data collected using X-ray diffraction method to create S-N curves to evaluate the effect of residual stress relaxation and stress ratios. Discussion of results is also provided.

\subsection{Deflection Method}

In order to evaluate the influence of heat treatment on shot peened $300 \mathrm{M}$ specimens, and how experimental results of deflection method correlates to residual stress were employed to obtain parameters in Zener-Wert-Avrami function are extensively discussed. To calculate percent residual stress relaxation for $300 \mathrm{M}$ high strength steel, equations introduced in Chapter 3 have been used. This chapter will further focus on stress relaxation mechanism at the microstructure level and its contribution in the thermal relaxation model. The results have been described by Zener-Wert-Avrami function. Creep theory was employed to characterize residual stress relaxation in landing gear steel strips. 


\subsubsection{Calculation of Residual Stress Relaxation}

The plot shown in figure 5-1 represents remaining compressive residual stress in $300 \mathrm{M}$ steel strips at five different temperatures as a function of time. This graph was plotted by measuring the changes in deflection of steel strips after each heat treatment time interval. Table A4 in appendix A shows initial deflection after shot peening and then subsequent decrease in deflection as a result of stress relieve at respective time. The deflection values were averaged for each stress relieve temperature and were normalized by initial deflection value to calculate percent stress remaining. These ratios $\sigma_{r s}^{T} / \sigma_{\mathrm{o}}$ are listed in table $5-1$

The temperatures were chosen to address a range of industrial applications where temperatures vary from values above the tempering temperature to the tempering temperature. From previous literature, it can also be seen that thermally activated stress relaxation starts to take place in steels at temperatures around $400^{\circ} \mathrm{F}$ to $425^{\circ} \mathrm{F}$ and above. As one of the objectives of the study was to verify this condition, this was also demonstrated in figure 4-1, where stress relaxation is more predominant at temperatures above $450^{\circ} \mathrm{F}$ than at $375^{\circ} \mathrm{F}$. In figure $5-1$, it can be observed that significant residual stress relaxation occurs at high temperatures, most noticeably above materials tempering temperature. It can be seen that the drop in residual stress is extremely high during the first one hour of heat treatment at all temperatures. 
Table 5-1: Percentage relaxation residual stress after heat treatment at each temperature

\begin{tabular}{|c|c|c|c|c|c|c|c|}
\hline \multirow{2}{*}{$\begin{array}{c}\text { Temperature } \\
\text { in }{ }^{\circ} \mathbf{F}\end{array}$} & $\mathbf{6}$ & $\mathbf{1 . 0 0}$ & $\mathbf{3 . 0 0}$ & $\mathbf{7 . 0 0}$ & $\mathbf{1 5 . 0 0}$ & $\mathbf{3 0 . 0 0}$ & $\mathbf{5 4 . 0 0}$ \\
\cline { 2 - 8 } & & & & & & & \\
\hline $\mathbf{3 7 5}$ & 100 & 94.71 & 94.09 & 93.89 & 93.64 & 93.45 & 93.29 \\
\hline $\mathbf{4 5 0}$ & 100 & 91.51 & 90.93 & 90.35 & 89.41 & 88.44 & 87.85 \\
\hline $\mathbf{5 2 5}$ & 100 & 89.93 & 88.61 & 86.62 & 85.03 & 84.38 & 82.85 \\
\hline $\mathbf{6 5 0}$ & 100 & 82.51 & 78.92 & 73.99 & 71.29 & 68.71 & 64.72 \\
\hline $\mathbf{8 7 5}$ & 100 & 68.69 & 57.64 & 50.55 & 45.22 & 41.10 & 38.07 \\
\hline
\end{tabular}

For specimens heat treated at temperature lower than $525^{\circ} \mathrm{F}$ the residual stresses are reduced at lower magnitude than at $650^{\circ} \mathrm{F}$ and $875^{\circ} \mathrm{F}$. It is notable that at $375^{\circ} \mathrm{F}$, after about 1 hour only a small reduction of approximately $5.3 \%$ of the residual stresses has occurred and after almost 54 hours residual stress dropped only $6.7 \%$. while at higher temperatures of $450^{\circ} \mathrm{F}$ and $525^{\circ} \mathrm{F}$ (below the tempering temperature) the relaxation continues to decrease gradually.

A significant relaxation of residual stress can be noticed at high temperatures of $650^{\circ} \mathrm{F}$ and $875^{\circ} \mathrm{F}$ which also continues to decrease at faster rate than temperatures below the tempering temperature of $300 \mathrm{M}$ steel. This clearly verifies that residual stress is relaxed as a consequence of shot peening. While main reason for stress relaxation at temperatures higher than the tempering temperature $\left(575^{\circ} \mathrm{F}\right)$ for landing gear steel is 
due to loss in mechanical and physical properties over re-tempering process. Cumulative hardness after heat treating at each temperature is given in Table 5-2. Steel strips heat treated at $650^{\circ} \mathrm{F}$ and $875^{\circ} \mathrm{F}$ (above the tempering temperature) showed the most reductions in hardness and strength and increase in ductility of steel strips

Table 5-2: Cumulative Hardness Values

\begin{tabular}{|c|c|}
\hline Heat Treat Temperature & Hardness (HRC) \\
\hline Original (Shot Peened) & 57.6 \\
\hline $375^{\circ} \mathrm{F}$ & 55.5 \\
\hline $450^{\circ} \mathrm{F}$ & 54.2 \\
\hline $525^{\circ} \mathrm{F}$ & 53.8 \\
\hline $650^{\circ} \mathrm{F}$ & 48.4 \\
\hline $875^{\circ} \mathrm{F}$ & 46.1 \\
\hline
\end{tabular}

Structural changes such as formation of transition carbides and lowering of the carbon content and transformation of retained austenite to ferrite and cementite replaced transition carbides and low-temperature martensite was produced at temperatures higher than tempering temperature at which desired properties were obtained during development stage. The size of cementite constituent influenced the mechanical behavior of tempered martensite. As the particle size increased with temperature the ferrite-cementite phase boundary area was reduced resulting in a softer and weaker material. The microstructure of material was affected at various temperatures and the 
effect of cold working on shot peened materials was lost significantly due to microstructural changes at these temperatures.

The landing gear steel strips were especially clamped to obtain elastic deformation so that changes in volume do not induce further residual stress during heat treatment process at higher temperatures. The rate of residual stress relaxation dropped after heat treating process at longer times mainly due to decrease in hardness and toughness. In heat treating of $300 \mathrm{M}$ at temperatures above the tempering temperature $\left(575^{\circ} \mathrm{F}\right)$, the shot peening effect is significantly reduced and mechanical properties of this alloy diminishes resulting more damage in materials.

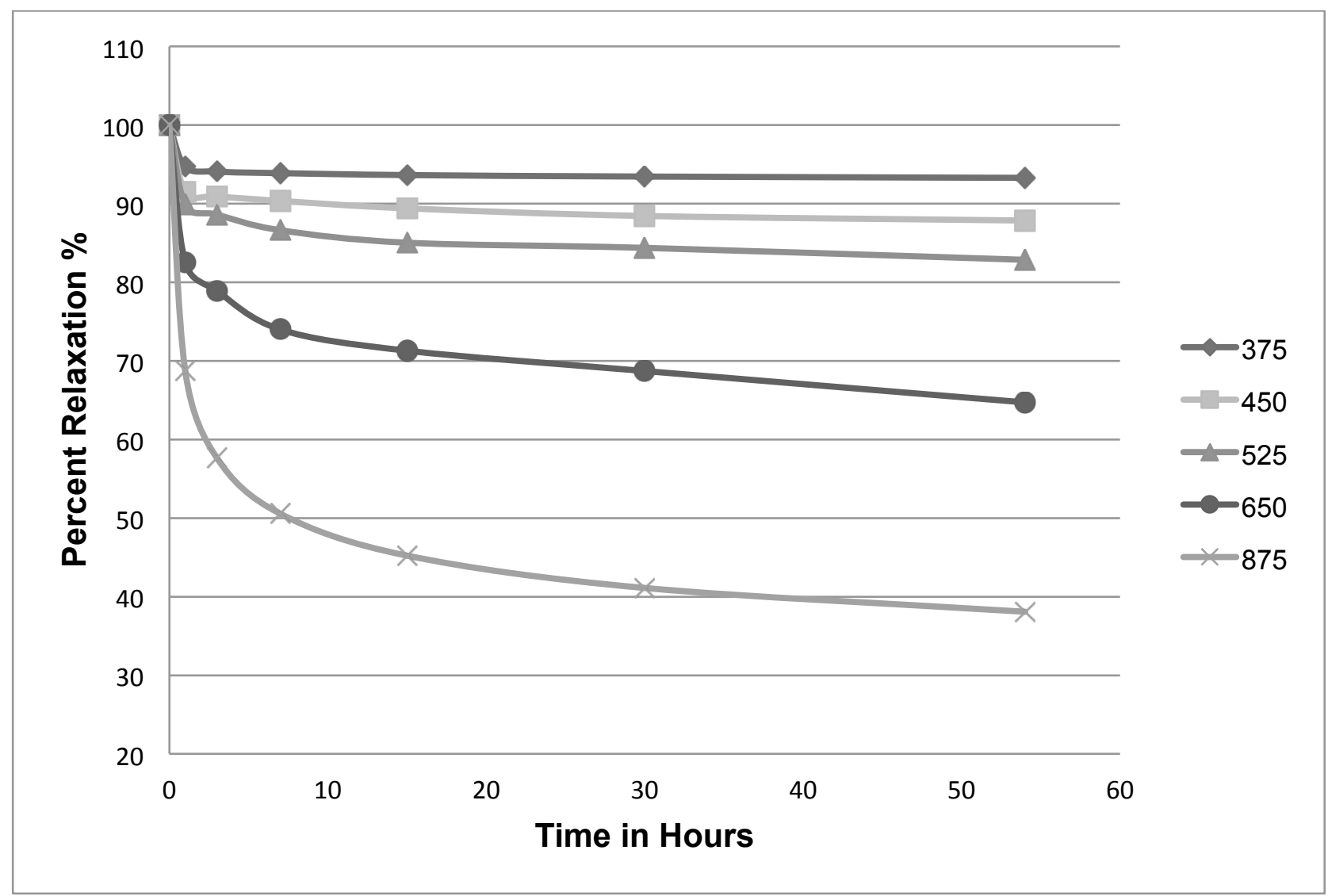

Figure 5-1: Actual Residual Stress ratio for all heat treatment temperatures as a function of heat-treating time 
At temperatures below the tempering temperature the micro structure and mechanical properties of material are not significantly affected although precipitation hardening may occur at temperatures above $425^{\circ} \mathrm{F}$ also called blue brittleness because it occurs at blue heat zone [52]. The stress relieve occurs more slowly because relaxation is associated to elastic strains due to residual stresses by Hook's law, which were converted into micro-plastic strains by shot peening application. Both creep and diffusion then control relaxation process as main affecting factors in the stability of residual stress.

The mechanism in creep deformation is dominant due to the climb of edge dislocations [30]. Dislocations are line defects that slip through a crystal lattice in polycrystalline structure of steel when the maximum resolved shear stress is applied. Dislocations initially slip along the closest packed planes since this requires the least energy to debond crystallographic planes [53]. In case of shot peened, 300M steel where dislocation densities are very high dislocations multiply at sources, and as the dislocation density increases, more dislocation interactions occurs [53].

Upon creep process in shot peened materials induced dislocations results in an increased strain energy stored in the materials. Creep phenomenon along with the high temperature, act as the driving force for the thermally activated relaxation process. Thermally activated relaxation reduces the dislocation density and the rearrangement of dislocations into lower energy in sub-grain boundaries. 


\subsubsection{Residual Stress Ratios}

To analyze recorded deflection data, a MATLAB program was developed. The inputs for this program are listed in Table A4 of appendix A. The corresponding matrix data consisted of 16 rows and 7 columns. The first 15 rows contain deflection of each shot peened strip in inches before and after heat treatment. The 16th row is used to input corresponding heat treating time. The program code is appended in appendix C.

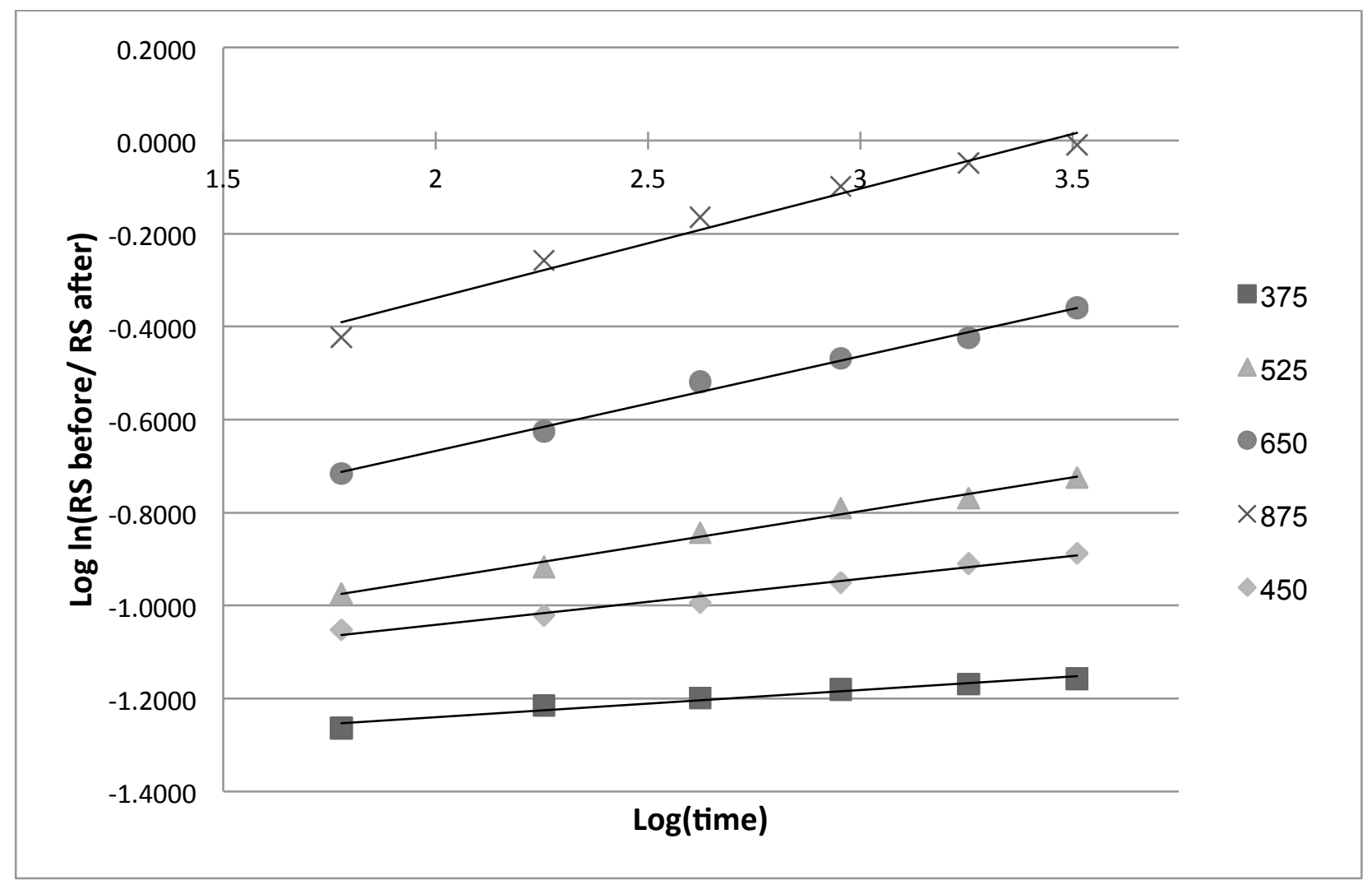

Figure 5-2: Influence of heat-treating time on residual stress

Zener-Wert-Avrami function of the general form were applied to the data, resulting in the plot of $\log \ln \left({ }^{\sigma_{r s}} / \sigma_{o}\right)$ versus $\log t$ with time converted to minutes. Figure $5-2$ 
presents straight lines for constant heat-treat temperatures representing how influential is the heat-treating time on residual stress.

Each straight line presents data measured at a given temperature. The slopes of straight lines show these lines are parallel with $m$ value used in Zener-Wert-Avrami function. Figure 5-3 shows that slopes of parallel lines fits data well. The value of material constant $m$ appears to be well within the expected range (0.1 to 0.3$)$ for this category of steel alloy.

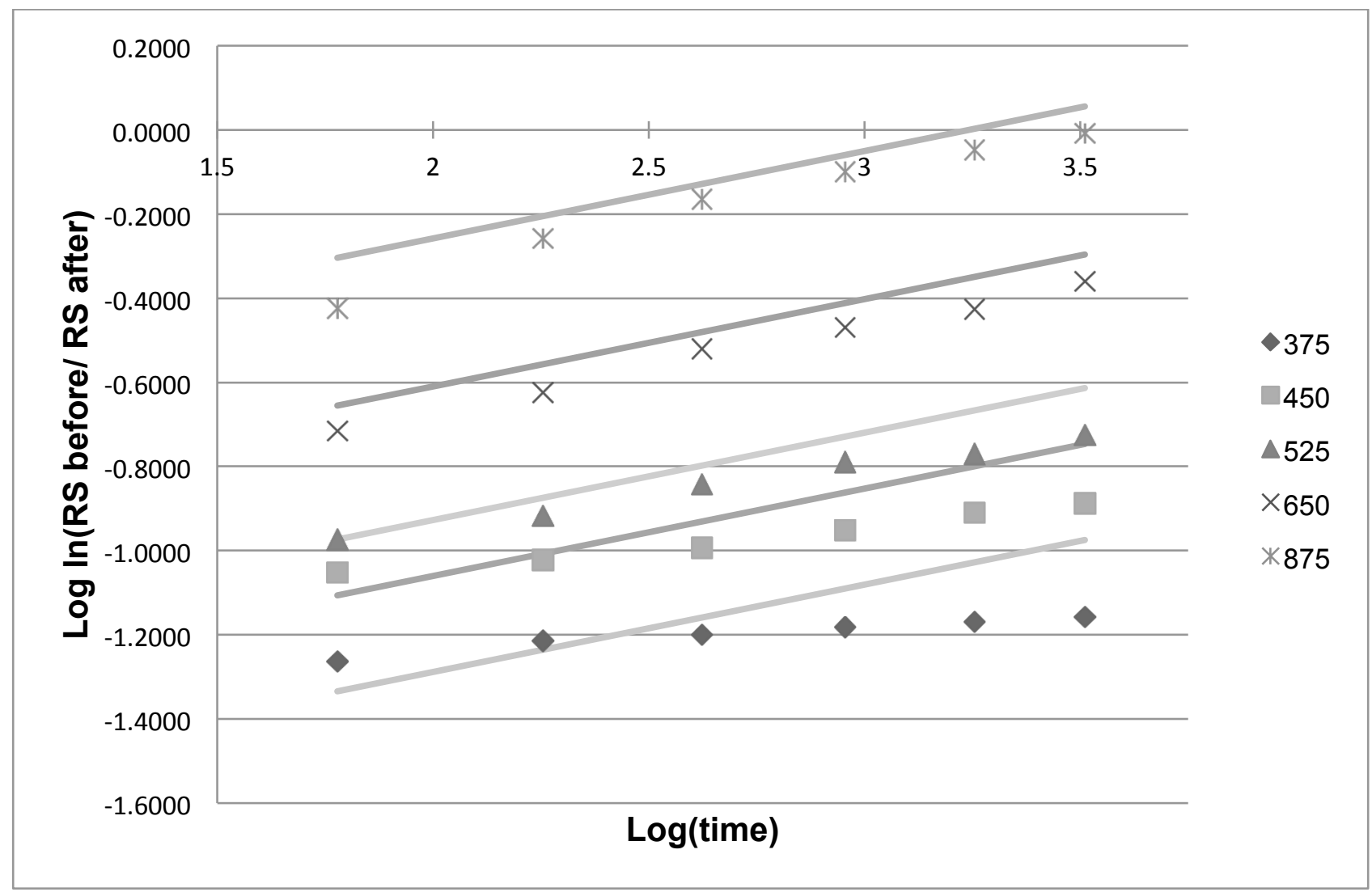

Figure 5-3: Best Fit parallel curves at various temperatures to obtain slope using MATLAB 


\subsubsection{Determination of Activation Energy}

Similarly, corresponding heat treating temperatures and times for constant ratios of $\sigma_{r s}^{T} / \sigma_{o}=$ constant were determined from plot of $\log t$ versus $1 / k T$ shown in figure 5-4, where temperature $T$ is taken as absolute temperature in degree Kelvin and using figure $5-4$, at constant values for the residual stress relaxation at intervals of $5 \%$. The subsequent heat-treating time values $(\log (t))$ are shifted to create plot of $\log t$ versus $1 / k T$ using MATLAB program. The values for $\sigma_{r s}^{T} / \sigma_{o}=$ constant lie on the straight lines to determine slope of straight lines as activation enthalpy for residual stress relaxation $(\mathrm{Q} / \ln (10))$ as described by equation 3-5 in chapter 3 . The parameters of Zener-WertAvrami function were determined from experiments are tabulated in table 5-3.

Table 5-3: Zener-Wart-Avrami Function parameters determined from experiment

\begin{tabular}{|l|l|}
\hline Parameter & Value \\
\hline m (Material Constant) & 0.1845 \\
\hline B (Material Constant) & $1.17 \times 10^{8} \mathrm{~min}^{-1}$ \\
\hline Q (Activation enthalpy) & $1.65 \mathrm{eV}$ \\
\hline C (Calculated constant) & $1.92 \times 10^{4} \mathrm{~K}$ \\
\hline
\end{tabular}

Equations 3-2 and 3-3 were used to determine the value of $B$ at constant time and various temperatures. Using equation 3-5 and equation 3-6 the percent of relaxation for residual stress relief for $300 \mathrm{M}$ steel was estimated. 
Percent Relaxation $=\left[\exp \left(-\left\{1.17 \times 10^{8} t e^{\frac{1.92 \times 10^{4}}{T}}\right\}^{0.1845}\right)\right] \times 100 \%$

where, $\mathrm{t}$ is in minutes and $\mathrm{T}$ is in degree Kelvin.

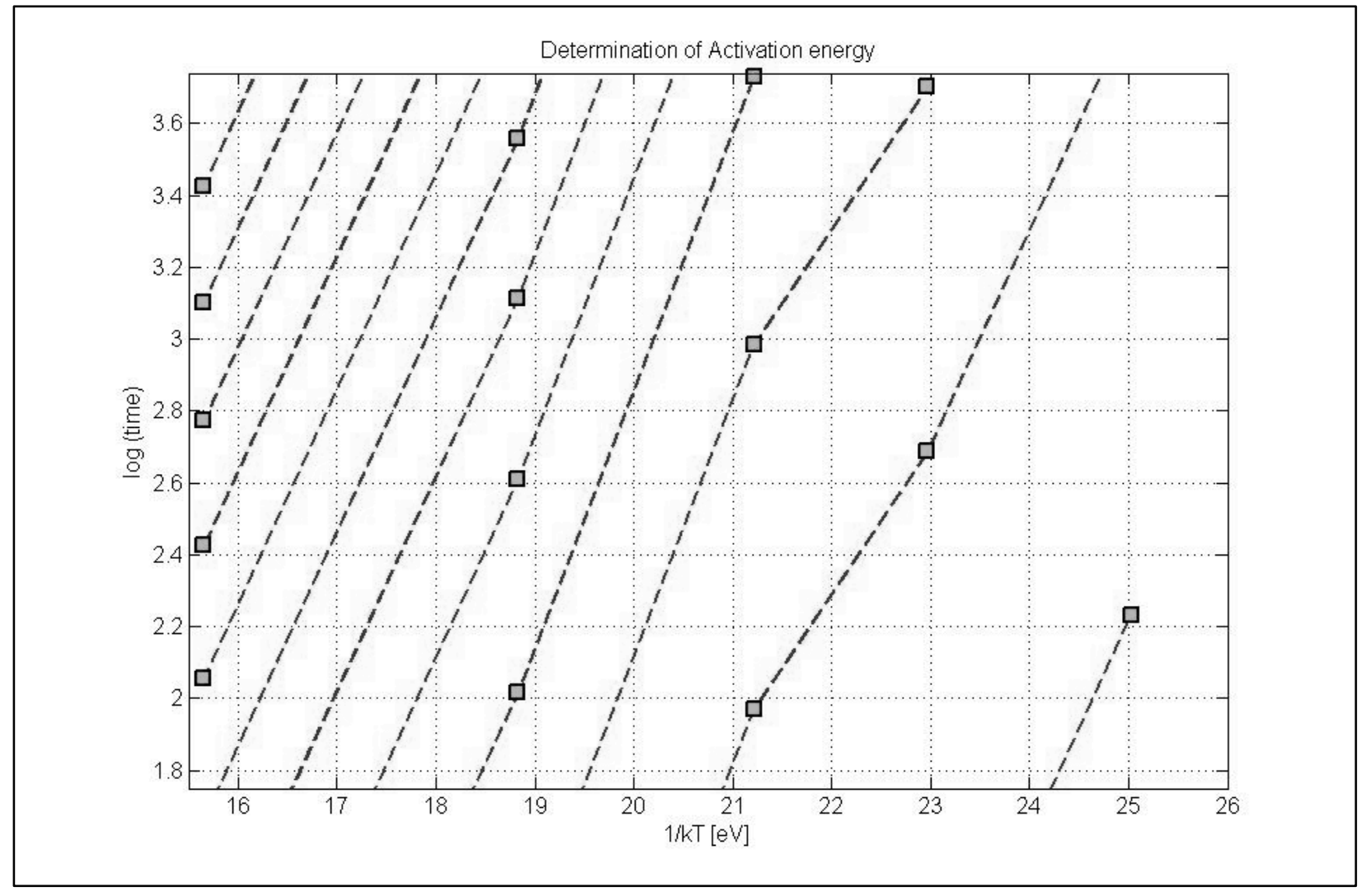

Figure 5-4: Actual and predicted slopes for determination of Activation Energy (Q)

The percent residual stress relaxation is then plotted verses heat treatment time at different heat treatment temperatures. Figure 5-5 compares the calculated and experimental values. 
The calculated residual stress relaxation ratios versus different heat treatment temperatures at various time intervals in a form of isochronal data are shown in figure 5-

6. The data required to generate these plots are given in appendix B table B2. Calculations of surface stress relaxation were determined using Zener-Wert-Avrami function, which linearizes the effect of heat treatment time. In thermally activated processes, the heat treatment temperature and time are interchangeable within certain limits.

\subsubsection{Comparison of Results and Discussion}

The comparison of experimental and calculated values in figure 5-6 verifies that this deflection method is capable to describe the measured values. This figure also shows the isothermally related parameters of heating time and residual stress relaxation ratio. Except the first stage of heat-treating time, at higher temperatures mechanical properties shows a drastic change. The calculated curves are based on Zener-WertAvrami function closely agreed the experimental values even at longer annealing process.

For thermally activated relaxation process, dislocation and atomic movement or selfdiffusion within the lattice are required. Since self-diffusion is only possible in a close packed lattice and if the atoms have enough energy to jump into a neighboring site and if there is a vacancy at that site, the relaxation will take place as atoms jump due to 


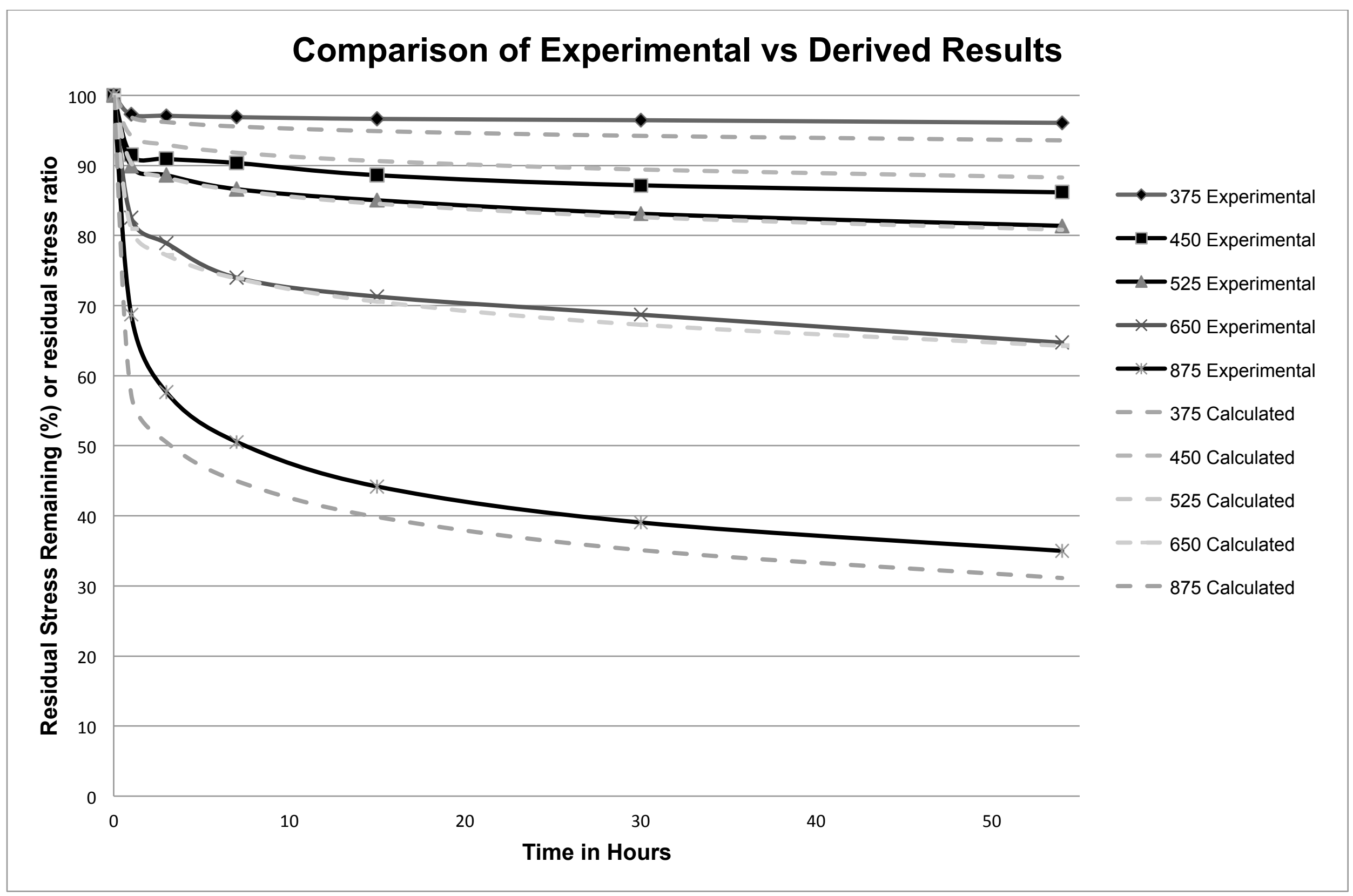

Figure 5-5: Calculated residual stress ratio at arbitrary heat treatment temperatures as a function of time 


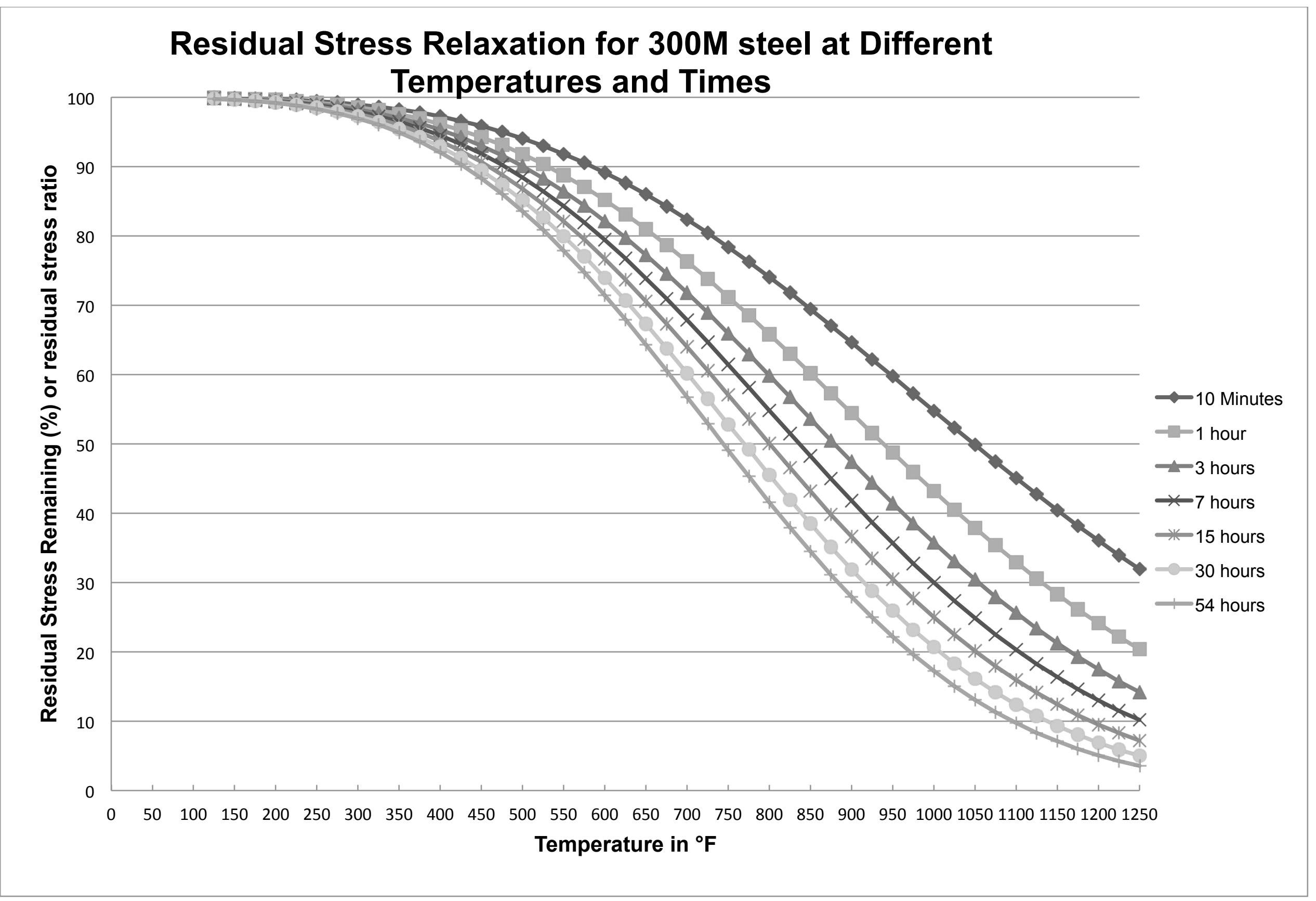

Figure 5-6:Calculated residual stress ratio at arbitrary heat treatment times as a function of temperature 
applied energy. As temperature increases atoms have more thermal energy and the equilibrium concentration of vacancies in a metal increases exponentially.

In case of steels, the activation enthalpy or activation energy is in range of 1.1 to $2.6 \mathrm{eV}$, and is lowest due to hardening. The slope of curves in figure 5-5 changes at temperatures below $450^{\circ} \mathrm{F}$, hence activation energy was calculated to be $1.15 \mathrm{eV}$ for temperatures below this. The calculated activation energy from figure 5-5 for temperatures above $450^{\circ} \mathrm{F}$ was determined to be $1.65 \mathrm{eV}$. Therefore values of calculated activation energies lie within the range for iron based material although it is not as high as expected for this family of steel alloys.

It was also noticed that activation energy is proportional to stress relaxation process, as temperature increases with increasing relaxation value. Due to the presence of more carbon atoms and alloying elements in steel microstructure, a higher activation energy is required for self-diffusion process to overcome obstacles such as grain boundaries, impurity particles in case of high carbon steel also hinder dislocations slip where carbon atoms act as impurity and greatly affect the rate of relaxation. Since, the experiment was conducted on the thin plates the activation energy value is closer to half of activation energy of self-diffusion of iron. Bulk diffusion predominated the relaxation and the value of activation energy became important which it should be enough to overcome stalking fault energy of carbon-steel microstructures [30]. 


\subsection{X-ray diffraction Measurement Method Results}

To evaluate the influence of heat treatment on shot peened $300 \mathrm{M}$ specimens at subsurface levels, X-ray diffraction technique was employed. The distribution of residual stress on subsurface levels was measured over various depths. The residual stress curves varied as the heat treating temperature magnitude changed. This section discusses the residual stress relaxation response at different depths in landing gear steel bars.

\subsubsection{Residual Stress Distribution}

The compressive residual stress versus subsurface depth of shot peened $300 \mathrm{M}$ steel bars is presented in figure 5-7. The measured values of residual stress were obtained from shot peened samples at room temperature. The in-depth residual stress was measured perpendicularly to the shot peening surface direction using electro polishing technique. Table A1 in appendix A tabulates the depth intervals and residual stress values. Figure 5-7 shows that the maximum residual stress is induced just beneath the surface and at the depth of approximately 0.004 inches. Residual stress reduces to zero at 0.009 inches beneath the surface.

The shot peening condition at which compressive residual stress versus over subsurface depths are obtained is given in Chapter 4. As expected the residual stress for typical high strength materials is maximized just below the surface. 


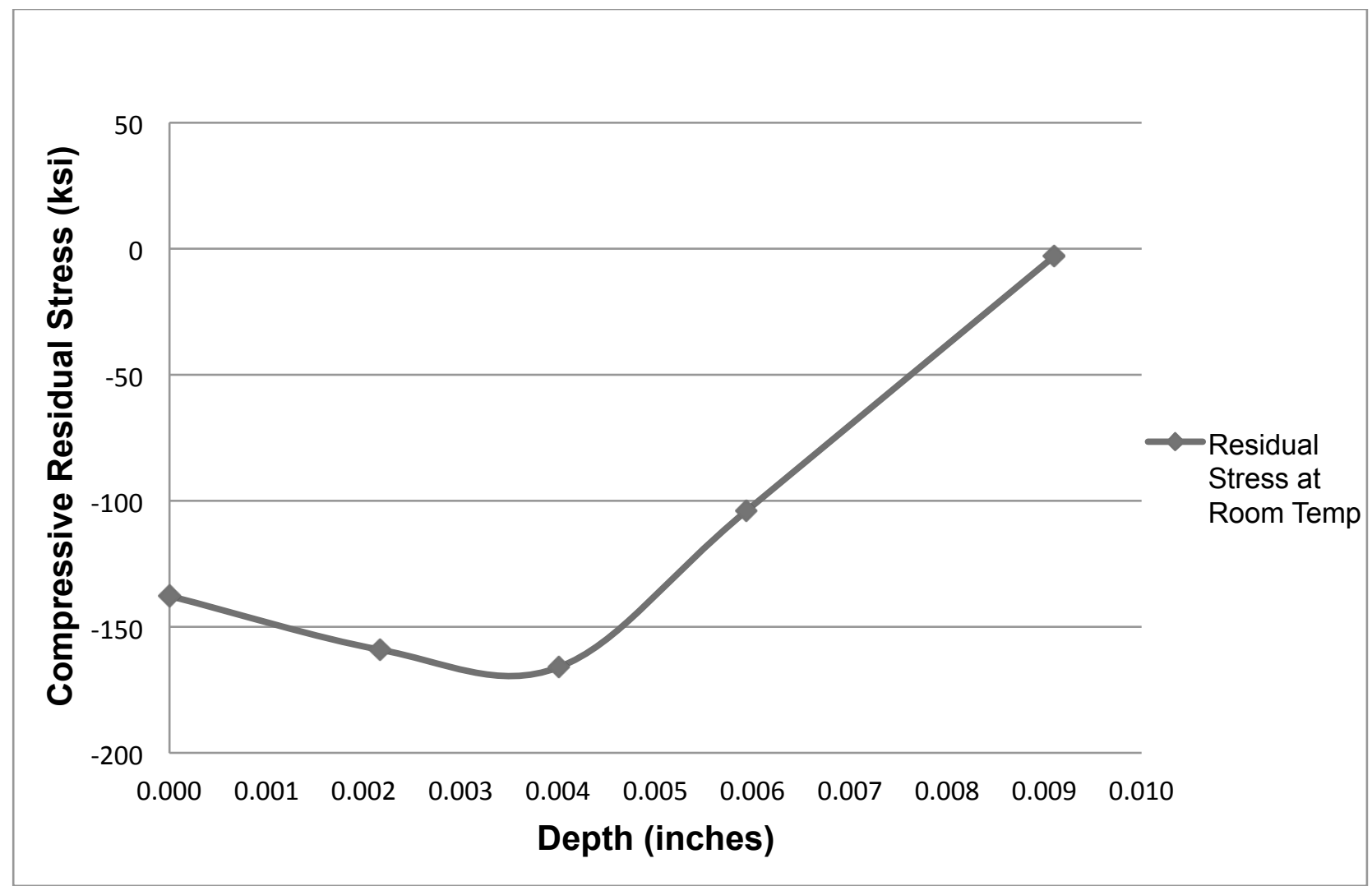

Figure 5-7: Residual stress distribution in 300M steel due to shot peening as function of depth

The plastic deformation extent was found dependent on the magnitude of the shot peening intensity. The residual stress induced on the surface is attributed to the stretching of the surface material due to peening process. In $300 \mathrm{M}$ steels the stretching effect is fundamentally related to plastic stretching of the immediate work piece surface and Hertz's compression or pressure [54]. During plastic stretching, the compressive plastic flow normal to the peened surface is accompanied by the tensile plastic flow in the tangential directions of the surface. The resultant stretched surface layer is then constrained in compression by sub-surface material. 
According to Hertz's compression, numerous shot indentations produce forces normal to the surface, which in turn stimulate a pressure in the metal. Figure 5-8a shows plastic deformation and formation of surface residual stress due to effect stretching of material and figure 5-8b shows effect of Hertzian compression due to shots hitting the material.

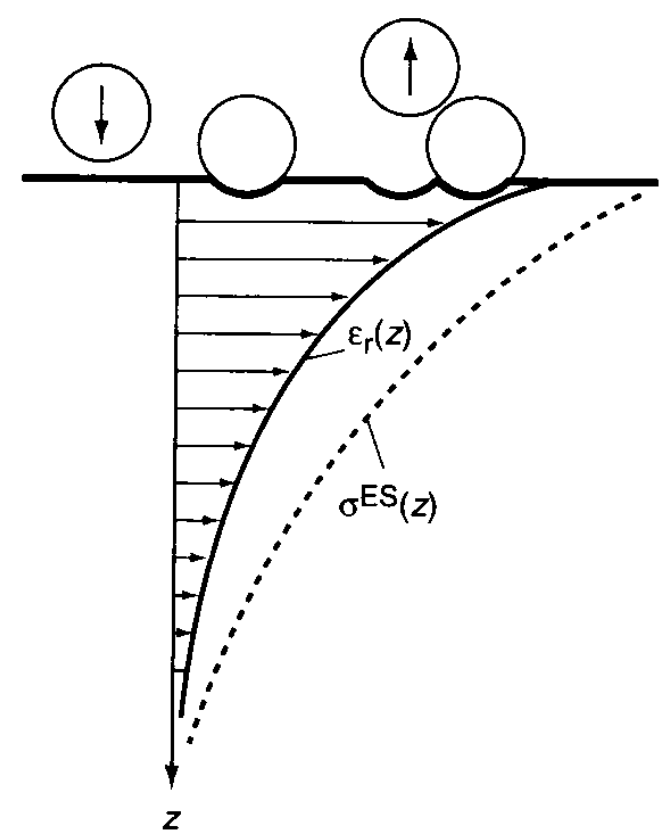

(a)

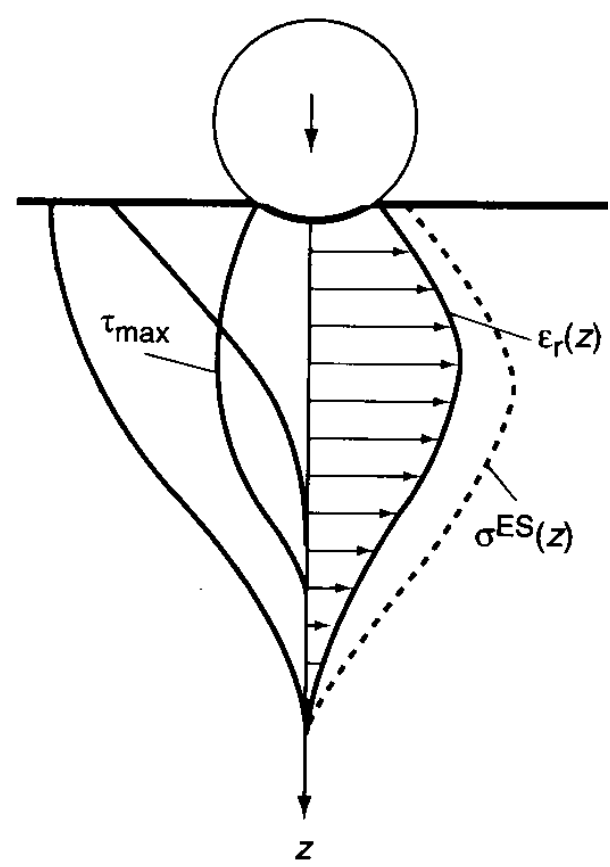

(b)

Figure 5-8: Residual Stress formation (a) Stretching surface layer (b) Hertzian pressure [55]

This pressure originates maximum shear stress at a given depth and if magnitude of this shear stress exceeds the flow stress, it leads to plastic elongation and to subsequent residual compressive stresses at that depth [54]. Plastic stretching and Hertz's pressure occur simultaneously as shots hit the material. The depth of plastic deformation at which the shear stresses are maximized is an index to determine the maximum residual stress in the peened surface [56]. 


\subsubsection{Effect of Heat Treating Temperature}

Residual stress values of surface and subsurface in 300M were tabulated in Table 5-4 after shot peening at various heat treated temperatures. In Figure 5-8, the residual stress values in $300 \mathrm{M}$ specimens were measured for heat-treating temperatures of $375^{\circ} \mathrm{F}$ and $525^{\circ} \mathrm{F}$ and heat treatment period of 4 hours. These curves were obtained using x-ray diffraction method at same depth values. These heat treating temperatures and their corresponding heat treating times were chosen to simulate actual annealing conditions in manufacturing of the landing gear and overhaul process. Hydrogen relief process of the components is performed at the lower temperature of $375^{\circ} \mathrm{F}$ and then both shot peening and plating operations are followed. At higher temperature of $525^{\circ} \mathrm{F}$ the stress relief is performed for high strength steels, as this temperature is $50^{\circ} \mathrm{F}$ below the tempering temperature of $300 \mathrm{M}$ steels.

Table 5-4: Average residual stress at each depth of shot peened and heat treated samples

\begin{tabular}{|c|c|c|c|}
\hline $\begin{array}{c}\text { Depth } \\
\text { (Inches) } \\
\text { (Average) }\end{array}$ & $\begin{array}{c}\text { Residual Stress (ksi) } \\
\text { at Room Temp }\end{array}$ & $\begin{array}{c}\text { Residual Stress (ksi) } \\
\text { Heat Treated at } 375^{\circ} \mathrm{F}\end{array}$ & $\begin{array}{c}\text { Residual Stress (ksi) } \\
\text { Heat Treated at } 525^{\circ} \mathrm{F}\end{array}$ \\
\hline 0.0000 & $-138 \pm 2$ & $-122 \pm 3$ & $-93 \pm 2$ \\
\hline 0.0021 & $-159 \pm 2$ & $-150 \pm 2$ & $-139 \pm 1$ \\
\hline 0.0040 & $-166 \pm 2$ & $-158 \pm 2$ & $-148 \pm 2$ \\
\hline 0.0060 & $-104 \pm 2$ & $-87 \pm 2$ & $-83 \pm 2$ \\
\hline 0.0091 & $-3 \pm 3$ & $+7 \pm 3$ & $+8 \pm 3$ \\
\hline
\end{tabular}


Similar to figure $5-8$, the variation in residual stresses in figure 5-9 shows that these stresses have been relaxed faster at the surface than those beneath the surface. This fact has been also reported by Schulze [31] on shot-peened steel components.

Compressive residual stress at the surface and the compressive residual stress at 0.004 inches were relaxed as high as $11.6 \%$ and $5.0 \%$ after heat treating at $375^{\circ} \mathrm{F}$ for 4 hours. Heat treating of $300 \mathrm{M}$ samples at $525^{\circ} \mathrm{F}$ resulted in the surface residual compressive stress and the maximum residual compressive stress to relax respectively at $32.2 \%$ and $11 \%$ after 4 hours

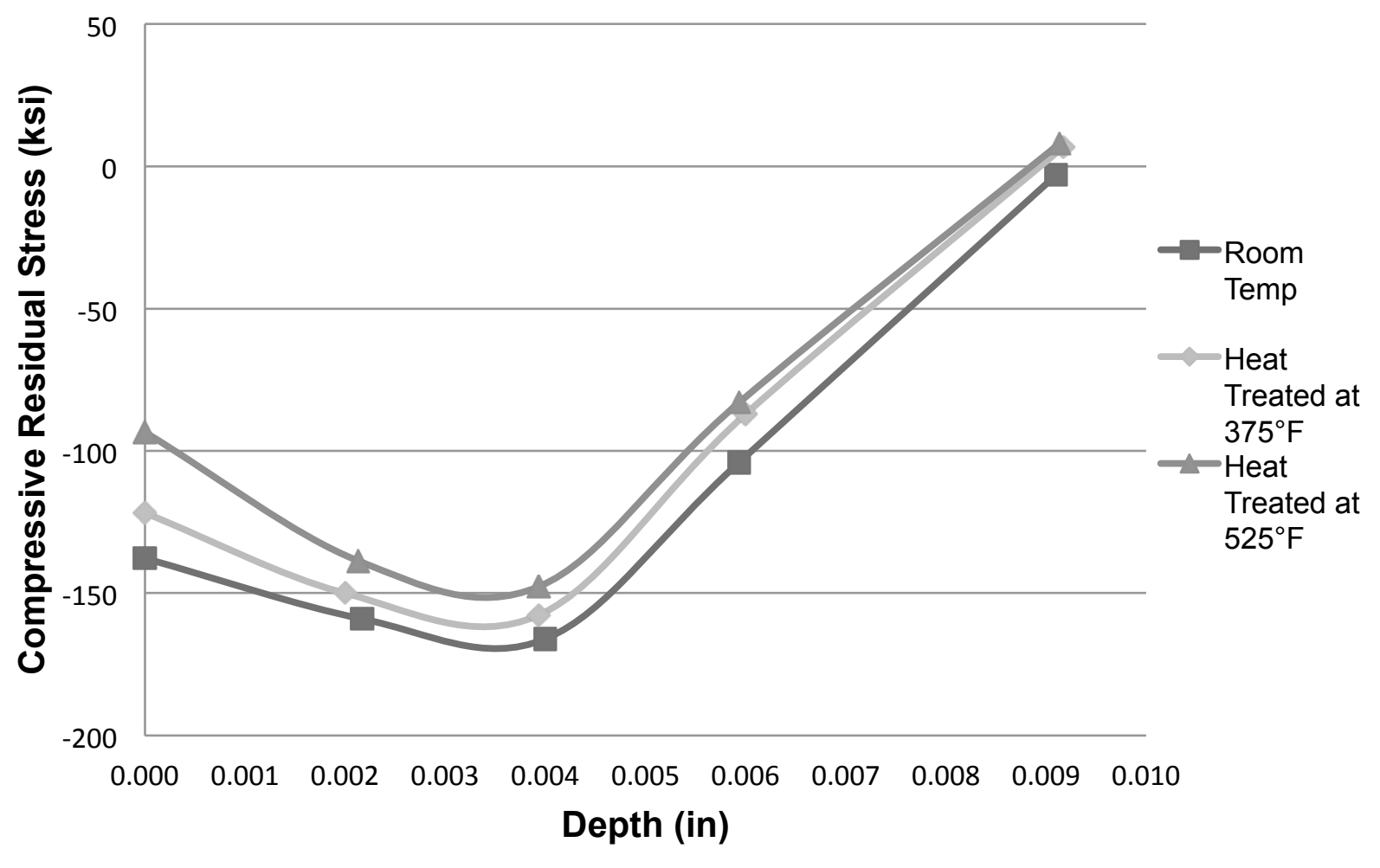

Figure 5-9: Residual Stress relaxation as a function of depth 
Figure 5-10 shows how the surface residual stress gets more easily relaxed than the inner maximum residual stress. In this figure residual stress relaxation curves are affected by heat treating temperatures. Residual stress relaxation values were found almost three times bigger at $525^{\circ} \mathrm{F}$ as compared with samples heat treated at $375^{\circ} \mathrm{F}$ as presented in figure 5-10. This difference in stress relaxation is about two times at depth of 0.0035 inches where maximum compressive residual stress is achieved.

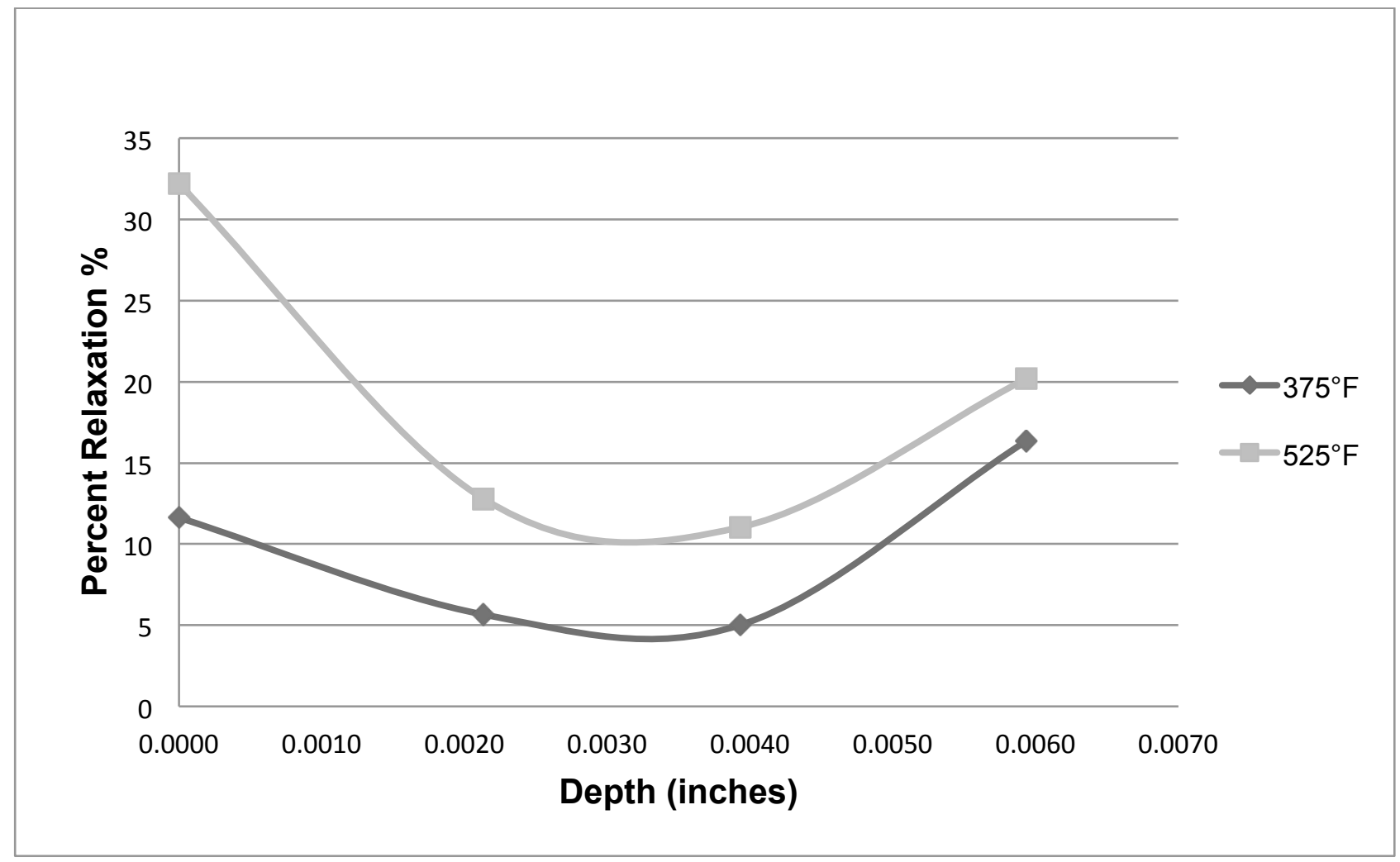

Figure 5-10: Comparison of residual stresses relaxation at different depths due to different temperatures.

It is evident from this figure that the magnitude of stress relaxation increases as heat treating temperature increases. The difference is noticeable at surface of shot peened material. This shows that compressive residual stresses generated due to direct plastic 
deformation at the surface are relaxed faster than stresses induced due to Hertz's compression as stress relaxation and its dislocation movement occurs on the material surface with fewer constraints. For relaxation at subsurface level, however, additional dislocation annihilation is necessary. Accordingly, the volume diffusion-controlled dislocation creep in the residual stress field that is dominated by climbing of edge dislocations should be the rate-controlling process for the relaxation of shot peening residual stresses [5]. Table 5-4 lists residual stress values. At about 0.009 inches beneath the surface, compressive residual stresses drop in magnitude or even turn to tensile residual stress form.

Effect of temperature on the stress relaxation rate is determined by the degree of atomic diffusion, dislocation motion and crystal slip in the material grain and grain boundary. The thermal relaxation of residual stress is related to temperature and time of heat treatment. The maximum rate of stress relaxation takes place mainly in the initial stage of heating process when the working temperature is the temperature with metal atoms' low diffusion rate or is far below the recrystallization temperature [57]. This effect was introduced in the present research study as experiments conducted in $300 \mathrm{M}$ steel strips were heat treated at temperatures below the recrystallization temperature. 


\subsection{Effect of Residual Stress Relaxation on Fatigue}

Since most high strength steels are good candidates for high cycle-long life applications such as landing gears, the process of shot peening is conducted to improve fatigue life of $300 \mathrm{M}$ steel. This process greatly retards the onset of micro crack at the surface of components initiated during cyclic loading.

The stress-fatigue life response of steels is a primary index to evaluate the life and durability of components against failure. Stress-life curves for landing gear materials $300 \mathrm{M}$ have been given in chapter 3 of this thesis.

Stress-fatigue life data and the induced residual stress values were related to evaluate the impact of residual stress values in fatigue life of shot peened and heat treated 300M samples. Both residual stress and fatigue were related parametrically through superposition of residual stress with mean stress over stress cycles [58].

\subsubsection{Residual Stress and Fatigue Life Formulation}

The analytical model is based on stress-controlled fatigue tests presented in literature that was used to model the effect of shot peening and subsequent relaxation of shot peening induced residual stress by thermal action. Characteristics of this model were assumed in analyzing fatigue life $\left(\mathrm{N}_{\mathrm{f}}\right)$ of $300 \mathrm{M}$ steel at varying applied stresses [40]. This model is based on tests conducted on unnotched $300 \mathrm{M}$ alloy forging at $\mathrm{K}_{t}=1.0$, 
with ultimate tensile strength of $274-294 \mathrm{ksi}$ at various stress ratios. The tests were conducted at room temperature. The sample size included 104 unnotched coupons, with $0.200-0.250$ inch diameter and yield strength of $227-247 \mathrm{ksi}$ [40].

Samples were finished ground to a surface finish of RMS 63 or better with light grinding parallel to specimen length and stress relieved. The fatigue test parameters include axial loading condition at frequency of 1800 to $200 \mathrm{cpm}$ (cycles per minute) [40].

The equivalent stress equation for landing gear 300M steel is described by empirical equation (5-2) as:

$$
\log N_{f}=14.8-5.38 \log \left(\sigma_{e q}-63.8\right)
$$

where,

$$
\sigma_{e q}=\sigma_{a}+0.48\left(\sigma_{m}\right)
$$

In equations (5-2) and (5-3), $\sigma_{a}$ is varying applied stress and $\sigma_{m}$ is mean stress in the specimen. The detail of equation (5-2) is given in reference [40]

The effect of residual stresses on fatigue life was encountered through mean stress applied on the components. The residual stress $\left(\sigma_{r s}\right)$ has been integrated to the mean 
stress in equation 5-3 to obtain modified equation 5-4 with following two critical assumptions:

1) Magnitude of residual stress is considered to be affecting entire specimen instead of thin layer of compressive residual stress at specimen surface.

2) Residual stress is stable during the cyclic loading process that is effect of residual stress relaxation due to mechanical loading is not considered.

$$
\sigma_{e q}=\sigma_{a}+0.48\left(\sigma_{m}+\sigma_{r s}\right)
$$

Equations (5-4) and (5-2) have been used to reconstruct S-N curves at stress ratio of $R$ $=-1$ and $R=-2$ at different residual stress magnitudes obtained from section $5-3 . A$ MATLAB program was developed to integrate the effect of residual stress and fatigue and to generate S-N data for various stress ratios (see Appendix D). The effect of residual stress relaxation on fatigue life of $300 \mathrm{M}$ steel were studied based on stress-life (S-N) data obtained at different stress ratios of $R=-1$ and -2 and the results of life evaluation are presented in figures 5-11 and 5-12.

Results obtained using this model are tabulated in Table 5-5 which also includes fatigue limit calculation for $R=-2$. In this table, fatigue limit is calculated at $N_{f}=5 \times 10^{6}$ cycles. The effect of residual stress ratios $R=-1$ and $R=-2$ when compared have significant effect on fatigue life. 
Table 5-5: Fatigue analysis results:

\begin{tabular}{|c|c|c|c|c|c|c|c|c|c|}
\hline \multirow{3}{*}{ Depth } & \multicolumn{3}{|c|}{ Room Temperature } & \multicolumn{3}{|c|}{ Heat treated to $375^{\circ} \mathrm{F}$} & \multicolumn{3}{|c|}{ Heat treated to $525^{\circ} \mathrm{F}$} \\
\hline & \multirow{2}{*}{$\begin{array}{l}\text { C.R.S. } \\
\text { in ksi }\end{array}$} & $R=-1$ & $R=-2$ & \multirow{2}{*}{$\begin{array}{l}\text { C.R.S. } \\
\text { in ksi. }\end{array}$} & $R=-1$ & $R=-2$ & \multirow{2}{*}{$\begin{array}{l}\text { C.R.S. } \\
\text { in ksi }\end{array}$} & $R=-1$ & $R=-2$ \\
\hline & & \multicolumn{2}{|c|}{$\begin{array}{l}\text { Fatigue Limit } \\
\text { (ksi) }\end{array}$} & & \multicolumn{2}{|c|}{$\begin{array}{l}\text { Fatigue Limit } \\
\text { (ksi) }\end{array}$} & & \multicolumn{2}{|c|}{$\begin{array}{l}\text { Fatigue Limit } \\
\text { (ksi) }\end{array}$} \\
\hline $\begin{array}{l}\text { At } \\
\text { surface }\end{array}$ & -138 & 162 & 135 & -122 & 154 & 127 & -92 & 140 & 112 \\
\hline $\begin{array}{l}\text { At } 0.004 \\
\text { inches. } \\
\text { depth }\end{array}$ & -166 & 175 & 148 & -158 & 171 & 144 & -148 & 167 & 140 \\
\hline
\end{tabular}

C.R.S. = Compressive Residual Stress

\subsubsection{Effect of depth of residual stress on S-N curve}

The effect of residual stress relaxation and shot peening on fatigue life of $300 \mathrm{M}$ samples were examined. Figure 5-11 presents the modified stress-fatigue life curves for critical (maximum) residual stress obtained at 0.004 inch beneath the surface at different temperatures as well at residual stress present at the surface for stress ratio of $R=-1$. The S-N data for non shot peened unnotched $300 \mathrm{M}$ steel coupons fall below other S-N curves while shot peened samples show a great influence on fatigue life of the parts and possess highest S-N data. The entire curve has been shifted up. Fatigue life at stress ratio of -1 , for example at given applied stress of $\sigma_{a}=160 \mathrm{ksi}$ has $\mathrm{N}_{\mathrm{f}}=1.322 \times 10^{4}$ cycles for non-shot peened and $N_{f}=1.982 \times 10^{8}$ for shot peened samples. This shows a huge 
increase in stress life of the component, which is due to shot peening. Endurance limit is also affected by shot peening, which also increased by $54 \%$

The effect of temperature on relaxation of residual stress is also incorporated through $\sigma_{r s}$ values for relaxed maximum compressive residual stresses and surfaces residual stresses obtained from table 5-5.

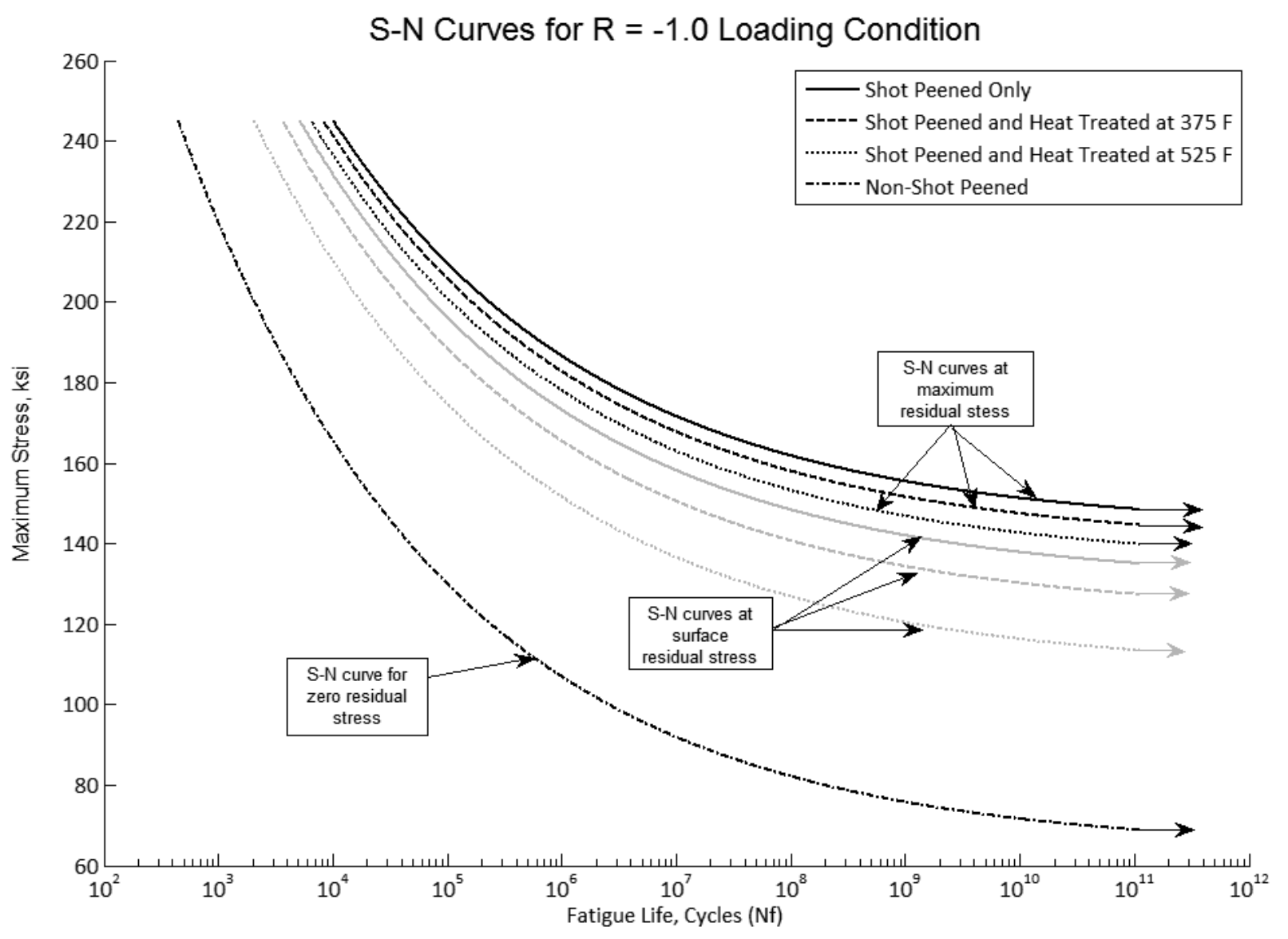

Figure 5-118: $S-N$ curve for unnotched 300M steel at $R=-1$ 
It was also noted that for the magnitude of residual stress taken at surface where relaxation is more dominate in decreasing residual stress at higher temperatures. Since fatigue cracks tend to initiate at surface first because of surface irregularities like corrosion, nicks, dents or wear marks, therefore effect of shot peening becomes significant in fatigue life of $300 \mathrm{M}$ steel components.

The heat treatment temperature has considerable effect of fatigue life of the $300 \mathrm{M}$ steel components and their endurance limit. It can inferred that at maximum residual stress location a decrease in $5 \%$ of residual stress after heat treating at $375^{\circ} \mathrm{F}$ leads to only $3.5 \%$ decrease in endurance limit. At $525^{\circ} \mathrm{F}$, decrease in $11 \%$ of residual stress after heat treating causes $6.7 \%$ decrease in endurance limit. Since residual stress is taken into account along with mean stress, the relationship between residual stress relaxation and fatigue life is proportional when mean stress is zero at $R=-1$. Thus, shot peening is of advantage for fatigue performance but improvement diminishes when applied stress increases.

In next case, the effect of residual stress on S-N curve is examined in the presence of mean stress at $R=-2$, a significant reduction in fatigue limit was detected. The endurance limit was reached much earlier at $1 \times 10^{6}$ cycles for the components affected by residual stress when compared to stress ratio of -1 . 


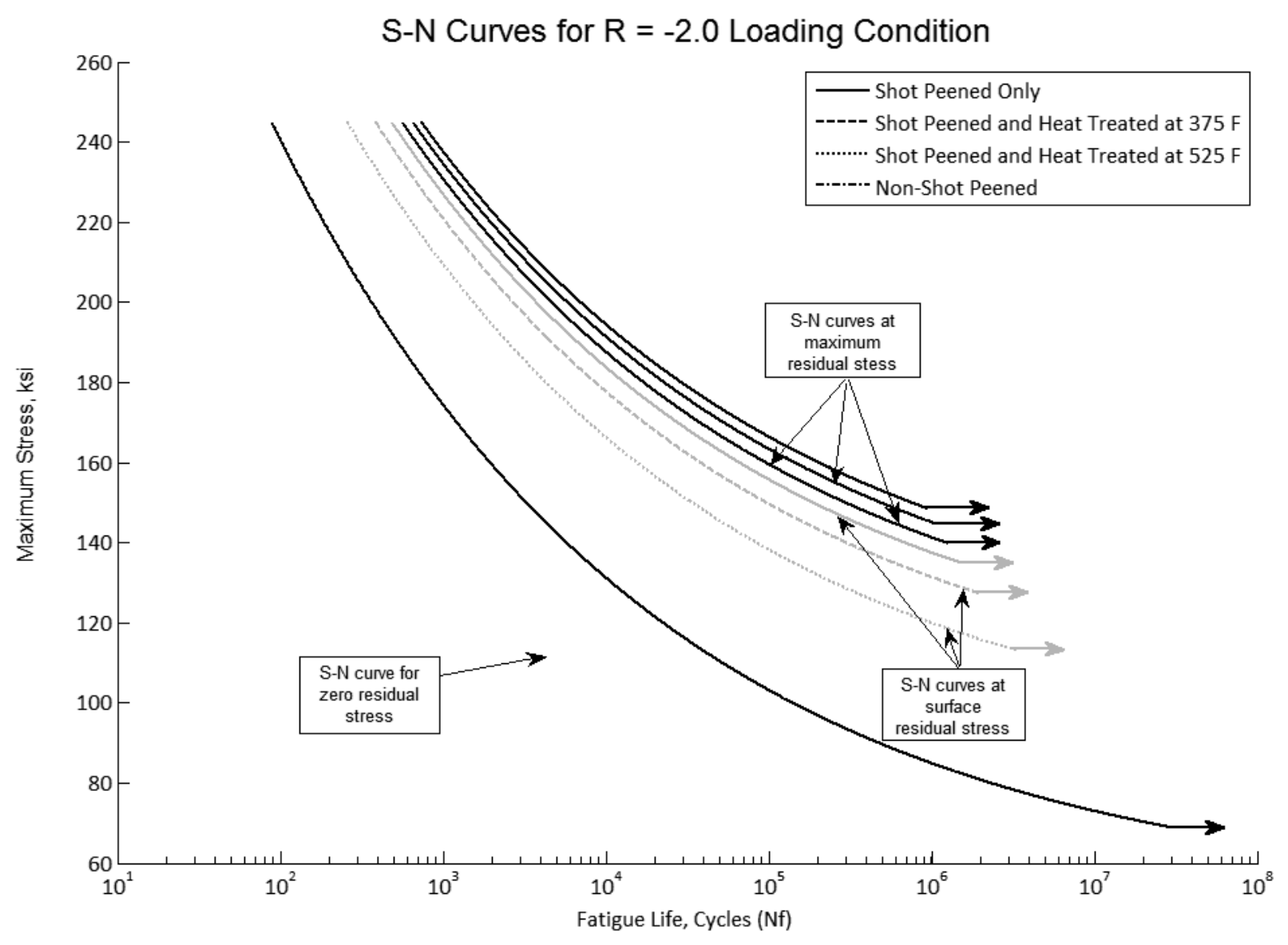

Figure 5-12: $S-N$ curve for unnotched $300 M$ steel at $R=-2$

An increase in endurance limit by $49 \%$ at surface residual stress and $54 \%$ at maximum residual stress was calculated. In the presence of mean stress, when calculated at surface residual stress a reduction of $12 \%$ in residual stress after heat treating at $375^{\circ} \mathrm{F}$, leads to $6 \%$ decrease in endurance limit while at $525^{\circ} \mathrm{F}$, reduction of $32 \%$ in residual stress after heat treating results in approximately $17 \%$ drop in the endurance limit. This may suggest that a decrease in residual stress due to thermal action is proportional to endurance limit where drop in every one percent of residual stress leads to decrease in endurance limit by almost half percent. Similar relation can also be determined for residual stress present at subsurface levels. 


\section{CHAPTER 6}

\section{Conclusions and Future Recommendations}

Shot peening is a common industrial technique employed to induce a layer of compressive residual stress on the surface of mechanical components where high resistance to fatigue cracks and stress-corrosion is required. Compressive residual stress layer acts as protection against fatigue crack initiation as well as retardation of fatigue crack growth. Since, compressive residual stresses induced by shot peening are such an important part of overall component performance, the stability of these stresses becomes an important issue.

In this study, experimental investigations were conducted to evaluate the effect of heat treatment on compressive residual stress induced by shot peening on landing gear $300 \mathrm{M}$ steel alloy. The heat-treating temperature affects the stability of induced residual stress. The level of influence was evaluated using an existing model based on thermally activated process. The effect of temperature on residual stress distribution as well as depth of compressive residual stress field in $300 \mathrm{M}$ shot peened steels at different temperatures was also examined. 
The thermal residual stress relaxation of shot peened $300 \mathrm{M}$ samples was examined by deflection and X-ray diffraction measuring methods. These techniques were employed to obtain sub-surface residual stress distribution. Almen strips made of $300 \mathrm{M}$ steel were shot peened and deflection was measured using Almen gauge. The residual stress as function of deflection in the material was estimated using deflection technique where overall reduction in deflection of strips were measured before and after heat treatment at distinct temperatures ranging from $375^{\circ} \mathrm{F}$ to $875^{\circ} \mathrm{F}$ and heat treatment times between 1 hour and 54 hours. The results showed a strong relationship between heat treatment temperature and time. It was concluded that the heat treatment temperature and time are interchangeable within certain limits.

For specimens heat treated at temperature lower than $525^{\circ} \mathrm{F}$ the residual stresses were reduced to lower magnitude than those tested at higher temperatures. At $375^{\circ} \mathrm{F}$, after one hour heat treating time only a small reduction of $5.3 \%$ in the residual stresses was observed while this reduction after 54 hours was only $6.7 \%$. At higher temperatures of $450^{\circ} \mathrm{F}$ and $525^{\circ} \mathrm{F}$ (below the tempering temperature) the relaxation continued to decrease gradually.

At lower temperatures the stress relaxation was considerably slower than for higher or medium temperatures and only major relaxation took place in first 1 hour of heat treatment. This could be due to strain ageing effects, which suppress the dominant dislocation creep at medium and higher temperatures. In order to describe thermal 
relaxation in the whole temperature range Zener-Wert-Avrami function was further employed. This function correlated the experimental results well over various temperatures. . The mechanism for thermal relaxation of residual stress at medium temperatures was described by creep theory at which climb in edge dislocations due to diffusion of atoms at microstructure level ignited by required activation energy at these temperatures. The activation energy $(Q)$ needed for relaxation was in range of energy needed for self-diffusion of iron atoms. It was also noticed that activation energy is proportional to stress relaxation process, as temperature increases with increasing relaxation value.

A significant relaxation of residual stress was noticed at high temperatures of $650^{\circ} \mathrm{F}$ and $875^{\circ} \mathrm{F}$ which also continued to decrease at faster rate than temperatures below the tempering temperature in $300 \mathrm{M}$ steel components. The main reason for stress relaxation at temperatures higher than the tempering temperature $\left(575^{\circ} \mathrm{F}\right)$ for landing gear steel was due to loss in mechanical and physical properties over re-tempering process.

The depth distributions determined by X-ray diffraction technique were described based on depth where residual stress was maximized just beneath the surface for hard materials. Effect of temperature on depth distribution reveled a shift in distribution curve, which was proportionally increased with heat-treating temperature. The relaxation varied from surface to core of the material. A lower magnitude of residual stress was 
measured at the surface after heating at $525^{\circ} \mathrm{F}$ for hours when compared to heating at $375^{\circ} \mathrm{F}$. It was seen that at surface, residual stress relaxation is almost three times when heat treated at $525^{\circ} \mathrm{F}$ as compared with those obtained at heat treating temperature of $375^{\circ} \mathrm{F}$. This magnitude of difference became two times at depth beneath the surface where compressive residual stress was maximized.

Effect of temperature on fatigue life of landowning gear $300 \mathrm{M}$ steel samples was examined analytically using stress-life data extracted from literature [40]. The influence of shot peening and therefore induced residual stress on the fatigue life of $300 \mathrm{M}$ steel samples were examined and compared with non-shot peened samples and shotpeened at various temperatures. The endurance limit is also increased by shot peening process. It however decreased when residual stress is relaxed due heat treatment. It was noticed that decrease in every $1 \mathrm{ksi}$ of residual stress due to heat treatment decreased the endurance limit by $0.5 \mathrm{ksi}$.

At temperatures under $525^{\circ} \mathrm{F}$, the residual stress relief was found less than approximately $15 \%$ hence the effect of shot peening for components in-service is not greatly reduced. The reduction in stress-life was found insignificant as compared with non-shot peened components with fully relaxed stress at very high temperatures. 
Further research is recommended to address the effect of various heat treating temperatures and times on residual stress distribution of the thickness of $300 \mathrm{M}$ samples. It is however suggested that heat treating high strength landing gear $300 \mathrm{M}$ steel alloy at temperatures above $525^{\circ} \mathrm{F}$ should be seriously avoided. The evidences show that beyond this temperature the hardness and ductility of $300 \mathrm{M}$ alloys are significantly affected. Heat-treating landing gear $300 \mathrm{M}$ steel at medium range of temperature relaxes the effect of shot peening (or compressive residual stress) by a small margin. More research is recommended to address the residual stress relaxation on shot peened and electroplated components and its rate by incorporating relaxation due to cyclic stresses. 


\section{APPENDICIES}

\section{Appendix A - Experimental Observations}

Table A1: Residual Stress readings for shot peened only specimens

\begin{tabular}{|c|c|c|c|}
\hline \multicolumn{4}{|c|}{ Part \#0251 } \\
\hline Depth (Inches) & $\begin{array}{l}\text { Measured } \\
\text { Stress (ksi) }\end{array}$ & $\begin{array}{l}\text { Gradient Corrected } \\
\text { Stress (ksi) }\end{array}$ & $\begin{array}{c}\text { Grad. \& Depth } \\
\text { Corr. Stress (ksi) }\end{array}$ \\
\hline 0.0000 & $-146 \pm 2$ & $-143 \pm 2$ & $-143 \pm 2$ \\
\hline 0.0021 & $-168 \pm 1$ & $-165 \pm 2$ & $-162 \pm 2$ \\
\hline 0.0038 & $-174 \pm 2$ & $-178 \pm 2$ & $-173 \pm 2$ \\
\hline 0.0059 & $-85 \pm 2$ & $-94 \pm 2$ & $-87 \pm 2$ \\
\hline 0.0093 & $-3 \pm 3$ & $-8 \pm 3$ & $0 \pm 3$ \\
\hline \multicolumn{4}{|c|}{ Part \#0252 } \\
\hline Depth (Inches) & $\begin{array}{l}\text { Measured } \\
\text { Stress (ksi) }\end{array}$ & $\begin{array}{c}\text { Gradient Corrected } \\
\text { Stress (ksi) }\end{array}$ & $\begin{array}{c}\text { Grad. \& Depth } \\
\text { Corr. Stress (ksi) }\end{array}$ \\
\hline 0.0000 & $-134 \pm 2$ & $-130 \pm 2$ & $-130 \pm 2$ \\
\hline 0.0023 & $-169 \pm 1$ & $-166 \pm 1$ & $-163 \pm 1$ \\
\hline 0.0041 & $-166 \pm 2$ & $-171 \pm 2$ & $-166 \pm 2$ \\
\hline 0.0060 & $-91 \pm 2$ & $-100 \pm 2$ & $-93 \pm 2$ \\
\hline 0.0091 & $+2 \pm 3$ & $-5 \pm 2$ & $+4 \pm 2$ \\
\hline \multicolumn{4}{|c|}{ Part \#0253 } \\
\hline Depth (Inches) & $\begin{array}{l}\text { Measured } \\
\text { Stress (ksi) }\end{array}$ & $\begin{array}{c}\text { Gradient Corrected } \\
\text { Stress (ksi) }\end{array}$ & $\begin{array}{l}\text { Grad. \& Depth } \\
\text { Corr. Stress (ksi) }\end{array}$ \\
\hline 0.0000 & $-141 \pm 5$ & $-140 \pm 5$ & $-140 \pm 5$ \\
\hline 0.0021 & $-156 \pm 3$ & $-155 \pm 3$ & $-152 \pm 3$ \\
\hline 0.0041 & $-163 \pm 2$ & $-164 \pm 2$ & $-159 \pm 2$ \\
\hline 0.0059 & $-133 \pm 2$ & $-139 \pm 1$ & $-132 \pm 1$ \\
\hline 0.0089 & $-14 \pm 3$ & $-22 \pm 3$ & $-13 \pm 3$ \\
\hline
\end{tabular}


Table A2: Residual Stress readings for shot peened and stress relieved at $375^{\circ} \mathrm{F}$

\begin{tabular}{|c|c|c|c|}
\hline \multicolumn{4}{|c|}{ Part \#3751 } \\
\hline Depth (Inches) & $\begin{array}{l}\text { Measured } \\
\text { Stress (ksi) }\end{array}$ & $\begin{array}{c}\text { Gradient Corrected } \\
\text { Stress }(\mathrm{ksi})\end{array}$ & $\begin{array}{c}\text { Grad. \& Depth } \\
\text { Corr. Stress (ksi) }\end{array}$ \\
\hline 0.0000 & $-120 \pm 2$ & $-117 \pm 3$ & $-117 \pm 3$ \\
\hline 0.0020 & $-150 \pm 1$ & $-147 \pm 2$ & $-145 \pm 2$ \\
\hline 0.0039 & $-157 \pm 2$ & $-161 \pm 2$ & $-156 \pm 2$ \\
\hline 0.0061 & $-78 \pm 2$ & $-86 \pm 2$ & $-79 \pm 2$ \\
\hline 0.0093 & $+6 \pm 3$ & $0 \pm 3$ & $+8 \pm 3$ \\
\hline \multicolumn{4}{|c|}{ Part \#3752 } \\
\hline Depth (Inches) & $\begin{array}{l}\text { Measured } \\
\text { Stress (ksi) }\end{array}$ & $\begin{array}{c}\text { Gradient Corrected } \\
\text { Stress (ksi) }\end{array}$ & $\begin{array}{c}\text { Grad. \& Depth } \\
\text { Corr. Stress (ksi) }\end{array}$ \\
\hline 0.0000 & $-131 \pm 2$ & $-129 \pm 3$ & $-129 \pm 3$ \\
\hline 0.0021 & $-157 \pm 1$ & $-154 \pm 1$ & $-152 \pm 1$ \\
\hline 0.0039 & $-161 \pm 2$ & $-165 \pm 2$ & $-160 \pm 2$ \\
\hline 0.0059 & $-89 \pm 2$ & $-97 \pm 2$ & $-91 \pm 2$ \\
\hline 0.0093 & $+5 \pm 3$ & $-1 \pm 3$ & $+7 \pm 3$ \\
\hline \multicolumn{4}{|c|}{ Part \#3753 } \\
\hline Depth (Inches) & $\begin{array}{l}\text { Measured } \\
\text { Stress (ksi) }\end{array}$ & $\begin{array}{c}\text { Gradient Corrected } \\
\text { Stress (ksi) }\end{array}$ & $\begin{array}{l}\text { Grad. \& Depth } \\
\text { Corr. Stress (ksi) }\end{array}$ \\
\hline 0.0000 & $-123 \pm 2$ & $-119 \pm 2$ & $-119 \pm 2$ \\
\hline 0.0019 & $-158 \pm 2$ & $-155 \pm 2$ & $-153 \pm 2$ \\
\hline 0.0040 & $-157 \pm 2$ & $-162 \pm 2$ & $-157 \pm 2$ \\
\hline 0.0060 & $-90 \pm 3$ & $-98 \pm 3$ & $-91 \pm 3$ \\
\hline 0.0089 & $+4 \pm 4$ & $-3 \pm 4$ & $+5 \pm 4$ \\
\hline
\end{tabular}


Table A3: Residual Stress readings for shot peened and stress relieved at $525^{\circ} \mathrm{F}$

\begin{tabular}{|c|c|c|c|}
\hline \multicolumn{4}{|c|}{ Specimen \#5251 } \\
\hline Depth (Inches) & $\begin{array}{l}\text { Measured } \\
\text { Stress (ksi) }\end{array}$ & $\begin{array}{c}\text { Gradient Corrected } \\
\text { Stress (ksi) }\end{array}$ & $\begin{array}{c}\text { Grad. \& Depth } \\
\text { Corr. Stress (ksi) }\end{array}$ \\
\hline 0.0000 & $-105 \pm 2$ & $-101 \pm 2$ & $-101 \pm 2$ \\
\hline 0.0021 & $-150 \pm 1$ & $-147 \pm 1$ & $-145 \pm 1$ \\
\hline 0.0039 & $-145 \pm 2$ & $-150 \pm 2$ & $-145 \pm 2$ \\
\hline 0.0059 & $-74 \pm 2$ & $-81 \pm 2$ & $-75 \pm 2$ \\
\hline 0.0092 & $+10 \pm 3$ & $+4 \pm 3$ & $+11 \pm 3$ \\
\hline \multicolumn{4}{|c|}{ Specimen \#5252 } \\
\hline Depth (Inches) & $\begin{array}{l}\text { Measured } \\
\text { Stress (ksi) }\end{array}$ & $\begin{array}{c}\text { Gradient Corrected } \\
\text { Stress (ksi) }\end{array}$ & $\begin{array}{c}\text { Grad. \& Depth } \\
\text { Corr. Stress (ksi) }\end{array}$ \\
\hline 0.0000 & $-97 \pm 2$ & $-94 \pm 2$ & $-94 \pm 2$ \\
\hline 0.0022 & $-134 \pm 1$ & $-131 \pm 1$ & $-129 \pm 1$ \\
\hline 0.0039 & $-142 \pm 2$ & $-146 \pm 2$ & $-142 \pm 2$ \\
\hline 0.0059 & $-74 \pm 2$ & $-81 \pm 2$ & $-75 \pm 2$ \\
\hline 0.0090 & $-3 \pm 3$ & $-7 \pm 2$ & $-1 \pm 2$ \\
\hline \multicolumn{4}{|c|}{ Specimen \#5253 } \\
\hline Depth (Inches) & $\begin{array}{l}\text { Measured } \\
\text { Stress (ksi) }\end{array}$ & $\begin{array}{c}\text { Gradient Corrected } \\
\text { Stress (ksi) }\end{array}$ & $\begin{array}{l}\text { Grad. \& Depth } \\
\text { Corr. Stress (ksi) }\end{array}$ \\
\hline 0.0000 & $-90 \pm 2$ & $-85 \pm 3$ & $-85 \pm 3$ \\
\hline 0.0021 & $-148 \pm 1$ & $-144 \pm 1$ & $-142 \pm 1$ \\
\hline 0.0040 & $-157 \pm 2$ & $-160 \pm 2$ & $-156 \pm 2$ \\
\hline 0.0060 & $-97 \pm 2$ & $-105 \pm 2$ & $-99 \pm 2$ \\
\hline 0.0092 & $+14 \pm 3$ & $+6 \pm 3$ & $+14 \pm 3$ \\
\hline
\end{tabular}




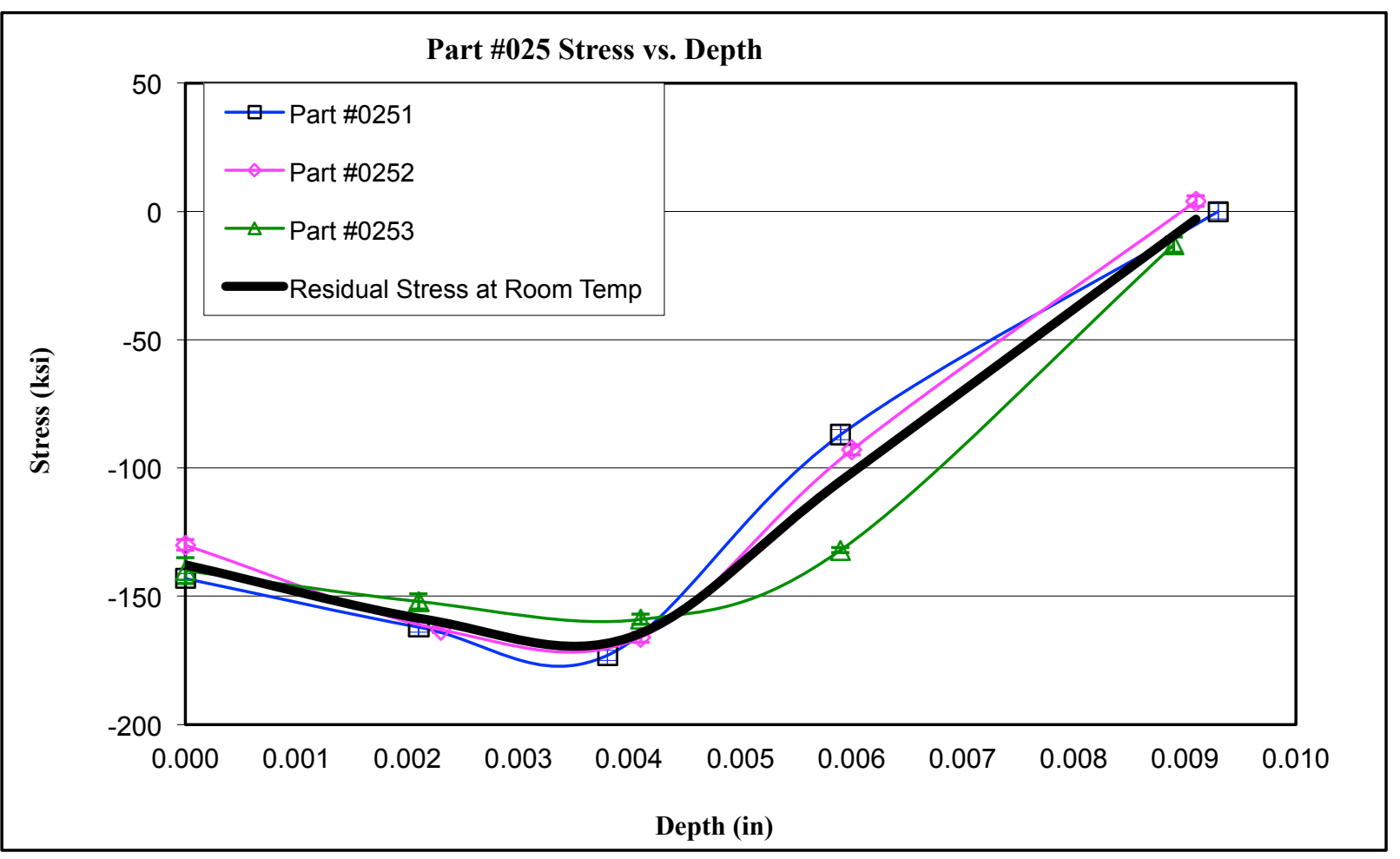

Figure A1: Residual stress distribution at room temperature for all specimens tested

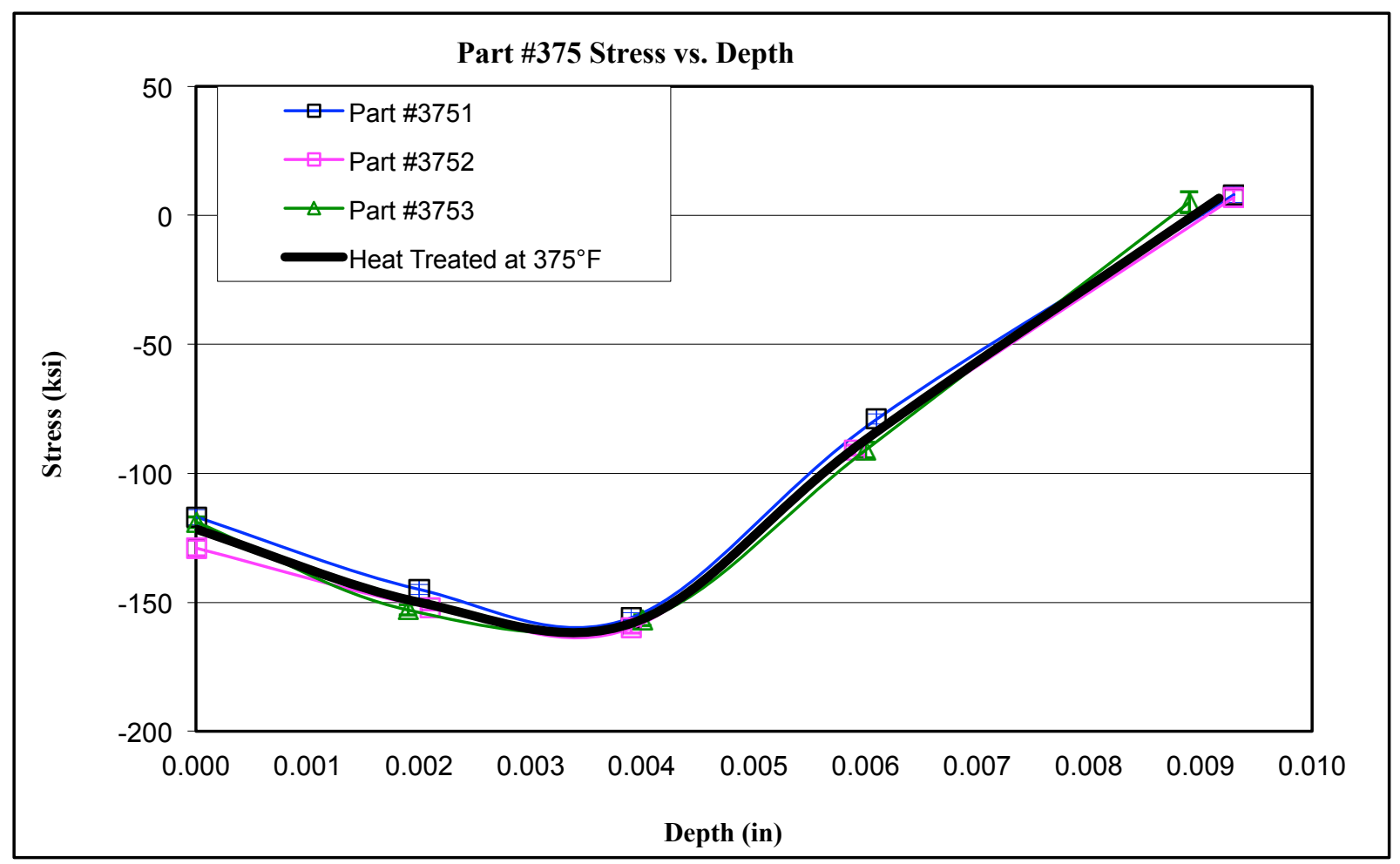

Figure A2: Residual stress distribution after heat treating at $375^{\circ} \mathrm{F}$ for 4 hours for all specimens tested 


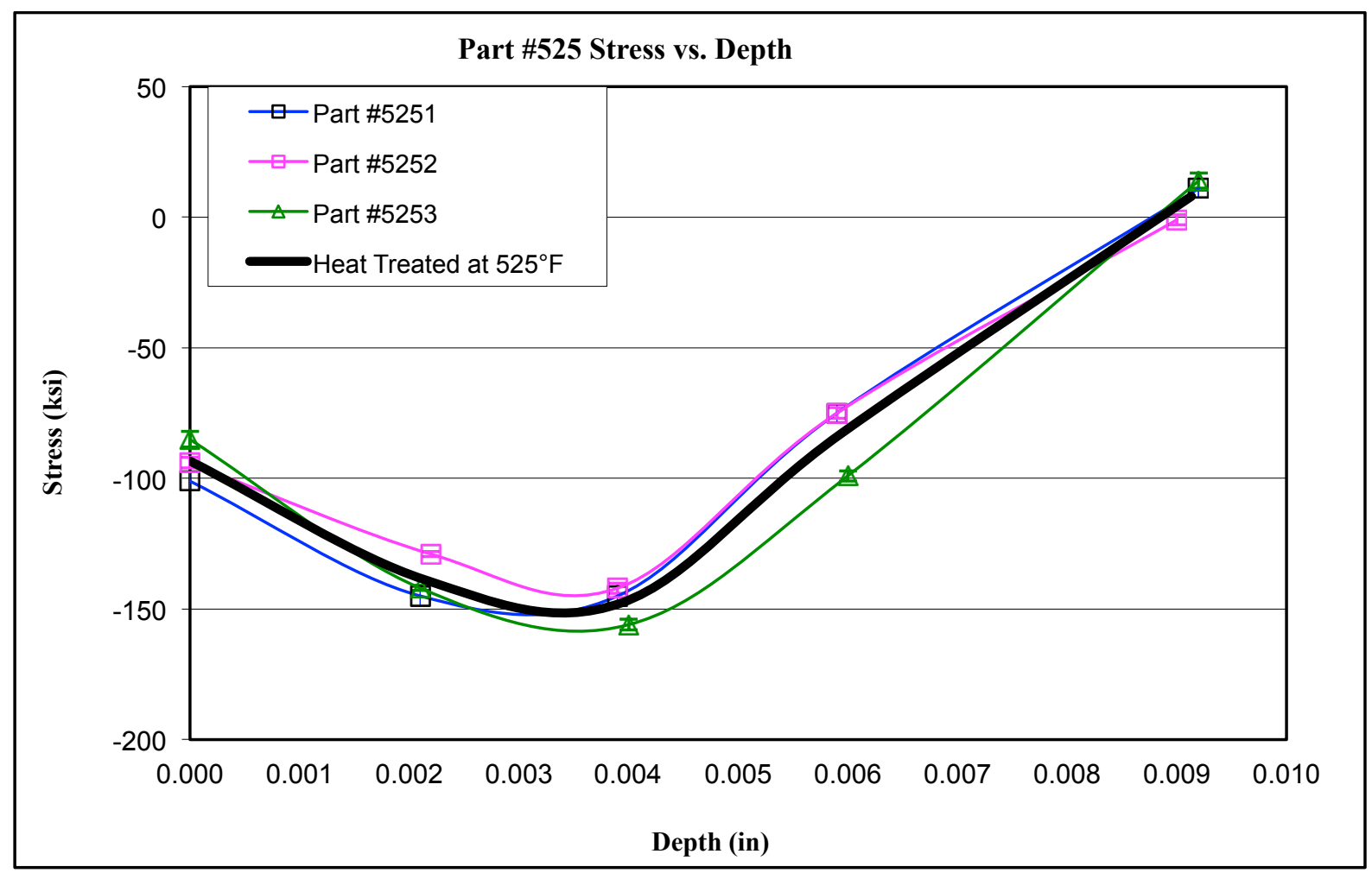

Figure A39: Residual stress distribution after heat treating at $525^{\circ} \mathrm{F}$ for 4 hours for all specimens tested 
Table A4: Deflection measurements values after each stress relieve interval

\begin{tabular}{|c|c|c|c|c|c|c|c|}
\hline \multirow{2}{*}{$\begin{array}{c}\text { Stress } \\
\text { Relieve } \\
\text { Temperature }\end{array}$} & \multirow{2}{*}{$\begin{array}{c}\text { Specimen } \\
\text { Number }\end{array}$} & \multicolumn{6}{|c|}{ Deflection Measurement } \\
\hline & & $\begin{array}{c}\text { After } 1 \\
\text { hour }\end{array}$ & $\begin{array}{l}\text { After } 3 \\
\text { hours }\end{array}$ & $\begin{array}{c}\text { After } 7 \\
\text { hours }\end{array}$ & $\begin{array}{c}\text { After } 15 \\
\text { hours }\end{array}$ & $\begin{array}{c}\text { After } 30 \\
\text { hours }\end{array}$ & $\begin{array}{c}\text { After } 54 \\
\text { hours }\end{array}$ \\
\hline \multirow{3}{*}{$375^{\circ} \mathrm{F}$} & 1 & 0.02200 & 0.02185 & 0.02175 & 0.02170 & 0.02165 & 0.02170 \\
\hline & 2 & 0.02700 & 0.02685 & 0.02690 & 0.02685 & 0.02680 & 0.02670 \\
\hline & 3 & 0.02720 & 0.02700 & 0.02690 & 0.02680 & 0.02675 & 0.02665 \\
\hline \multirow{3}{*}{$450^{\circ} \mathrm{F}$} & 4 & 0.01620 & 0.01610 & 0.01600 & 0.01580 & 0.01555 & 0.01540 \\
\hline & 5 & 0.01710 & 0.01700 & 0.01690 & 0.01670 & 0.01660 & 0.01655 \\
\hline & 6 & 0.01430 & 0.01420 & 0.01410 & 0.01400 & 0.01385 & 0.01375 \\
\hline \multirow{3}{*}{$525^{\circ} \mathrm{F}$} & 7 & 0.02260 & 0.02230 & 0.02180 & 0.02120 & 0.02100 & 0.02060 \\
\hline & 8 & 0.02170 & 0.02140 & 0.02090 & 0.02060 & 0.02050 & 0.02015 \\
\hline & 9 & 0.02360 & 0.02320 & 0.02270 & 0.02240 & 0.02220 & 0.02180 \\
\hline \multirow{3}{*}{$650^{\circ} \mathrm{F}$} & 10 & 0.02220 & 0.02120 & 0.01920 & 0.01820 & 0.01820 & 0.01670 \\
\hline & 11 & 0.02470 & 0.02410 & 0.02220 & 0.02190 & 0.02090 & 0.02040 \\
\hline & 12 & 0.02440 & 0.02290 & 0.02260 & 0.02160 & 0.02030 & 0.01890 \\
\hline \multirow{3}{*}{$875^{\circ} \mathrm{F}$} & 13 & 0.02190 & 0.01800 & 0.01570 & 0.01390 & 0.01240 & 0.01110 \\
\hline & 14 & 0.01800 & 0.01420 & 0.01350 & 0.01110 & 0.00980 & 0.00870 \\
\hline & 15 & 0.02130 & 0.01940 & 0.01580 & 0.01550 & 0.01470 & 0.01450 \\
\hline
\end{tabular}




\section{Appendix B: Analysis Data}

Following tables show data analysis carried in Microsoft Excel to create plots in Chapter 5.

Table B1: Percent Residual Stress remaining in each strip (actual)

\begin{tabular}{|c|c|c|c|c|c|c|}
\hline \multirow{2}{*}{ STRIP \# } & \multicolumn{6}{|c|}{ Residual Stress Remaining in percent } \\
\cline { 2 - 7 } & $1 \mathrm{hr}$ & $3 \mathrm{hrs}$. & $7 \mathrm{hrs}$. & $15 \mathrm{hrs}$. & $30 \mathrm{hrs}$. & 54 hrs. \\
\hline 1 & 93.62 & 92.98 & 92.55 & 92.34 & 92.13 & 92.34 \\
\hline 2 & 95.07 & 94.54 & 94.72 & 94.54 & 94.37 & 94.01 \\
\hline 3 & 95.44 & 94.74 & 94.39 & 94.04 & 93.86 & 93.51 \\
\hline 4 & 91.53 & 90.96 & 90.40 & 89.27 & 87.85 & 87.01 \\
\hline 5 & 91.94 & 91.40 & 90.86 & 89.78 & 89.25 & 88.98 \\
\hline 6 & 91.08 & 90.45 & 89.81 & 89.17 & 88.22 & 87.58 \\
\hline 7 & 89.68 & 88.49 & 86.51 & 84.13 & 83.33 & 81.75 \\
\hline 8 & 90.04 & 88.80 & 86.72 & 85.48 & 85.06 & 83.61 \\
\hline 9 & 90.08 & 88.55 & 86.64 & 85.50 & 84.73 & 83.21 \\
\hline 10 & 82.22 & 78.52 & 71.11 & 67.41 & 67.41 & 61.85 \\
\hline 11 & 82.61 & 80.60 & 74.25 & 73.24 & 69.90 & 68.23 \\
\hline 12 & 82.71 & 77.63 & 76.61 & 73.22 & 68.81 & 64.07 \\
\hline 13 & 71.57 & 58.82 & 51.31 & 45.42 & 40.52 & 36.27 \\
\hline 14 & 68.97 & 54.41 & 51.72 & 42.53 & 37.55 & 33.33 \\
\hline 15 & 65.54 & 59.69 & 48.62 & 47.69 & 45.23 & 44.62 \\
\hline
\end{tabular}

Table B2: Calculated Percent Residual Stress remaining after heat treatment

\begin{tabular}{|c|c|c|c|c|c|c|c|}
\hline \multirow{2}{*}{$\begin{array}{c}\text { Temperature } \\
\text { in }{ }^{\circ} \mathrm{F}\end{array}$} & \multicolumn{7}{|c|}{ Time in Hours/ Percent stress remaining } \\
\cline { 2 - 8 } & 0 & 1.00 & 3.00 & 7.00 & 15.00 & 30.00 & 54.00 \\
\hline 375 & 100 & 96.88 & 96.19 & 95.56 & 94.90 & 94.23 & 93.58 \\
\hline 450 & 100 & 94.22 & 92.97 & 91.82 & 90.64 & 89.42 & 88.28 \\
\hline 525 & 100 & 96.88 & 96.19 & 95.56 & 94.90 & 94.23 & 93.58 \\
\hline 650 & 100 & 80.97 & 77.20 & 73.88 & 70.56 & 67.27 & 64.27 \\
\hline 875 & 100 & 57.29 & 50.51 & 44.97 & 39.83 & 35.11 & 31.12 \\
\hline
\end{tabular}


Table B3: Data for plot in figure 5-6

\begin{tabular}{|c|c|c|c|c|c|c|}
\hline \multirow{2}{*}{ Temperature in ${ }^{\circ} \mathrm{F}$} & \multicolumn{6}{|c|}{ Time in Hours/ Percent stress remaining } \\
\hline & 1.00 & 3.00 & 7.00 & 15.00 & 30.00 & 54.00 \\
\hline 375 & 96.88 & 96.19 & 95.56 & 94.90 & 94.23 & 93.58 \\
\hline 400 & 96.12 & 95.27 & 94.49 & 93.68 & 92.84 & 92.05 \\
\hline 425 & 95.24 & 94.19 & 93.24 & 92.26 & 91.24 & 90.28 \\
\hline 450 & 94.22 & 92.97 & 91.82 & 90.64 & 89.42 & 88.28 \\
\hline 475 & 93.07 & 91.57 & 90.21 & 88.81 & 87.38 & 86.03 \\
\hline 500 & 91.78 & 90.02 & 88.42 & 86.78 & 85.11 & 83.55 \\
\hline 525 & 90.34 & 88.29 & 86.44 & 84.55 & 82.62 & 80.83 \\
\hline 550 & 88.75 & 86.39 & 84.27 & 82.11 & 79.92 & 77.88 \\
\hline 575 & 87.02 & 84.33 & 81.92 & 79.48 & 77.01 & 74.73 \\
\hline 600 & 85.14 & 82.11 & 79.40 & 76.67 & 73.92 & 71.40 \\
\hline 625 & 83.13 & 79.73 & 76.71 & 73.69 & 70.67 & 67.90 \\
\hline 650 & 80.97 & 77.20 & 73.88 & 70.56 & 67.27 & 64.27 \\
\hline 675 & 78.70 & 74.55 & 70.92 & 67.31 & 63.76 & 60.54 \\
\hline 700 & 76.30 & 71.78 & 67.84 & 63.96 & 60.16 & 56.74 \\
\hline 725 & 73.80 & 68.90 & 64.67 & 60.53 & 56.50 & 52.91 \\
\hline 750 & 71.20 & 65.94 & 61.43 & 57.05 & 52.82 & 49.08 \\
\hline 775 & 68.52 & 62.91 & 58.14 & 53.55 & 49.15 & 45.29 \\
\hline 800 & 65.77 & 59.83 & 54.83 & 50.05 & 45.52 & 41.57 \\
\hline 825 & 62.98 & 56.73 & 51.52 & 46.58 & 41.95 & 37.96 \\
\hline 850 & 60.14 & 53.62 & 48.22 & 43.17 & 38.47 & 34.46 \\
\hline 875 & 57.29 & 50.51 & 44.97 & 39.83 & 35.11 & 31.12 \\
\hline 900 & 54.42 & 47.43 & 41.78 & 36.60 & 31.89 & 27.96 \\
\hline 925 & 51.57 & 44.40 & 38.68 & 33.48 & 28.82 & 24.97 \\
\hline 950 & 48.74 & 41.43 & 35.67 & 30.50 & 25.92 & 22.18 \\
\hline 975 & 45.94 & 38.54 & 32.77 & 27.66 & 23.19 & 19.60 \\
\hline 1000 & 43.19 & 35.73 & 29.99 & 24.98 & 20.66 & 17.23 \\
\hline 1025 & 40.51 & 33.03 & 27.35 & 22.47 & 18.31 & 15.06 \\
\hline 1050 & 37.89 & 30.43 & 24.86 & 20.12 & 16.15 & 13.09 \\
\hline 1075 & 35.36 & 27.95 & 22.51 & 17.95 & 14.18 & 11.32 \\
\hline 1100 & 32.91 & 25.60 & 20.30 & 15.94 & 12.39 & 9.74 \\
\hline 1125 & 30.55 & 23.37 & 18.25 & 14.10 & 10.78 & 8.34 \\
\hline 1150 & 28.30 & 21.28 & 16.35 & 12.42 & 9.33 & 7.10 \\
\hline 1175 & 26.15 & 19.31 & 14.60 & 10.90 & 8.05 & 6.02 \\
\hline 1200 & 24.11 & 17.48 & 12.99 & 9.53 & 6.91 & 5.08 \\
\hline 1225 & 22.17 & 15.78 & 11.52 & 8.30 & 5.90 & 4.26 \\
\hline 1250 & 20.35 & 14.20 & 10.19 & 7.20 & 5.02 & 3.56 \\
\hline
\end{tabular}




\section{Appendix C:}

\section{MATLAB Code to generate plots for calculation of activation energy (Q)}

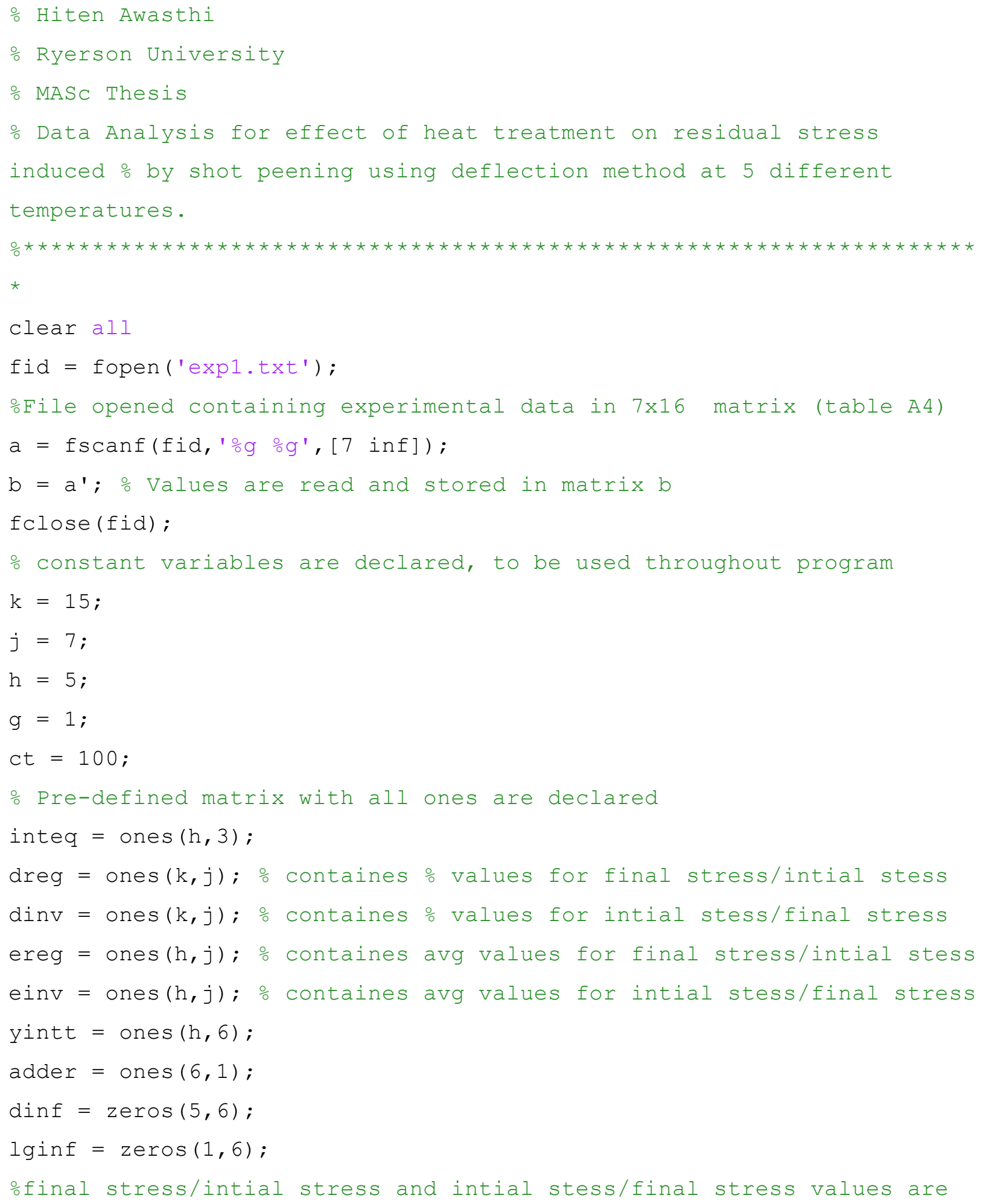




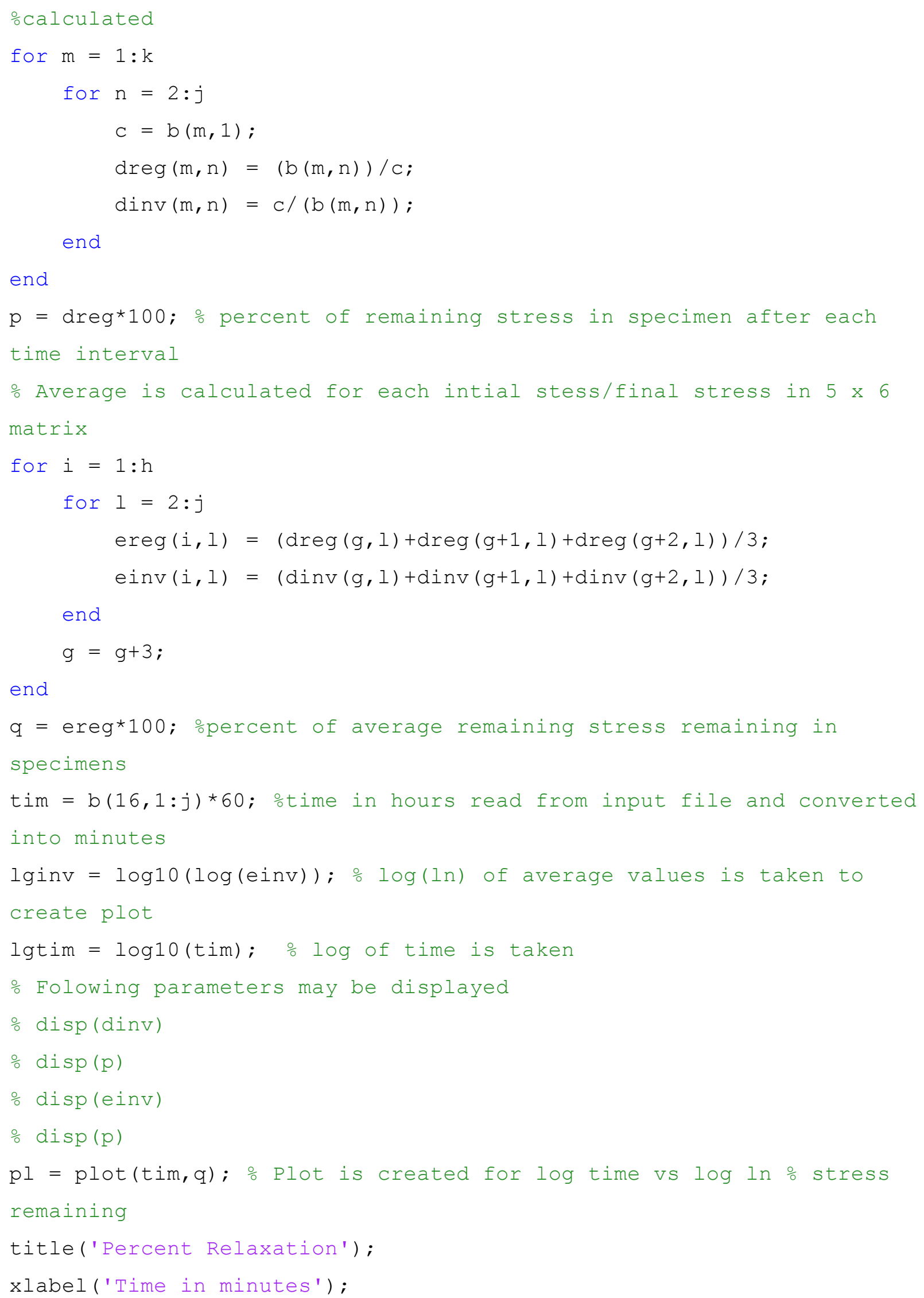




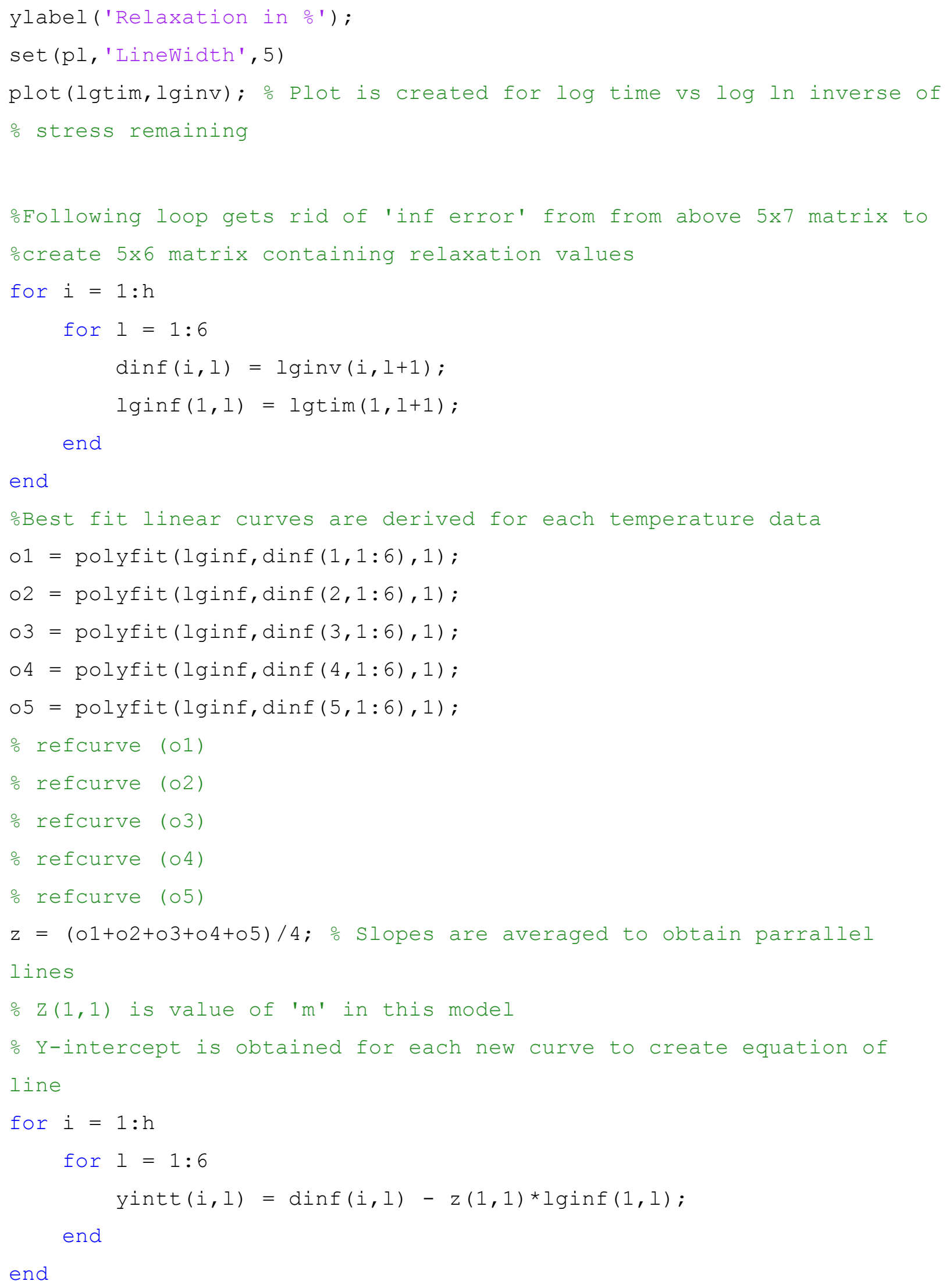




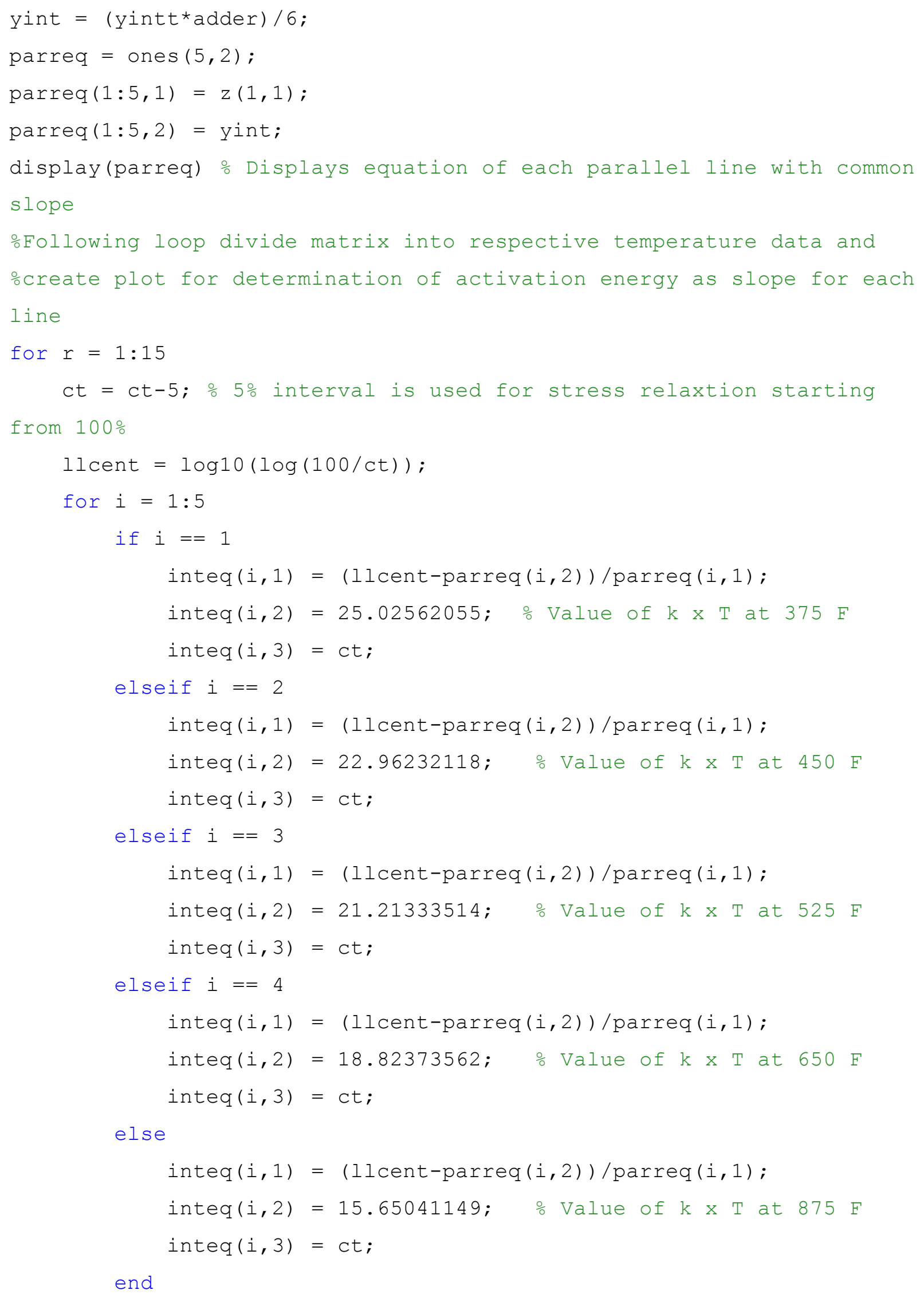


end

grid on

- Generation of Plot

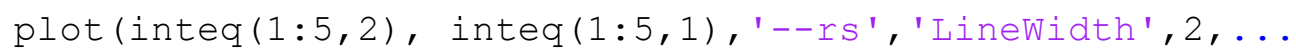

'MarkerEdgeColor', 'k', ...

'MarkerFaceColor', 'g', ...

'MarkerSize', 10)

hold on

end 


\section{Appendix D}

MATLAB Code for generation of S-N plots

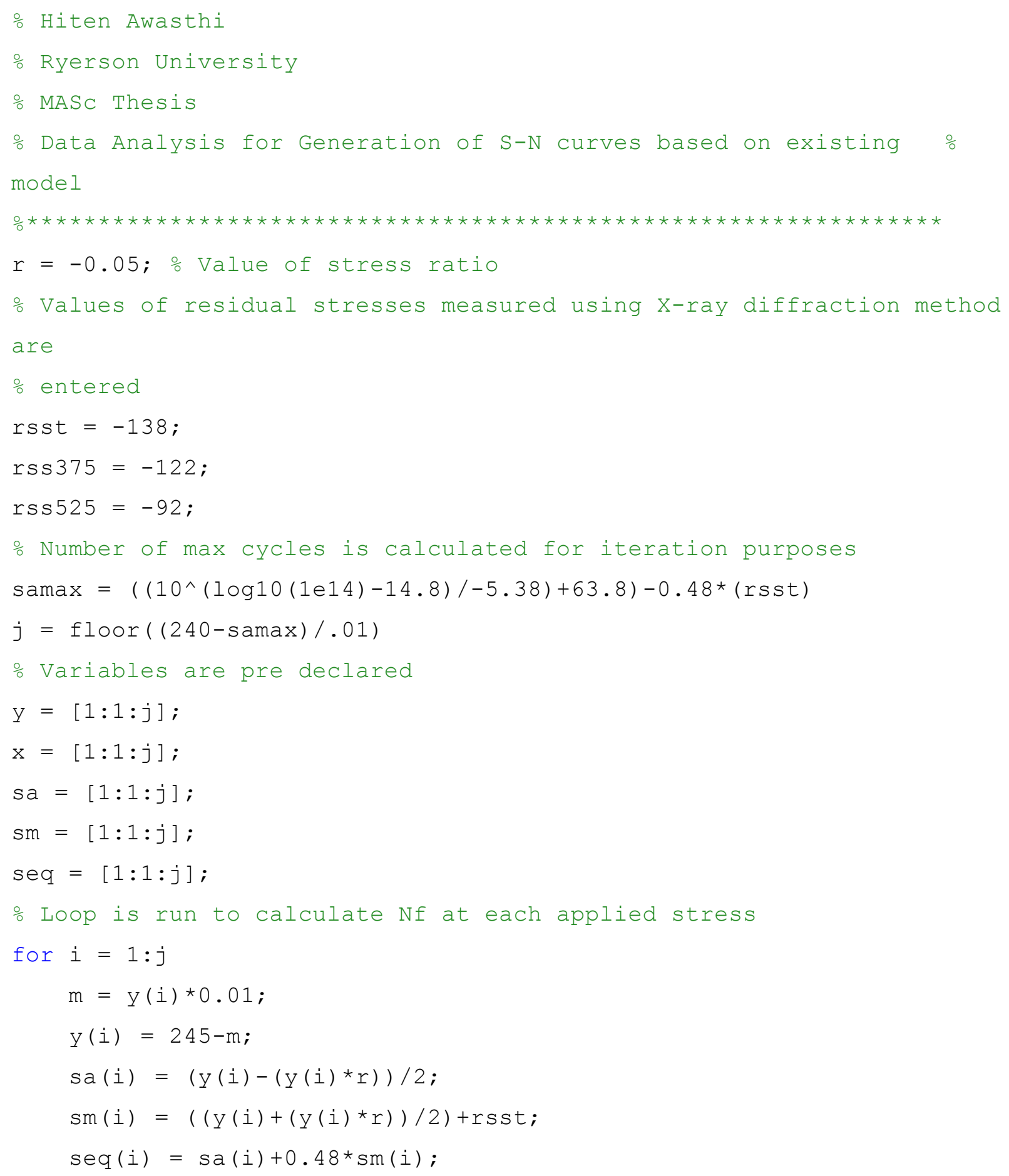




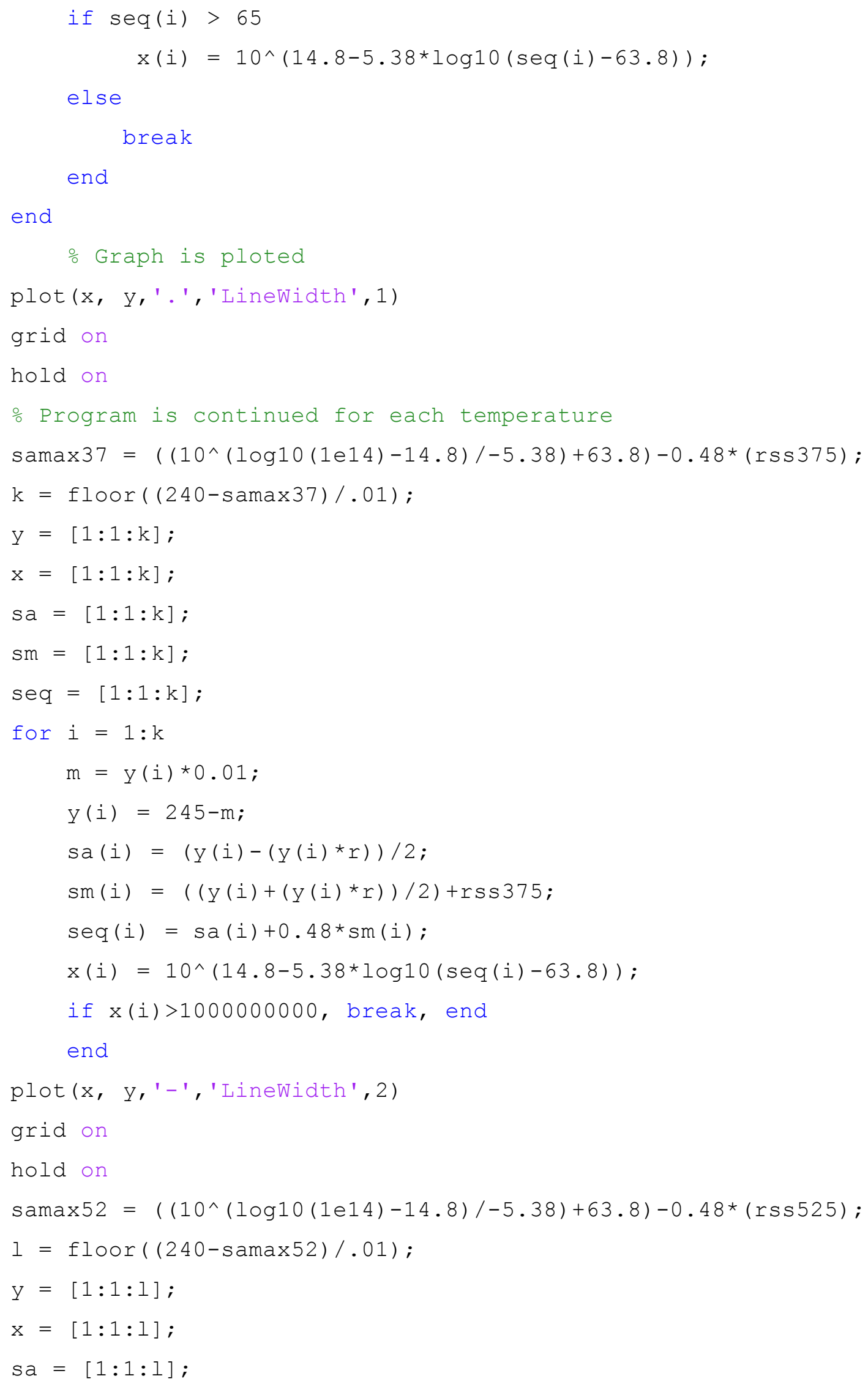




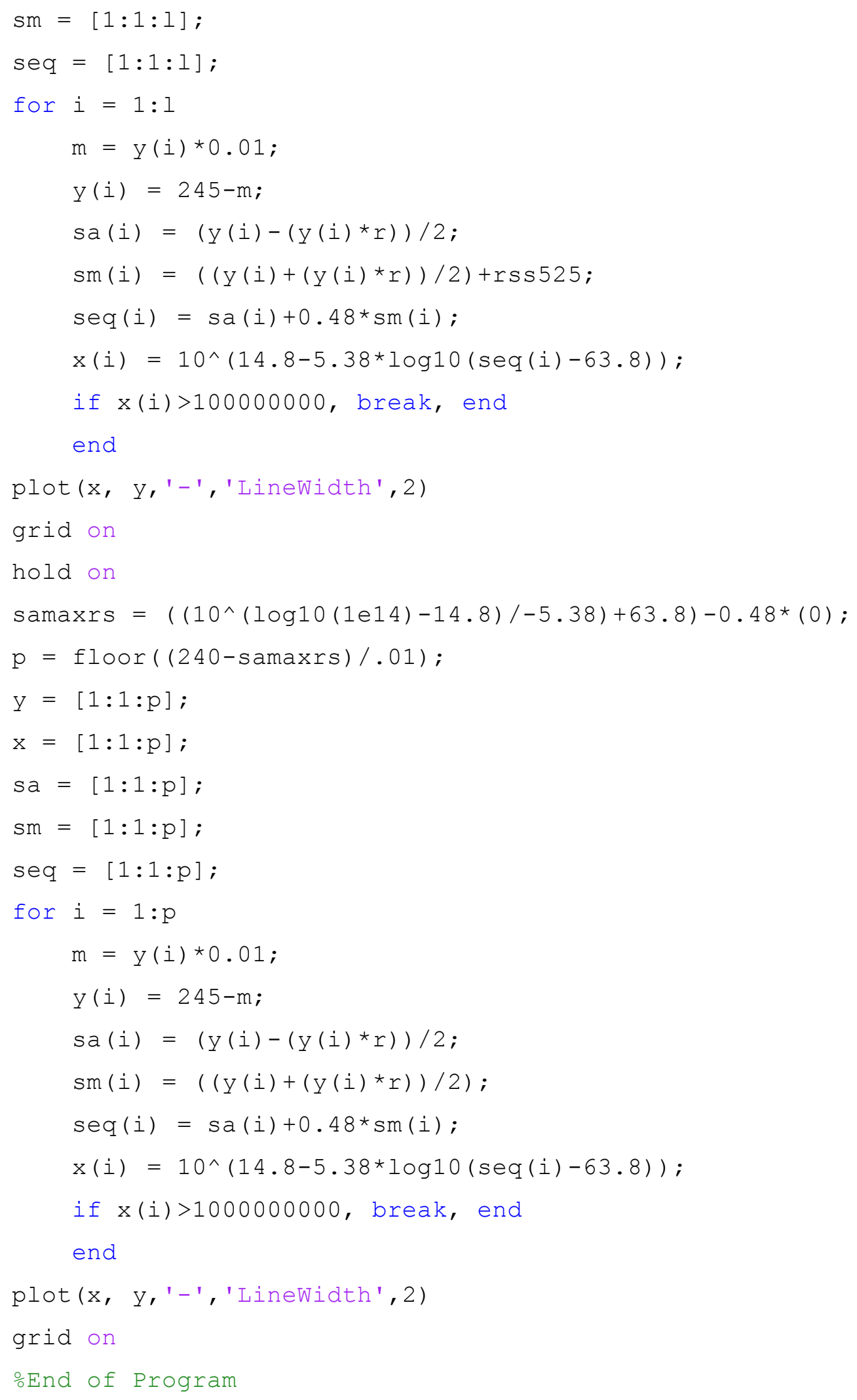




\section{REFERENCES}

1. KARUPPANAN, S. A Theoretical and Experimental Investigation into the Development of Coverage in Shot Peening. In: WAGNER, L. Shot Peening. Clausthal-Zellerfeld: WILEY-VCH Verlag GmbH \& Co. KGaA, 2003.

2. FENG, B. X. et al. Residual stress field and thermal relaxation behavior of shotpeened TC4-DT titanium alloy. Materials Science and Engineering A, Xian, January 2009.

3. HUANG, M.; POTDAR, Y. K.; AKKARAM, S. Analytical Model to Predict Thermomechanical Relaxation of Shot Peening Induced Residual Stress. Journal of Engineering for Gas Turbines and Power, Niskayuna, v. 132, p. 092505-1-5, September 2010.

4. PARMESWARAN, P.; MATE, S. V.; NADGIR, M. S. Reintroduction of Residual Stress by Shot Peeing for Rejuvenation of Aircraft Landing Gears. International Conference on Shot Peening and Blast Cleaning. p. 250-261. 2001.

5. LOHE, D.; VOHRINGER, O. Stability of Residual Stresses. In: TOTTEN, G.; HOWES, M.; INOUE, T. Handbook of Residual Stress and Deformation of Steel. Karlsruhe: ASM, 2003.

6. SHEPARD, M. J. Relaxation of Shot Peening Induced Residual Stresses in Ti-6Al$4 \mathrm{~V}$ : Impact on Damage Tolerant Design. Air Force Research Laboratory. WrightPatterson AFB. 1997.

7. VERGANI, L.; GUAGLIANO, M. Fatigue Crack Growth behaviour of Nitrided and Shot Peened Specimens. Dipartimento di Meccanica. MILANO. 2005

8. SCHULZE, V. Characteristics of Surface Layers Produced by Shot Peening. In: WAGNER, L. Shot Peening. Clausthal-Zellerfeld: WILEY-VCH Verlag GmbH \& Co. KGaA, 2003. 
9. LOCKE, J. E.; KUMAR, B.; SALAH, L. Effect of Shot Peening on the fatigue endurance and fatigue crack growth rate of 7050 \& 7075 aluminum alloys. National Institute of Aviation Research \& Department of Aerospace Engineering. Wichita. 2005.

10. WOOD, W. G. Metals Handbook, Surface Cleaning, Finishing and Coating. 9th. ed. : ASM Commitee on Shot Peening, v 5, 1994.

11. DALAEI, K.; KARLSSON, B.; SVENSSON, L.-E. Stability of shot peening induced residual stresses and their influence on fatigue lifetime. Gothenburg. 2010.

12. BANNANTINE, J. A. Fundamentals of Metal Fatigue Analysis. Upper Saddle River: Prentice-Hall Inc, 1990.

13. ZAGAR, S.; ZEROVNIK, P.; GRUM, J. Surface Layer Analysis after shot peening by Barkhausen Noise Signal. The 10th International Conference of the Slovenian Society for Non-Destructive Testing. Ljubljana: Application of Contemporary NonDestructive Testing in Engineering. 2009.

14. RENAUD, F. P. Optimization of the Shot Peening Parameters. In: WAGNER, L. Shot Peening. Clausthal-Zellerfeld: WILEY-VCH Verlag GmbH \& Co. KGaA, 2003.

15. BATCHELOR, A. W.; LAM, L. N.; CHANDRASEKARAN, M. Materials Degradation and its Control by Surface Engineering. London: Imperial College Press, 2002.

16. KYRIACOU. The Sixth International Conference on Shot Peening. ICSP6. 1996.

17. MIL-S-13165C. Shot peening of metal parts. 1989.

18. HOLZAPFEL, $\mathrm{H}$. et al. Residual stress relaxation in an AISI 4140 steel due to quasistatic and cyclic loading at higher temperatures. Materials Science and Engineering A, 28 January 1998.

19. TAKAHASHI, K. et al. Improvement of fatigue limit by shot peening for spring steel 
specimens containing an artificial surface defect. Yokohama. Yokohoma National University.

20. KONIG, G. W. Life Enhancement of Aero Engine Components by Shot Peening: Opportunities and Risks. In: WAGNER, L. Shot Peening. Clausthal-Zellerfeld: WILEY-VCH Verlag GmbH \& Co. KGaA, 2003.

21. LANDGRAF, R. W.; CHERNENKOFF, R. A. Analytical and Experimental Methods for Residual Stress Effects in Fatigue. ASTM STP 100, Philadelphi, 1988.

22. WILCOX, G.; POLAK, T. Handbook of Surface Treatments and Coatings. New York: Professional Engineering Publishing, 2003.

23. PREVEY, P. S. The Effect of Cold Work on the Thermal Stability of Residual compression in surface Enhanced IN718. 20th ASM Materials Solutions Conference. St. Louis: Lambda Technologies. 2000.

24. ALMEN, J. O.; BLACK, P. H. Residual Stresses and fatigue in Metals. McGraw-Hill Book Company, 1963.

25. JAMES, M. et al. Residual Stresses and Fatigue Performance. Engineering Failure Analysis, 2006.

26. LU, J. Handbook of Measurement of Residual Stresses. Lilburn: Society for Experimental Mechanics, 1996.

27. AMS-S-13165. Aerospace Material Specification. 1997.

28. PERVEY, P. S.; CAMMETT, J. T. The Effect of Shot Peening Coverage on Residual Stress, Cold Work and Fatigue in a Ni-Cr-Mo Low Alloy Steel. Proceedings from International Conference on Shot Peening. Garmisch-Partenkirchen: Lambda Technologies. 2002.

29. HOFFMANN, J. et al. Thermal relaxation of shot peening residual stresses in the 
differently heat treated plain carbon steel Ck 45. Proceedings of the 3rd International Conference on Shot Peening. Garmisch-Partenkirchen:1987.

30. ROTH, M. Thermal Stability of Residul Stresses in Shot Peened Surfaces. In: MACHERAUCH, E.; HAUK, V. Residual Stresses in Science and Technology. Alle Rechte vorbehalten: DGM Informationsgesellschaft mbH, v. 1, 1987. p. 435-440.

31. SCHULZE, V.; VOHRINGER, O.; MACHERAUCH, E. Thermal relaxation of shot peening induced residual stresses in a quenched and tempered steel $42 \mathrm{Cr}$ Mo 4. Proceedings of the 5th International Conference on Shot Peening. Oxford. 1993.

32. TUFFT, M. Modeling of fatigue behavior due to shot peening conditions. Proceedings of the 8th International Conference on Shot Peening. GarmischPartenkirchen. 2002.

33. CHILDS, W. The effect of elevated temperature on shot peened 403 stainless steel. Analytical and Experimental Methods for Residual Stress Effects in Fatigue, 1988.

34. IMRIE, W. M. Undercarriage Material Requirements. Philosophical Transactions of the Royal Society of London. Series A, Mathematical and Philosophical Transactions of the Royal Society of London. Series A, Mathematical and Physical Sciences, Gloucester, v. 282, n. 1307, p. 91-104, July 1976.

35. VOORWALD, H. J. C. et al. Improvement in the fatigue strength of chromium electroplated AISI 4340 steel by shot peening. Fatigue and Fracture of Engineeing Materials, Guaratingueta, p. 97-104, December 2008.

36. DICKERSON, C.; GARBER, R. M. Maintainance of High Stregth Components. 2003.

37. GORDON, D. J. Hydrogen Re-embrittlement susceptibility of Ultra High Strength Steels. Cranfield University. Cranfield, 2005.

38. SHIH, C. H.; AVERBACH, C. H.; COHEN, M. Some Effects of Silicon on the 
Mechanical Properties of High Strength Steels. Trans ASM, 1956. p86.

39. Alstetter, C. J.; COHEN, M.; AVERBACH, B. F. Effect of Silicon on the Tempering of AISI 43XX Steels. Trans ASM, 1962. p287.

40. DEFENCE, D. O. Military Handbook - MIL-HDBK-5H: Metallic Materials and Elements for Aerospace Vehicle Structures. U.S. Department of Defense, 2008. Chapter 2

41. VOHRINGER, O. Advances in Surface Treatment. International Guidebook on Residual Stresses, Oxford, 1987.

42. LU, J. Prestress Engineering of Structrual Material. In: TOTTEN, G.; HOWES, M.; INOUE, T. Handbook of Residual Stress and Deformation of Steels. Troyes: ASM, 2003. p. 11-26.

43. DESVIGNES, M.; GENTIL, B.; VELIZY. Fatigue Progressing of Shot Peened Steel. In: MACHERAUCH, E.; HAUK, V. Residual Stresses in Science and Technology. Paris: Informationsgesellschaft, v. I, 1987. p. 441-448.

44. BANNANTINE, J. A.; COMER, J. J.; HANDROCK, J. L. Fundamentals of Metal Fatigue Analysis. Upper Saddle River: Prentice Hall, 1990. 15 p.

45. WALTON, H. W. Deflection Methods to Estimate Residual Stress. In: TOTTEN, G.; HOWES, M.; INOUE, T. Handbook of Residual Stress and Deformation in Steel. Materials Park: ASM International, 2003. p. 89-98.

46. J442. Test Strip, Holder, and Gage for Shot Peening. 2008.

47. AMS2759/11. Aerospace Material Specification. Materials Park. 2005.

48. RUUD, C. Measurement of Residual Stresses. In: TOTTEN, G.; HOWES, M.; INOUE, T. Handbook of Residual Stress and Deformation of Steel. Materials Park: ASM Inernational, 2003. 
49. PROTO MANUFACTURING INC. Proto Manufacturing - Residual Stress Information. 2011.

50. SAE J784A. Residual Stress Measurement by X-ray diffraction. New York. 1971.

51. CULLITY, B. D.; STOCK, S. R. Elements of X-ray Diffraction. Upper Saddle River: Prentice Hall, 2001.

52. INTERNATIONAL, A. Tempering Process/Technology. Heat Treater's Guide: Practices and Procedures for Irons and Steels, 1995. 96-110.

53. PLAYMOUTH UNIVERSITY. Mechanisms of Creep in metals, Plymouth, p. 1-5. Disponivel em: <www.tech.plym.ac.uk/sme/mats340/cpmech.pdf>. Acess 10/2011.

54. WOHLFAHRT, H. The Influence Of Peening Conditions On The Resulting Distribution Of Residual Stress. International Conferences on Shot Peening-2. Chicago. 1984. p. 316-331.

55. WUBBENHORST, W.; KRITZLER, J. Inducing Compressive Stresses through Controlled Shot Peening. In: TOTTEN, G.; HOWES, T.; INOUE, T. Handbook of Residual Stress and Deformation of Steel. Materials Park: ASM, 2003. p. 345-360.

56. DIEPART, C. P. Effect of Residual Stresses induced by Shot Peening on Metal Fatigue. In: MACHERAUCH, E.; HAUK, V. Residual Stresses in Science and Technology. Amilly: DFM Informationsgesellschaft mbH, v. 1, 1986. p. 457-466.

57. FENG, B. X. et al. Residual Stress field and Thermal Relaxation behaviour of shotpeened TC4-DT titanium alloy. Materials Science and Engineering A, Xian, n. 512, p. 105-108, January 2009.

58. LOHE, D.; LANG, K. H.; VOHRINGER, O. Residual Stresses and Fatigue Behaviour. In: TOTTEN, G.; HOWES, M.; INOUE, T. Handbook of Residual Stress and Deformation of Steel. Materials Park: AMS, 2003. p. 27-53. 